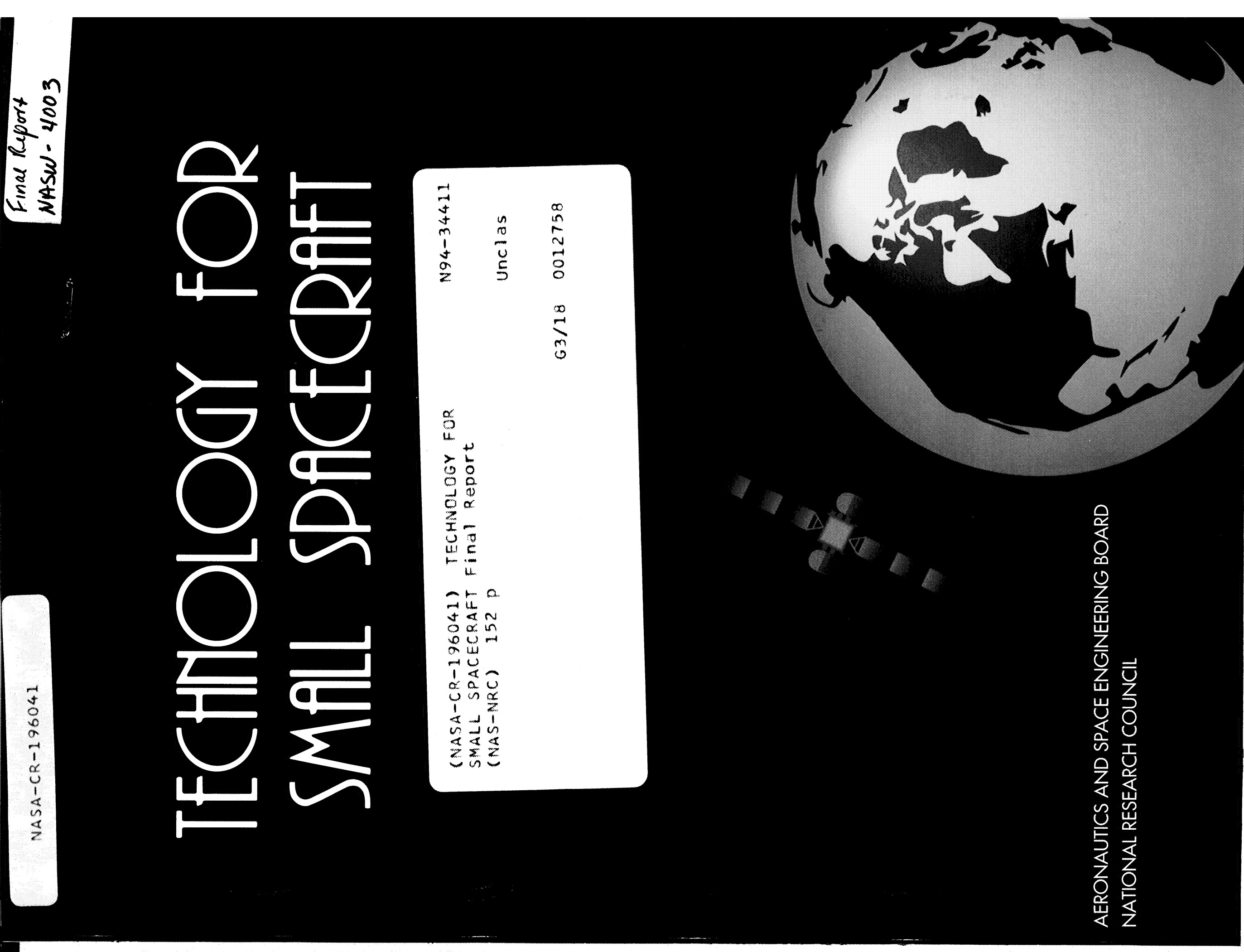




\section{Technology for Small Spacecraft}

Panel on Small Spacecraft Technology

Committee on Advanced Space Technology

Aeronautics and Space Engineering Board

Commission on Engineering and Technical Systems

National Research Council

National Academy Press

Washington, D.C. 1994 
NOTICE: The project that is the subject of this report was approved by the Governing Board of the National Research Council, whose members are drawn from the councils of the National Academy of Sciences, the National Academy of Engineering, and the Institute of Medicine. The members of the panel responsible for the report were chosen for their special competencies and with regard for appropriate balance.

This report has been reviewed by a group other than the authors according to procedures approved by a Report Review Committee consisting of members of the National Academy of Sciences, the National Academy of Engineering, and the Institute of Medicine.

The National Academy of Sciences is a private, nonprofit, self-perpetuating society of distinguished scholars engaged in scientific and engineering research, dedicated to the furtherance of science and technology and to their use for the general welfare. Upon the authority of the charter granted to it by the Congress in 1863, the Academy has a mandate that requires it to advise the federal government on scientific and technical matters. Dr. Bruce Alberts is president of the National Academy of Sciences.

The National Academy of Engineering was established in 1964, under the charter of the National Academy of Sciences, as a parallel organization of outstanding engineers. It is autonomous in its administration and in the selection of its members, sharing with the National Academy of Sciences the responsibility for advising the federal government. The National Academy of Engineering also sponsors engineering programs aimed at meeting national needs, encourages education and research, and recognizes the superior achievements of engineers. Dr. Robert M. White is president of the National Academy of Engineering.

The Institute of Medicine was established in 1970 by the National Academy of Sciences to secure the services of eminent members of appropriate professions in the examination of policy matters pertaining to the health of the public. The Institute acts under the responsibility given to the National Academy of Sciences by its congressional charter to be an adviser to the federal government and, upon its own initiative, to identify issues of medical care, research, and education. Dr. Kenneth I. Shine is president of the Institute of Medicine.

The National Research Council was organized by the National Academy of Sciences in 1916 to associate the broad community of science and technology with the Academy's purposes of furthering knowledge and advising the federal government. Functioning in accordance with general policies determined by the Academy, the Council has become the principal operating agency of both the National Academy of Sciences and the National Academy of Engineering in providing services to the government, the public, and the scientific and engineering communities. The Council is administered jointly by both Academies and the Institute of Medicine. Dr. Bruce Alberts and Dr. Robert M. White are chairman and vice-chairman, respectively, of the National Research Council.

This study was supported by Contract NASW-4003 between the National Academy of Sciences and the National Aeronautics and Space Administration.

Library of Congress Catalog Card Number 94-67334

International Standard Book Number 0-309-05075-8

Available in limited supply from:

The Aeronautics and Space Engineering Board

2101 Constitution Avenue, N.W.

Washington, D.C. 20418

Additional copies available for sale from:

National Academy Press

2101 Constitution Avenue, N.W., Box 285

Washington, D.C. 20055

$1-800-624-6242$ or (202) 334-3313

Copyright 1994 by the National Academy of Sciences. All rights reserved.

Printed in the United States of America 


\section{PANEL ON SMALL SPACECRAFT TECHNOLOGY}

Laurence J. Adams, Martin Marietta (Ret.), Consultant, Potomac, MD, Chair

Steven Aftergood, Senior Research Analyst, Federation of American Scientists, Washington, DC

Jay E. Boudreau, President, Ballena Systems Corporation, Los Alamos, NM

Bernard Budiansky, Gordon McKay Professor of Structural Mechanics and Abbot and James

Lawrence Professor of Engineering, Harvard University, Cambridge, MA

Robert S. Cooper, President and Chief Executive Officer, Atlantic Aerospace Electronics Corporation, Greenbelt, MD

Fred E. Culick, Professor, Mechanical Engineering and Jet Propulsion, California Institute of

Technology, Altadena, CA

Wolfgang H. Demisch, Managing Director, Bankers Trust, New York, NY

Emanuel J. Fthenakis, Fairchild Industries (Ret.), Potomac, MD

Clark W. Hawk, Director, Propulsion Research Center, Professor, Mechanical Engineering, University of Alabama, Huntsville, Huntsville, AL

John M. Hedgepeth, President, Digisim Corporation, Santa Barbara, CA

Mary V. Jones, Director, Engineering Support, Atlantic Research Corporation, Gainesville, VA

Frank E. Marble, Richard L. Hayman and Dorothy M. Hayman Professor of Mechanical Engineering, and Professor of Jet Propulsion, California Institute of Technology, Pasadena, CA

Franklin D. Martin, Director, Scientific Space Programs, NASA Space Flight Programs, Space Systems

Division, Lockheed Missiles and Space Company, Inc., Sunnyvale, CA (Term ended 2/28/94)

John H. McElroy, Dean of Engineering, University of Texas, Arlington, Arlington, TX

Duane T. McRuer, Chair, Aeronautics and Space Engineering Board, Chairman, Systems

Technology, Inc., Hawthorne, CA

Norman F. Parker, Varian Associates (Ret.), Cardiff by the Sea, CA

Robert O. Ritchie, Director, Center for Advanced Materials, Lawrence Berkeley Laboratory, Berkeley, CA

William C. Schneider, Consultant, Silver Spring, MD

Alfred Schock, Director, Energy System Dept., Fairchild Space and Defense Corporation, Germantown, MD

Richard R. Weiss, Sr. Staff Specialist, Office of the Undersecretary of Defense (Acquisitions), Arlington, VA

John B. West, Professor of Medicine, Department of Medicine, University of California, San Diego, La Jolla, CA

William L. Whittaker, Director \& Senior Research Scientist, Carnegie Mellon University, Pittsburgh, PA

Advisor

Wiley J. Larson, Associate Professor, U. S. Air Force Academy, Department of Astronautics, Colorado Springs, $\mathrm{CO}$

Staff

JoAnn Clayton, Director

Allison C. Sandlin, Study Director

William E. Campbell, Senior Project Assistant

Maryann Shanesy, Project Assistant 


\section{COMMITTEE ON ADVANCED SPACE TECHNOLOGY}

Laurence J. Adams, Martin Marietta (Ret.), Consultant, Potomac, MD, Chair

Jay E. Boudreau, President, Ballena Systems Corporation, Los Alamos, NM

Bernard Budiansky, Gordon McKay Professor of Structural Mechanics and Abbot and James

Lawrence Professor of Engineering, Harvard University, Cambridge, MA

Robert S. Cooper, President and Chief Executive Officer, Atlantic Aerospace Electronics Corporation, Greenbelt, MD

Fred E. Culick, Professor, Mechanical Engineering and Jet Propulsion, California Institute of Technology, Altadena, CA

Emanuel J. Fthenakis, Fairchild Industries (Ret.), Potomac, MD

Clark W. Hawk, Director, Propulsion Research Center, Professor, Mechanical Engineering, University of Alabama, Huntsville, Huntsville, AL

Mary V. Jones, Director, Engineering Support, Atlantic Research Corporation, Gainesville, VA

Franklin D. Martin, Director, Scientific Space Programs, NASA Space Flight Programs, Space Systems

Division, Lockheed Missiles and Space Company, Inc., Sunnyvale, CA

John H. McElroy, Dean of Engineering, University of Texas, Arlington, Arlington, TX

Norman F. Parker, Varian Associates (Ret.), Cardiff by the Sea, CA

Robert O. Ritchie, Director, Center for Advanced Materials, Lawrence Berkeley Laboratory, Berkeley, CA

William C. Schneider, Consultant, Silver Spring, MD

Richard R. Weiss, Sr. Staff Specialist, Office of the Undersecretary of Defense (Acquisitions), Arlington, VA

John B. West, Professor of Medicine, Department of Medicine, University of California, San Diego, La Jolla, CA

William L. Whittaker, Director \& Senior Research Scientist, Carnegie Mellon University, Pittsburgh, PA

\section{Ex Officio}

Duane T. McRuer, Chair, Aeronautics and Space Engineering Board, Chairman, Systems

Technology, Inc., Hawthorne, CA

\section{Staff}

JoAnn Clayton, Director

Allison C. Sandlin, Study Director

William E. Campbell, Senior Project Assistant

Maryann Shanesy, Project Assistant 


\section{AERONAUTICS AND SPACE ENGINEERING BOARD}

Duane T. McRuer, Chair, Aeronautics and Space Engineering Board, Chairman, Systems Technology, Inc., Hawthorne, CA

Bernard L. Koff, Chair, National Aeronautical Test Facilities Study, Executive Vice President, Engineering and Technology, Pratt \& Whitney, West Palm Beach, FL

Steven Aftergood, Senior Research Analyst, Federation of American Scientists, Washington, DC

Joseph P. Allen, President and Chief Executive Officer, Space Industries International, Inc., Washington, DC

James M. Beggs, Senior Partner, J.M. Beggs Associates, Arlington, VA

Guion S. Bluford, Jr., Vice President and General Manager of Engineering Services Division, NYMA, Inc., Greenbelt, MD

John K. Buckner, Vice President, Special Projects, Lockheed Fort Worth Company, Fort Worth, TX

Raymond S. Colladay, Vice President, Strategic Defense Systems, Martin Marietta Corporation, Denver, CO

Ruth M. Davis, President and Chief Executive Officer, Pymatuning Group, Inc., Alexandria, VA

Wolfgang H. Demisch, Managing Director, Bankers Trust, New York, NY

Steven M. Dorfman, President, Telecommunications and Space Sector, General Motors Hughes Electronics, Los Angeles, CA

John M. Hedgepeth, President, Digisim Corporation, Santa Barbara, CA

Takeo Kanade, Director, The Robotics Institute, U.A. and Helen Whitaker, Professor of Computer Science and Robotics, Carnegie Mellon University, Pittsburgh, PA

Jack L. Kerrebrock, R.C. Maclaurin Professor of Aeronautics and Astronautics, Massachusetts Institute of Technology, Cambridge, MA

Donald J. Kutyna, Corporate Vice President, Advanced Space Systems, Loral Corporation, Colorado Springs, CO John M. Logsdon, Director, Space Policy Institute, George Washington University, Washington, DC

Robert R. Lynn, Bell Helicopter Textron, Euless, TX

Frank E. Marble, Richard L. Hayman and Dorothy M. Hayman Professor of Mechanical Engineering and Professor of Jet Propulsion, California Institute of Technology, Pasadena, CA

C. Julian May, Executive Vice President, Tech/Ops International, Inc., Kennesaw, GA

Earll M. Murman, Professor and Department Head, Aeronautics and Astronautics, Massachusetts Institute of Technology, Cambridge, MA

Bradford W. Parkinson, Professor, Aeronautics and Astronautics, Stanford University, Stanford, CA

Alfred Schock, Director, Energy System Department, Fairchild Industries, Germantown, MD

John D. Warner, President, Boeing Computer Services, Seattle, WA

\section{Staff}

JoAnn Clayton, Director

Alan C. Angleman, Senior Program Officer

Thomas C. Mahoney, Senior Program Officer

Allison C. Sandlin, Senior Program Officer

Noel E. Eldridge, Program Officer

Paul J. Shawcross, Program Officer
Anna L. Farrar, Administrative Associate

Susan K. Coppinger, Administrative Assistant

William E. Campbell, Senior Project Assistant

Beth A. Henry, Project Assistant

Maria M. Kneas, Project Assistant

Ted W. Morrison, Program Assistant 


\section{Preface}

This report gives the results of a study by the National Research Council's Panel on Small Spacecraft Technology that reviewed the National Aeronautics and Space Administration's (NASA's) technology development program for small spacecraft and assessed technology within the U.S. government and industry that is applicable to small spacecraft.

The panel found that there is a considerable body of advanced technology currently available for application by NASA and the small spacecraft industry that could provide a substantial improvement in capability and cost over those technologies used for current NASA small spacecraft. These technologies are the result of developments by commercial companies; Department of Defense agencies; and, to a lesser degree, NASA. The panel also found that additional technologies are being developed by these same entities that could provide additional substantial improvement if development is successfully completed.

This report provides recommendations for future technology development efforts by NASA across a broad technological spectrum. Those that hold the promise of offering major improvements in capability or cost are identified as highest priority. However, all of the recommendations have the potential to bring significant benefits to future small spacecraft programs. The panel did not make specific cost estimates for each of its recommendations or recommend future management strategy for NASA's technology program, since it was considered beyond the scope of the panel's statement of task.

The panel's technology survey was extensive, but not all inclusive. The panel believes that this report is representative of the current state of technology and of projections into the relatively short-term future. All of the evaluations contained in this report represent the judgment of this panel of experts and are based on considerable review of the technologies by the panel members and on the members' individual expertise and knowledge of the subject matter.

In conducting this study, the Panel on Small Spacecraft Technology visited many facilities and requested numerous briefings from government agencies and companies regarding their technology programs for small spacecraft, launch vehicles, and ground operations. The panel wishes to thank all of the individuals, companies, and agencies listed in Appendix E for their cooperation and contributions during this study.

Laurence J. Adams, Chair

Panel on Small Spacecraft Technology

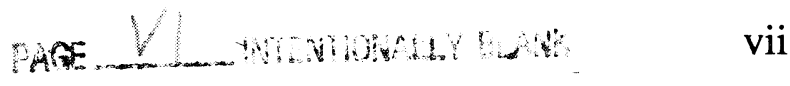




\section{TABLE OF CONTENTS}

List of Tables $\quad$ xii

List of Acronyms $\quad$ xiii

Executive Summary 1

1. Introduction 6

The Task, 6

Background and Status, 7

Approach, 11

2. Systems Engineering and Operations

Background and Status, 12

Small Spacecraft Systems Engineering, 13

Small Spacecraft Launch Operations, 15

Small Spacecraft Mission Operations, 18

Prioritized Recommendations, 21

3. Spacecraft Propulsion Technology

Background and Status, 23

Chemical Propulsion, 24

Solar Propulsion, 26

Nuclear Propulsion, 29

Findings and Prioritized Recommendations, 29

4. Spacecraft Electric Power

Background and Status, 31

Power Sources, 31

Battery Technology for Energy Storage, 37

Findings and Prioritized Recommendations, 39

5. Spacecraft Structures and Materials

Background and Status, 42

$i x$

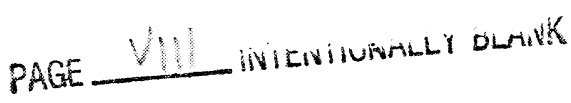


Structures, 42

Materials, 44

Structure/Materials Systems, 48

Findings and Prioritized Recommendations, 48

6. Small Spacecraft Communications Technology

Background and Status, 50

NASA Programs, 52

DoD Programs, 53

Industry Programs, 53

Spacecraft-to-Spacecraft Communications, 54

Multiple Access, 54

Communications Component Technology, 55

Spectrum Utilization, 55

Findings and Prioritized Recommendations, 56

7. Guidance and Control Technology

Background and Status, 57

Guidance and Control Components, 58

Autonomous Systems, 62

Radiation Hardening, 62

Electronics Packaging, 62

Interfaces, 63

Findings and Prioritized Recommendations, 63

8. Sensors for Small Spacecraft

Background and Status, 66

NASA Programs, 66

DoD Programs, 67

Findings and Prioritized Recommendations, 68

9. Robotics, Automation, and Artificial Intelligence

Background and Status, 70

Small Robotic Planetary Explorers, 71

Small Robots in Low Earth Orbit, 72

Other Agency Programs, 73

Findings and Prioritized Recommendations, 73

10. Launch Vehicle Technology for Small Spacecraft

Background and Status, 75

Small Launch Vehicles, 75

Lowering Cost of Launching Small Spacecraft, 77

Environmental Considerations, 80

Prioritized Recommendations, 81 
11. Overall Findings and Recommendations

Current Emphasis and Justification, 83

Small Spacecraft Capabilities, 83

Response to Task Statement, 84

List of References

Appendix A: Title I of the National Aeronautics and Space Act of 1958, as Amended (Public Law 85-568)

Appendix B: Small Spacecraft Applications

Appendix C: Office of Advanced Concepts and Technology's Small Spacecraft Technology Initiative

Appendix D: Current NASA and DoD Small Spacecraft Programs

Appendix E: Study Participants 


\section{List of Tables}

TABLE 2-1 Examples of Current Small Spacecraft and Launch Vehicle Activities

TABLE 6-1 Some Recently Proposed Mobile Satellite Systems 51

$\begin{array}{lll}\text { TABLE 10-1 Representative U.S. Launch Vehicles } & 76\end{array}$

TABLE 11-1 Currently Available Technologies for Small 88 Spacecraft within NASA, Other Government Agencies, and Industry

TABLE 11-2 Technologies Under Development within NASA, Other Government Agencies, and Industry

TABLE $11-3$

Prioritized Technology Recommendations

97 


\section{List of Acronyms}

ACTS

APSA

ARPA

BMDO

CPV

DoD

DOE

GPS

GSFC

IPD

IPV

JPL

LeRC

MSTI

NASA

OACT

RTG
Advanced Communications Technology Satellite

Advanced Photovoltaic Solar Array

Advanced Research Projects Agency

Ballistic Missile Defense Organization

Common pressure vessel

Department of Defense

Department of Energy

Global Positioning System

Goddard Space Flight Center

Integrated product development

Individual pressure vessel

Jet Propulsion Laboratory

Lewis Research Center

Miniature Sensor Technology Integration

National Aeronautics and Space Administration

Office of Advanced Concepts and Technology

Radioisotope thermoelectric generator 
TIMED

TDRSS
Thermosphere Ionosphere Mesosphere Energetics and Dynamics

Tracking and Data Relay Satellite System 


\section{Executive Summary}

In 1992, the National Research Council's Aeronautics and Space Engineering Board established the Panel on Small Spacecraft Technology to

- review the National Aeronautics and Space Administration's (NASA) plans for a new small spacecraft technology development program;

- review NASA's current technology program and priorities for relevance to small spacecraft, launch vehicles for small spacecraft, and small spacecraft ground operations;

- examine small spacecraft technology programs of other government agencies;

- assess technology efforts in industry that are relevant to small spacecraft, launch vehicles, and ground operations; and

- identify technology gaps and overlaps and prioritize areas in which greater investments are likely to have high payoff, considering the current and projected budgets, the NASA mission statement (see Appendix A), and the needs of industries that utilize space.

Although many missions have been carried out with large, expensive, and very capable spacecraft, smaller systems have key advantages that make them attractive. Small spacecraft are incrementally less expensive and more tolerant of funding, schedule, and technical risk than large, expensive spacecraft. In addition, small spacecraft are not dependent on the costly Space Shuttle or Titan IV launch vehicles required for large spacecraft. The panel believes that using smaller, less-expensive spacecraft will encourage use of more advanced technology, because the consequences of failure are reduced.

The panel concluded that with advanced technology, significant scientific, communications, and remote sensing missions can be performed using a single small spacecraft or constellations of small spacecraft. A vigorous NASA technology development program could provide technology that facilitates the use of small spacecraft for a higher percentage of NASA's future space missions. Potential technologies are identified and prioritized in this report.

The 22-member Panel on Small Spacecraft Technology was composed of recognized experts in key space mission technologies. The panel, established in late 
1992, heard over 32 briefings by representatives from NASA, the Department of Defense (DoD), industry, and by other key individuals in the space industry. Numerous site visits to various aerospace companies, NASA centers, and other government facilities were conducted to gain first-hand knowledge of the people, processes, and technologies available to facilitate development of small spacecraft.

The panel reviewed most of the technologies associated with spacecraft, payloads, launch systems, mission operations, and ground systems. It identified technologies that are currently available; identified technologies that are under development by NASA, DoD, and industry; and made recommendations for future NASA technology development. In addition, the panel reviewed the infrastructure within government and industry to support the growing small spacecraft industry. The panel also addressed the initial spacecraft concept design and development, systems engineering, and life-cycle cost issues that could facilitate small spacecraft development.

\section{Principal Findings and Recommendations}

The principal deterrent to the expanded use of space, both for NASA and industry, is high cost. This is true for NASA because of today's budget and political climate and for industry because of the high cost in providing a potential service to a buyer, along with increasing international competition in the small spacecraft and launch vehicle business. If technology can be developed that will enable the use of small spacecraft to increase mission capability while maintaining the ability to produce the spacecraft at reasonable cost, the utilization of space by both NASA and industry could expand.

The panel believes that the initial phase of a program is very important in establishing the methods by which cost will be reduced. The decisions made at the beginning of a program regarding the use of existing and new technology, systems engineering and operation, and management can have a large impact on the implementation of the program. In addition, maximum use of certain applicable commercially developed and commercially supported technology is the key to reducing schedule duration and program cost. Some of NASA's technology budget should be allocated to space qualifying commercially available technologies and technologies developed by other agencies. The panel found that there is no cure-all technology to reduce the cost of space missions and facilitate small spacecraft development. The challenge is to find a proper mix of technologies to pursue and then to maintain the focus and funding support necessary to bring them to fruition.

The panel believes that there are numerous opportunities in the development of technology applicable to small spacecraft. Prioritized recommendations or specific technology areas are listed at the end of each chapter. In Chapter 11, the prioritized technology recommendations from each chapter are prioritized across technology areas. The panel believes that each recommendation in this report is worthy of implementation. However, recognizing the uncertainty of NASA funding for technology development, the panel has identified those areas as highest priority, which in its judgment, offer the 
greatest potential for enhancing the mission capability and reducing the cost of small spacecraft. The remaining areas were identified as either high or higher priority. The assumption is that all of the remaining areas will be pursued at some point, with those in the highest priority level being funded first. The fact that the development of a particular technology may not come to fruition for several years should not bias a decision regarding early funding. In prioritizing all of the recommendations as high, higher, or highest, the panel applied the following criteria (not in priority order):

- the potential to reduce mission cost;

- the cost to develop the technology;

- the potential to reduce weight (permitting a higher payload mass fraction or use of a smaller launch vehicle);

- the likelihood of a successful development; and

- the potential to enable key mission goals.

Since hard data regarding these criteria are not available, the qualitative judgment of the panel members, based upon their experience and background, was the determining factor. In order to balance out differences in judgments, the priority selections were made independently by two separate groups of panel members, and then a consensus was reached by the entire panel.

The recommendations, in general, address technology development programs rather than generic research activities. However, the panel believes generic research is also an essential part of a total technology program. Such programs are necessary not only to continue to extend the state of the art but also to provide an opportunity for NASA to attract talented college graduates to work in NASA's laboratories and for it to engage universities, graduate students, and industry in stimulating research and development activity under contract to NASA.

In addition, since many of the technologies that can be used on small spacecraft have been developed by DoD and industry, the panel believes that a normal part of NASA's research and development activity should include the continual monitoring by NASA of research and development activities of other government agencies, foreign governments and organizations, and industry.

Some technologies that the panel believes have the highest potential to make a large impact on the cost and capability of small spacecraft are

- technologies to reduce cost and improve efficiency of up-front systems engineering and launch and mission operations;

- the Global Positioning System (GPS) for precision guidance and control;

- high-efficiency solar electric power generation and electric propulsion;

- hybrid propulsion for launch vehicles; and

- miniaturization of electronic devices.

It has been demonstrated that a fundamental design philosophy for minimization of costs is to design, build, and operate the system with minimal personnel and only the 
absolutely necessary documentation. Broad application of these techniques in combination with new technology development programs can have a major impact on the cost and utility of future NASA and commercial space systems.

Many launch and mission operations functions that are now performed by ground personnel can be automated with lightweight, low-cost, on-board systems. For example, on-board vehicle monitoring and, in some cases, defect correction can be automated, enabling factory-to-launch operations without the requirement for extensive intermediate ground testing. On-board launch trajectory monitoring for range safety purposes is achievable using GPS on board the spacecraft, eliminating the need for ground-based radar tracking during launch. Automated, on-board orbit determination and station keeping is also possible using GPS, which simplifies the mission operations task. Highdensity computers and memory devices combined with advanced software techniques enable extensive on-board data processing and screening, reducing the amount of data to be stored and transmitted to Earth. The compact memory devices reduce the requirement for numerous data-reception locations on the ground. Communication systems can be developed that will permit direct delivery of data, partially processed on board, to researchers in their own laboratories, where they have powerful computing capability at their desks. Chapter 2 provides more detail on these and other technologies that could be applied to make substantial reductions in the personnel required to launch and operate a space mission using a small spacecraft.

Two potential applications of GPS to small spacecraft, as noted above, are launch trajectory monitoring and automated on-board orbit determination. The panel believes that GPS also has great potential in other applications. Use of GPS in various combinations with other guidance components can determine position and attitude very accurately, probably at significantly reduced weight and cost. GPS also provides the capability to precisely fly clusters of small spacecraft in close proximity to one another, simulating a much larger spacecraft.

Electric propulsion is a very promising technology that can enable more ambitious missions in high-altitude orbits and at interplanetary distances. Such missions, however, must be able to tolerate orbit transfer times of several days or even months, and to allow for increased radiation exposure due to the longer transfer times. Small, lightweight spacecraft are particularly suited to this technology because of the relatively high thrustto-weight ratios achievable with these very low-thrust electric propulsion systems. In order to gain maximum potential from these high specific impulse systems, a high electric power level is required. Advanced technology in solar-generated power could supply the required power levels with array sizes and weights compatible with small spacecraft. Extensive development work on both the solar power and electric propulsion technologies has been conducted in the past, but a concentrated, well-funded development activity is needed to bring these technologies to fruition.

Hybrid propulsion is a technology that has great potential for application to small spacecraft launch vehicles and has been under development for some time. Hybrid propulsion systems offer unique advantages over conventional solid propulsion systems because of their inherent inertness during manufacturing and shipping and over both solid and liquid systems during launch operations. The reduction in special safety requirements 
should translate into reduced cost. Hybrid propulsion systems have the added advantage of an environmentally acceptable exhaust product, which could be an important factor if environmental restrictions increase.

Advances in miniaturization of electronic devices have the potential to increase the payload mass fraction, lower the spacecraft weight, reduce the power requirements, and reduce overall cost. These devices can be combined to form highly capable systems for remote sensing, guidance and control, communications, and on-board operations. Continued investment in advanced design and ground testing techniques for adapting commercial products for the space environment can assure the availability of up-to-date technology for space application.

The panel believes that advanced technology has the potential to greatly enhance the ability of small spacecraft to perform meaningful missions at low cost. It is the opinion of the panel that the totality of the recommendations within this report, if implemented, would enable an important part of the U.S. space science program to be accomplished economically with small spacecraft. It would also provide a strong technology base for the emerging small spacecraft commercial industry. 


\section{1}

\section{Introduction}

\section{THE TASK}

The National Research Council's Aeronautics and Space Engineering Board established the Panel on Small Spacecraft Technology to

- review the National Aeronautics and Space Administration's (NASA) plans for a new small spacecraft technology development program;

- review NASA's current technology program and priorities for relevance to small spacecraft, launch vehicles for small spacecraft, and small spacecraft ground operations;

- examine small spacecraft technology programs of other government agencies;

- assess technology efforts in industry that are relevant to small spacecraft, launch vehicles, and ground operations; and

- identify technology gaps and overlaps and prioritize areas in which greater investments are likely to have high payoff, considering the current and projected budgets, the NASA mission statement (see Appendix A), and the needs of industries that utilize space.

Small spacecraft are variously defined within the aerospace industry as weighing less than 1,000 pounds, as weighing less than 1,000 kilograms, or as allowing the selection of a smaller launch vehicle. NASA uses the terms miniature spacecraft or micro-spacecraft to imply the reduction of mass, volume, and components to allow downsizing by one or more launch vehicle classes over current practice (Hanks, 1993). However, for consistency in this report, small spacecraft will be defined as those weighing approximately 600 kilograms or less. 


\section{BACKGROUND AND STATUS}

In the past, NASA has focused a large percentage of its resources on the large manned system programs: Apollo, Space Shuttle, and Space Station. These types of programs not only have long duration and very expensive engineering and manufacturing phases, but commit NASA to very high operational costs extending over a period of ten to twenty years. Also, many of NASA's unmanned space programs such as the Tracking and Data Relay Satellite System, Viking, and the large observatories (High Energy Astronomy Observatory, Gamma Ray Observatory, and Hubble Space Telescope) cost hundreds of millions to billions of dollars during development and manufacture, and up to hundreds of millions of dollars in yearly operations costs. The national importance and visibility of these programs resulted in an environment in which the consequences of failure were so severe that any degree of technological risk to improve performance or reduce cost was unacceptable. It also brought about a large bureaucracy that included numerous levels of oversight review. In an effort to reverse this trend, NASA has indicated its intent to emphasize the use of small spacecraft to conduct the majority of its future space science and applications missions (Goldin, 1993). This approach is intended to result in a space program with more frequent flights at markedly lower cost per flight. It is anticipated that such a program will engender a more aggressive approach to the application of advanced technology in its flight programs because of the higher tolerance for risk that will result from the much lower cost for each flight. NASA believes that this approach will also enable much shorter times from program initiation to flight (two to three years total), with the resultant greater versatility, improved responsiveness to mission requirements, and enhanced efficiency. Another stated objective is to develop technology and transfer it to industry, both in the aerospace and nonaerospace sectors, in order to enhance national competitiveness and stimulate the creation of jobs for Americans.

The high cost of NASA's large space programs has resulted in minimal spending for advanced technology research and development, since most of the funds available to NASA have been spent in support of the large programs. As a consequence, much of the technology required to carry out future small spacecraft missions economically is not available from the NASA technology program. Fortunately, the Department of Defense (DoD), several of its agencies, and numerous industrial firms have had active small spacecraft technology development programs in the past, and the results of these efforts are now available for use by NASA. However, expenditures for national defense have been severely curtailed in recent years, and additional cutbacks are projected for the future. The United States is facing increasing international competition in the commercial space areas of communications, remote sensing, and in the launch vehicle market (Mintz, 1994; NRC, 1992; Pelton et al., 1992). If NASA is going to provide the leadership for itself and the commercial sector, it must maintain an evolving, long-term, continuous technology program specifically aimed at enabling future, highly demanding space missions at a reasonable cost. 


\section{Space Systems Costs}

The overriding factor inhibiting access to space is cost. The cost drivers are the development and construction of the spacecraft, the mission sensors, the launch vehicle, launch and mission operations, and extensive testing and reviews to lower the perceived risk to an acceptable level. Advanced technology that has been sufficiently developed by NASA, other government agencies, and industry to permit incorporation in NASA small spacecraft can contribute to the reduction in cost for each of these elements and is addressed in this report.

An effective way to lower launch costs is to reduce the weight of the spacecraft, including the mission payload sensors. For most spacecraft, the principal weight drivers are (1) electrical power systems, (2) propulsion and propellant systems, (3) structures, and (4) guidance and control systems. Payload instruments also can contribute significantly to the overall spacecraft weight (Auclair, et al., 1993; Davis, 1993; Larson and Wertz, 1992).

Although not directly a technology issue, it is worth noting that the cost of developing and constructing the spacecraft can be influenced markedly by the customer and contractor program management implementation. NASA, DoD, and industry have demonstrated with recent small spacecraft technology development programs that simplified technical requirements, coupled with a design-to-cost approach and closely integrated engineering, operational, and manufacturing development activity, can reduce the cost of space missions. Such programs include the Small Explorer spacecraft program; the Miniature Sensor Technology Integration (MSTI) program; and the Microsats program. ${ }^{1}$ The panel believes these techniques can be successfully extended to future small spacecraft programs.

\section{Small Spacecraft Applications}

Technology has progressed so rapidly, particularly in the electronics arena, that much can be accomplished now with the use of integrated circuits, high-capacity computers, and small devices with large memory capability. In addition, there have been impressive advances in miniaturized instruments, lightweight materials and structures, high-output and small power sources, and accurate position determination through use of the Global Positioning System (GPS). These technologies, combined with the changes in the approach to systems engineering, management, and operations processes, can

\footnotetext{
${ }^{1}$ The Small Explorer program for science missions is sponsored by NASA's Goddard Space Flight Center (GSFC); the MSTI program is sponsored by the Ballistic Missile Defense Organization (BMDO), the U.S. Air Force Phillips Laboratory, and the Jet Propulsion Laboratory (JPL) to test miniature sensor technology; and the Microsats program is sponsored by the Advanced Research Projects Agency (ARPA) to provide improvements to small spacecraft communications technology.
} 
permit small spacecraft to be far more efficient and cost effective, as well as to accomplish missions with much greater capability than previously believed possible.

Using currently available technology augmented by a vigorous technology development program, the panel believes that:

- For many missions, a small spacecraft can be used to achieve the mission requirements with capability approaching that of today's large spacecraft. The Small Explorer program is an example of a program that uses a small spacecraft to achieve significant scientific objectives.

- For many of the more demanding missions, small spacecraft can achieve a significant percentage of the mission objectives at much lower cost. The Mars Pathfinder program (formerly called the Mars Environmental Survey (MESUR)/Pathfinder program) is an example of a current effort to apply this philosophy to the unmanned exploration of Mars.

- It is likely that some missions requiring simultaneous measurements by multiple sensors can be accomplished with constellations of small spacecraft.

- Some missions that require larger, more complex spacecraft can be accomplished at significantly lower cost through application of technologies developed for small spacecraft.

Not all small spacecraft missions are both faster and less expensive than large spacecraft, since technology research and development for miniaturization is costly. The panel further recognizes that the use of multiple spacecraft in constellations may not be less expensive than large spacecraft. However, the use of small spacecraft in constellations distributes the risk among several spacecraft and launch vehicles rather than concentrating all the risk with one large spacecraft. This distribution of risk should result in a less costly systems engineering approach. Because of the lower cost to build and launch a small spacecraft replacement, the use of such constellations can enable a much more economical replacement of an instrument that fails on orbit than if it were one of several on a large spacecraft.

A more detailed description of current and potential small spacecraft applications is given in Appendix B.

\section{Current Small Spacecraft Programs}

Although NASA's combined investments in large science missions (Voyager, Hubble, Galileo) are greater than its total investment in the more numerous small spacecraft missions, small spacecraft have served a long-standing role in NASA missions that predates the current enthusiasm for small spacecraft. Numerous space physics and astrophysics missions have been completed through the Explorer and Small Explorer programs, and JPL has participated in a number of DoD small spacecraft programs that served to advance component technology in several key areas. 
In order to transition from large, one-of-a-kind spacecraft to smaller spacecraft, NASA has initiated several programs. For example, the NASA Office of Space Science has initiated the Discovery program, which consists of a series of science missions that are intended to proceed from development to flight in three years or less at a development cost of less than $\$ 150$ million each (FY 1992 dollars). The first mission, known as the Near Earth Asteroid Rendezvous, led by the Johns Hopkins University's Applied Physics Laboratory, is scheduled for launch in February 1996 (Leary, 1993). JPL is the lead center on the Mars Pathfinder mission, the second Discovery mission, which is also projected for launch in 1996. JPL also has proposed the Pluto Fast Flyby mission. The goal is to launch two small spacecraft of less than 140 kilograms each on a direct trajectory to Pluto by 2001 (Staehle et al., 1993).

In addition, NASA has proposed the Thermosphere Ionosphere Mesosphere Energetics and Dynamics (TIMED) mission, which includes a system of probes to study little-known aspects of the Earth's upper atmosphere. TIMED is to be the first of the Office of Space Science's series of small spacecraft missions, known as the Solar Terrestrial Probes.

In support of the emphasis on small spacecraft, the Spacecraft and Remote Sensing Division was created within the Office of Advanced Concepts and Technology (OACT) at NASA Headquarters. This division is responsible for the development of technology to reduce the cost and launch weight of spacecraft through miniaturized components, advanced instrumentation, operations technology, and sensors integrated into advanced design concepts. The Spacecraft and Remote Sensing Division is currently working with the Office of Space Science to develop and infuse advanced technology into three scientific small spacecraft missions: (1) the proposed TIMED mission, (2) Mars Pathfinder, and (3) the proposed Pluto Fast Flyby mission (NASA/OACT, 1993). In addition to the technology infusion activities, OACT's Spacecraft and Remote Sensing Division has established a Small Spacecraft Technology Initiative. This program will demonstrate a new approach to technology integration. Two technology demonstration flights are planned within three years; each is designed to envelop a range of mission requirements and develop standard hardware and software interfaces for various applications. A Request for Proposal for the Small Spacecraft Technology Initiative was released February 28, 1994, with award dates scheduled for the second quarter of 1994. Programmatic and budget details of the Small Spacecraft Technology Initiative and current NASA programs are discussed further in Appendices C and D. The rate of progress of this initiative is in question, since it received less than one-half of NASA's requested budget for fiscal year 1994.

As noted previously, DoD and its agencies have active small spacecraft programs. Appendix D gives a summary of those activities. In addition, a new small spacecraft industry is emerging, based to a large extent on past and current government programs. A listing of some commercial programs is given in Chapter 6 of this report. 


\section{APPROACH}

The Panel on Small Spacecraft Technology was established in late 1992 and met in January, April, May, June, September, and December, 1993. At the first three meetings, the entire panel heard over 32 briefings by representatives from many government agencies and industry and from other experts on small spacecraft technology issues. In addition, the panel formed subpanels in several technical areas: (1) power and propulsion; (2) automation, robotics, and artificial intelligence; (3) materials and structures; (4) communications, guidance and control; (5) sensors; (6) launch vehicles; and (7) ground operations, infrastructure, and cost analysis. The subpanels conducted 23 site visits to various aerospace companies, NASA centers, and government laboratories. Appendix $\mathrm{E}$ lists the industry and government participants in this study. The panel membership is listed in the front of this report.

At the June meeting, the panel met and discussed each subpanel's preliminary findings and recommendations. In December, the panel met to discuss and prioritize the overall findings and recommendations. In September and November of 1993, and January 1994, a writing team composed of several panel members met to work on the draft report.

The data obtained by the panel during its meetings and site visits form the basis for this report. Detailed information on key, enabling technologies for small spacecraft are discussed in the various chapters of the report along with specific findings and recommendations. Overall findings and prioritized recommendations on small spacecraft technology and NASA's small spacecraft program are noted in the last chapter of this report. 


\section{2 \\ Systems Engineering and Operations}

\section{BACKGROUND AND STATUS}

Major factors in space system costs are the launch and mission operations. Since the ultimate cost is determined at the time the system is designed, operations must be a major consideration during the initial systems design. The emerging small spacecraft industry has been supported to a significant degree by ARPA and BMDO and, to some degree, by the Small Explorer and the MSTI programs. These agencies have largely abandoned the design, development, and systems engineering practices employed by producers of large spacecraft systems. The companies that develop small spacecraft systems are also creating new approaches to launch and mission operations that are simpler and much less costly per mission than their larger counterparts.

Several companies and consortia are currently engaged in the design of new communications systems that employ low-Earth-orbit constellations of small, low-cost spacecraft, which will have graceful system degradation and shorter transmission delay than is achievable with geosynchronous orbits (Seitz, 1993a; Seitz and de Selding, 1993). Numerous agencies and companies are engaged in small spacecraft activities. Several examples are included in Table 2-1. Some of these programs are successfully demonstrating systems for tracking, telemetry, and mission data operations that employ, when appropriate, the latest standard commercial communications equipment, data processing equipment, and software, as well as substantial automation technology, to reduce cost while maximizing performance. It has been demonstrated that such systems can provide sophisticated services with high reliability at costs well below those achievable with the conventional approach, and they can do so in much shorter periods of time. It also has been demonstrated that a fundamental design philosophy for minimization of costs is to design, build, and operate the system with minimal personnel and only the absolutely necessary documentation. Broad application of these techniques in combination with new technology development programs can have a major impact on the cost and utility of future NASA and commercial space systems. 
TABLE 2-1 Examples of Current Small Spacecraft and Launch Vehicle Activities

\begin{tabular}{ll}
\hline \multicolumn{1}{c}{ AGENCY/COMPANY } & \multicolumn{1}{c}{$\begin{array}{c}\text { SMALL SPACECRAFT/LAUNCH } \\
\text { VEHICLE ACTIVITY }\end{array}$} \\
NASA GSFC & Small Explorer Program \\
JPL & $\begin{array}{l}\text { Mars Pathfinder } \\
\text { BMDO/U.S. Air Force Phillips }\end{array}$ \\
Laboratory/JPL & Miniature Sensor Technology Integration \\
BMDO/Naval Research Laboratory & Program (MSTI) \\
(NRL)/NASA & Deep Space Program Science Experiment \\
ARPA/Defense Systems Incorporated/ & Microsats, DARPASAT \\
U.S. Air Force & Space Test Experiment Platform (STEP) \\
Orbital Sciences Corporation & Pegasus, Taurus, Orbcomm, Pegastar \\
Lockheed/Motorola/Iridium Inc. & LLV-1, IRIDIUM ${ }^{\mathrm{TM} / \mathrm{SM}}$ \\
Ellipsat & Ellipso \\
Starsys Global Positioning, Inc. & Starsys \\
\hline
\end{tabular}

\section{SMALL SPACECRAFT SYSTEMS ENGINEERING}

The initial phase of a program is very important in establishing the methods by which cost will be reduced. Decisions involving trade-offs among mission objectives, mission operation concepts, system and subsystem performance, life-cycle cost, schedule, risk, and reliability can have a large impact. These trades should be performed as the first step, before committing to a specific spacecraft configuration and design approach. By utilizing advanced technology on small spacecraft, increased capabilities can be achieved for a wide variety of missions, with only small reductions in performance relative to the performance of large systems. These trade-offs could result in substantially different system configurations. For example, several small complementary spacecraft with specific capabilities could be used in combination to achieve the total mission objectives. Alternatively, a higher failure rate could be accepted by using new technology that has not yet been qualified by space flight but that offers a large advantage in cost, weight, or performance. A complete backup could be provided in case of failure, and the cost might still be lower.

Since personnel costs associated with ground operations have been shown to be a major contributor to space system life-cycle costs, systems trade-offs may require the shifting of ground functions to the spacecraft for more autonomous, lower-cost space operations (Larson and Wertz, 1992). In other cases, however, lower system costs may result from shifting functionality to Earth-based, yet automated, facilities. Furthermore, since many past failures 
have resulted due to human error, technology that reduces the number of personnel can possibly reduce the risk of failure. Some key technologies that may play a role in determining these trade-offs are miniaturized digital electronics; built-in self testing; expert systems techniques; high-density, solid-state memory; on-board communications and data processing; autonomous GPS navigation, guidance, and spacecraft attitude control; and massively parallel computers employed in open system architectures, often using commercially available hardware and software.

Another important trade-off concerns selection of the launch vehicle and the desirability of a spacecraft having compatibility with several different launch vehicles. The various launch vehicle options that can be considered are (1) use of one of the existing or one of several soon-to-be-available small spacecraft launch vehicles; (2) use of a medium launch vehicle that can launch several small spacecraft at once; or (3) use of a medium or large launch system (e.g., the Space Shuttle) that can launch a small spacecraft in conjunction with other payloads.

Currently, models and simulations of the trade-off process cover costs of the systems engineering, design, and production of the spacecraft with minimal consideration of the life-cycle costs, which frequently are a large part of the overall commitment. There is little published data on small spacecraft costs, so there is some probability of error. However, significant improvement in accuracy over current costing practice could be achieved with modeling that includes a database of recent small spacecraft costs.

Several other factors not necessarily involving technology have a major impact on the cost of a small spacecraft program. A number of guidelines to reduce cost of small spacecraft are listed below:

- Use a design-to-cost philosophy, which permits achievement of most of the original objectives with resources available to the program.

- Use small, integrated product development teams for design, manufacture, test, launch operations, and flight operations. Preferably, the engineers who design the system will also use the system. The result is simpler, easier-to-operate systems, such as the Microsats spacecraft.

- Keep outside oversight at an appropriately low level with emphasis on personal accountability of the individuals doing the work.

- Maintain close, well-coordinated relationships among users, operators, and funding sponsors that enable straightforward and rapid negotiation of key requirements.

- Compare the use of existing launch facilities and infrastructure versus the employment of small spacecraft launch facilities and innovative mission operation concepts and architectures.

- To the largest extent possible, use off-the-shelf hardware and software. This may require innovation to allow the use of technology that has not been flight qualified. For example, the Solar Anomalous and Magnetospheric Particle Explorer (SAMPEX) program was able to use a standard commercial microprocessor that was not radiation hardened by 
placing it in a location that was protected from space radiation by other elements of the spacecraft.

- Provide as much on-board data storage and processing as possible, combined with data compression techniques, to minimize the frequency of ground-station interaction. A large memory also allows more commands to be installed for later execution and a programmable memory permits later alteration.

\section{SMALL SPACECRAFT LAUNCH OPERATIONS}

The cost of launch operations can be a major factor in total space system costs. High costs result when a large number of people and extended periods of time are required to prepare the launch vehicle and the spacecraft after reaching the launch site. The high cost of such systems requires a highly reliable launch. This demands extensive oversight and review activities, which place additional burdens on the launch crew. All launch operations are inhibited by several payload and operational constraints; for example, the early need of the payload for vehicle integration, inability to access the payload during the countdown, compliance with range rules and overflight restrictions, and extensive safety requirements associated with very energetic propellants and ordnance. Technologies, as discussed below, can be used to ameliorate several of these constraints and lower the cost of launch operations.

\section{Spacecraft/Launch Vehicle Checkout and Health Monitoring}

The task of ensuring that the space system is functioning properly is a large consumer of manpower and equipment. The ability to ship the flight vehicles directly from the factory to the launch site and to launch without further testing except to verify interfaces between the spacecraft and the launch vehicle would be optimal. This idea can be approached through the use of on-board health monitoring and, where economical, fault correction. The DoD agencies have made extensive use of built-in-test capability to simplify operations and reduce equipment and personnel requirements in the field for aircraft and missile systems. Under the National Launch System program, which was terminated, the U.S. Air Force sponsored architecture and instrumentation technologies to monitor vehicle and engine system health. Many of these developments could have application to small spacecraft and launch vehicles. In addition, NASA has ongoing technology efforts to evaluate architecture, instrumentation, and software for both vehicle and propulsion system health monitoring. NASA also currently sponsors a center of excellence at the University of Cincinnati for condition health monitoring.

For those checkout requirements that demand extensive ground equipment, the number of people and the amount of equipment could be reduced by using a single set of checkout equipment located at the factory. The equipment could communicate by data link with the vehicle at the launch site. Data could be transmitted over commercially 
available systems, utilizing, if necessary, data storage and reconstitution devices for overload conditions. This approach could reduce the number of people at the launch site who are often idle between launches. For example, the Radio Amateur Satellite Organization has successfully used personal computers to interface with its spacecraft during launch and reduce the personnel required.

With the use of existing launch vehicles, if anomalies are detected during the launch process and a component or subsystem must be replaced, there is often the need to restart the countdown (or a major portion thereof). The result is long delays, missed opportunities, consternation, and cost increases. New launch vehicles and components should be developed that permit component or subsystem replacement without the need to restart the preparation process from the beginning, while still bearing in mind the requirements for pad and personnel safety.

\section{Spacecraft/Launch Vehicle Integration}

The time required to verify the spacecraft/launch vehicle interfaces during integration is a function of the complexity of the interfaces. This can be an especially complicated problem when using a launch vehicle that must accommodate numerous spacecraft configurations. Several contractors and government agencies are pursuing the development of standard spacecraft buses. This issue has been addressed to some extent in the Ariane program by providing a standard interface, which greatly simplifies the integration of very small spacecraft. However, since there is no coordination between various agencies and companies, existing launch vehicles must still accommodate several different spacecraft configurations. Standardization of components and system architecture offers an opportunity for time and cost savings. Standardization at the interface level, with the resultant reduction in interface negotiations, documentation integration, and checkout effort, could produce large cost savings. While this approach might require some degree of mission-specific cabling, the majority of the interfaces could be standardized.

\section{Range Safety Considerations}

One of the current unavoidable costs in launch operations is that of range safety tracking, which is done using a series of ground radars that track the launch vehicle's flight. A range safety officer monitors the trajectory and initiates a destruct command if the launch vehicle displays performance that is outside of preset limits. Much ground equipment and many maintenance and operations personnel could be eliminated if a highly reliable and accurate on-board system for determination of trajectory were available. It is conceivable that GPS could be used to perform this function and transmit the trajectory information to the range safety officer if determined by range safety experts to be an acceptable alternative to the current practices. 


\section{Spacecraft Accessibility and Safety}

Some space missions require access to the spacecraft late in the countdown procedure, for example, to enable insertion of life science experiment specimens or to repair a spacecraft component. The design of current systems does not permit access after the payload shroud is installed. Also, access to the pad is severely restricted on current systems by safety requirements, especially those associated with highly reactive propellants and ordnance devices. One possible solution to the shroud problem is to provide a means for installation of the shroud late in the countdown, but this would require development of attachment methods that are simple, safe, and verifiable. Another method is to provide access into the spacecraft through the shroud.

Resolution of the ordnance problem is more difficult. Various methods have been proposed. One requires developing ordnance devices that would be inert until activated remotely. A possible concept would entail insertion late in the countdown using robotic devices. Another approach would be to use inert materials such as memory metals (e.g., Nitinol), which undergo a phase transformation upon heating, to sever structural connections.

Significant costs for operation of current systems are the result of safety requirements associated with the very energetic and environmentally sensitive propellants used, including the high-energy solid rocket motors. Use of hybrid rockets ${ }^{1}$ would preclude the need for these extensive safety measures because of the improved operability offered by the inherent inertness of the propellant elements up to the time combustion is initiated at launch. The American Rocket Company, with other industry support, has carried out privately funded development work in this area for several years. Their hybrid rocket motor has been test fired, but it is not yet flight qualified (Boyer, 1993). Additionally, there has been independent research and development work on hybrid propulsion by other industrial firms and the U.S. Air Force Academy. Recently, an industry and government consortium was formed for hybrid technology with support from NASA and DoD under the federal Technology Reinvestment Program (American Rocket Company, 1994; NASA, 1993b; U.S. Congress, 1993).

\section{Flight Programming}

Another major element of launch operations costs (and of flight operations costs) is the preparation of the flight programming software required for each individual mission and for each individual launch vehicle. A computer program for flight programming that would prepare the flight programming software for the launch upon insertion of several trajectory and launch vehicle parameters could reduce the time and cost required for this activity. The BMDO/McDonnell Douglas Single-Stage-to-Orbit project was working on the development of such a program prior to its cancellation

\footnotetext{
${ }^{1}$ Hybrid rockets employ a liquid oxidizer with a solid, inert fuel.
} 
(Palsulich and Raspet, 1993). At the time of this report, announcements indicate the single-stage-to-orbit technology efforts will be continued under the auspices of NASA (Iannotta, 1994). The previously mentioned MSTI program also has as one of its objectives the demonstration of automation of the design of the control software and flight code software (Matlock et al., 1993).

\section{SMALL SPACECRAFT MISSION OPERATIONS}

Mission operations, which include the people, hardware, software, ground systems, and space assets necessary to conduct day-to-day activities, are a significant lifecycle cost driver for many space systems. In fact, recent procurements suggest that the cost of mission operations for longer, more complex missions can equal or exceed development cost. In the past, mission operators got involved too late in the project definition phase to have opportunities to reduce the life-cycle cost significantly. For small spacecraft missions, the mission operations concept and supporting space mission architecture must be addressed early in the program. In fact, if possible, the spacecraft should be developed by the team of spacecraft designers and the engineers and technicians who will operate and use it.

Today NASA maintains and operates a number of facilities for transmitting and processing spacecraft data. These facilities, which represent the existing infrastructure for NASA operations, consist of

- the Tracking and Data Relay Satellite System (TDRSS) network, which uses large geosynchronous satellites and a major Earth station in New Mexico (this network services most U.S. low Earth-orbiting spacecraft and the Space Shuttle);

- the Deep Space Network, maintained and operated by JPL for planetary and high Earth orbit missions;

- the Ground/Space Tracking and Data Network, which is made up of various smaller ground facilities for general tracking and data reception and retransmission;

- the Wallops Island ground station, which is used for the Small Explorer program; and

- a number of services maintained and operated by commercial and common carriers.

The TDRSS, Deep Space Network, and Ground/Space Tracking and Data Network all offer some standardized communications interfaces.

During the last decade, the developers and operators of low-cost, small Earthorbiting spacecraft systems have avoided using the existing infrastructure. It was found to be complex, costly, and incompatible with the overall concepts of short development time and low-cost operations. However, dedicated receiving and tracking facilities on the ground are too costly if there is a mission requirement for real-time data, and reliance 
must be placed on space-borne systems such as TDRSS. To increase the usage of the TDRSS for small spacecraft support (particularly for real-time high-data-rate missions) or to permit high-data-rate transmission directly to the ground (with dedicated or specialized ground antennas), several efforts are underway in private industry and in government to replace the costly, heavy transponders needed today. The private ventures seem to have reached the limit of corporate independent research and development funding and may need enhanced government support to take them from laboratory ventures to flight-qualified status. The principal companies involved are Motorola, Cincinnati Electronics, and Stanford Electronics. Several NASA facilities (GSFC, JPL, and Wallops Island) are also interested in developing ways to increase TDRSS's use with small spacecraft.

Another major cost element in mission operations is personnel. Mission operations is a labor-intensive activity. Most approaches to reducing its cost involve one or a combination of the following:

- distribution of ground control functions or portions of them to other areas (e.g., on-board orbit determination and controls, distributed processing of remote sensing and scientific data);

- standardization of interfaces and communications;

- automation of repetitive, labor-intensive functions; and

- reuse of existing software, hardware, and procedures.

\section{Distributed Functions}

An effective way to reduce mission operations costs is to reduce the number of functions required of the mission operations team. Application of currently available technology for on-board orbital position determination would enable the spacecraft to autonomously determine its orbit parameters and command the proper systems to maintain the desired orbit parameters, achieving autonomous station keeping. The MSTI program has an objective to demonstrate this capability using an advanced star tracking system. An on-board GPS receiver could also provide the position information for most Earth-orbiting spacecraft.

The distribution of payload data analysis also could relieve the mission operations team of a large workload. Payload data for remote sensing and scientific missions could be processed on-board and the processed data transmitted to the ground to reduce transmission load, and it could be distributed directly to locations where further processing could be done more cost effectively. The computing power to handle much of the processing load is readily available. The technical challenge is to develop a data distribution system that gets the data from the spacecraft to the user's computers in the appropriate timeframe and medium. For example, the Radio Amateur Satellite Organization and the NASA Solar Mesosphere Explorer program both have ground stations that allow experimenters to receive data directly from the spacecraft. 


\section{Standardization}

Standardization of certain aspects of mission operations has the potential of reducing cost. However, imposition of numerous standards carries the risk of overly restricting the creativity of small spacecraft system design teams and requiring excessive documentation, which could conceivably result in increased cost. Mandatory standards should be chosen very selectively, but the availability of standards, which the design teams could choose to adapt, could have large potential for cost savings. The following are specific areas of standardization for consideration (Wall and Ledbetter, 1991).

- $\quad$ Tracking and orbit data formats require use of a common data structure for spacecraft tracking data and a common set of conventions for the models and coordinate systems used to process the tracking data by all agencies participating.

- $\quad$ Telecommunications characteristics require using common frequency bands; ground-timing stability criteria; and command, telemetry, and ranging bandwidths among and within all facilities and agencies participating.

- Standard-format data units require use of a common data structure for transfer of data between any elements of the ground data system.

- Common time-code formats require all spacecraft and ground systems to use a common format for time and to select that format from a predetermined set of formats. On-board clocks would be limited to specific oscillator frequencies, formats, and characteristics.

- $\quad$ Packetized ${ }^{2}$ telecommands require all ground-prepared commands for transmission to a spacecraft to conform to a common data structure, including frame size and format.

- Packetized telemetry requires payload and housekeeping data on the spacecraft to conform to a common data structure, including frame size and format.

- $\quad$ Telemetry channel coding requires data coded on a spacecraft to select from a set of acceptable downlink coding algorithms.

\section{Automation}

Automation of carefully selected tasks can reduce the cost of space mission operations. Typical goals of automation are to reduce life-cycle cost, enhance efficiency, and reduce the number and frequency of errors. The key is to automate the appropriate tasks in the spacecraft or on the ground. Candidates for automation are straightforward,

\footnotetext{
${ }^{2}$ Packetized - consolidated communications commands that can be accepted or rejected as a group.
} 
repetitive tasks like command verification, trend analysis of spacecraft subsystems, fault detection, and even operations status briefings. Expert systems may even be useful to augment the efforts of people performing mission operations.

\section{Reuse of Software, Hardware, and Procedures}

Reusing software and procedures for mission operations, if done properly, can greatly reduce development cost. Many software routines and procedures are resident within the existing mission operations infrastructure, where they have been developed, tested, and used to conduct mission operations. A program can realize the greatest savings by reviewing existing software, hardware, and procedures early in the program and adopting acceptable items. Spacecraft developers and mission operations teams can then design other necessary software and procedures to be compatible with the existing resource. Goddard Space Flight Center, for example, has doubled the amount of software and procedures they reuse, from 40 percent to 82 percent (Boden and Larson, 1994).

\section{PRIORITIZED RECOMMENDATIONS}

In order to enhance engineering and operations of small spacecraft systems, the Panel on Small Spacecraft Technology makes the following prioritized recommendations for NASA:

1. Capabilities and design tools should be developed that facilitate improved up-front concept development for low-cost small spacecraft missions. These capabilities and tools should facilitate in-depth trades that result in improving the ability to estimate and in lowering overall life-cycle costs. Key trades include:

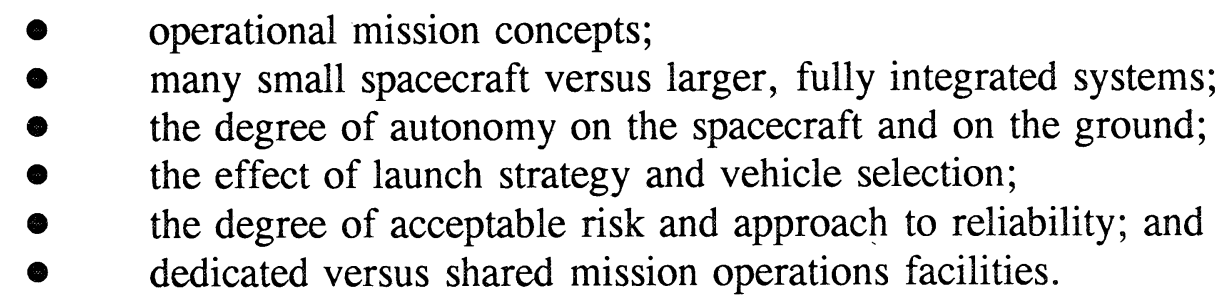

Tools that would be useful are

- data bases and cost estimating software that address life-cycle cost of small missions; and

- nationally available data bases for existing parts, components, and new technologies. 
2. Technologies and techniques should be developed that would reduce the required number of mission operations personnel. These techniques include:

- autonomous orbit determination and correction;

- on-board data screening to reduce the amount of data to be transmitted to the ground; and

- communication systems for distribution of mission data directly from the spacecraft to the data users.

3. Technologies and practices required to enable a factory-to-launch sequence with minimum checkout at the launch site should be developed and demonstrated. These should utilize expert systems when appropriate, including, as a minimum, the following:

- on-board health monitoring and checkout and, where economical, fault correction, for both the launch vehicle and the spacecraft;

- $\quad$ techniques for remote system checkout;

- automated preparation of flight software for guidance and control of both the launch vehicle and spacecraft;

- a set of standard hardware interfaces for small launch vehicles and spacecraft;

- $\quad$ on-board launch trajectory determination for range safety tracking;

- $\quad$ spacecraft accessibility late in the countdown; and

- reduction of launch pad safety requirements through use of technologies such as hybrid propulsion and nonexplosive separation devices.

4. Data storage and transmission techniques should be developed that meet the needs unique to small spacecraft. These techniques should utilize:

- low-cost, miniaturized, high-capacity, reliable data storage devices;

- efficient, high-data-rate transmission techniques;

- better forward error-correction codes; and

- efficient protocols for high-speed-data interactive transactions.

5. Standardized communications interfaces for mission control functions should be developed. Areas for standardization include:

\footnotetext{
- tracking and orbit data formats;

- telecommunications characteristics;

- $\quad$ standard-format data units;

- time-code formats;

- packetized telecommands;

- $\quad$ packetized telemetry; and

- telemetry channel coding.
} 


\section{3 \\ Spacecraft Propulsion Technology}

\section{BACKGROUND AND STATUS}

Propulsion systems on board spacecraft perform orbit transfer, attitude pointing and control, orbit altitude maintenance, north-south or east-west station keeping in geosynchronous orbits, orbit raising from low Earth orbits up to and including geosynchronous Earth orbit, and in-space primary propulsion. Each maneuver places an emphasis on various performance characteristics of the propulsion system, such as thrust level and specific impulse, and not all missions require the propulsion unit to perform all of the cited operations. However, the propulsion system must be capable of operating in various modes to meet the needs of the mission. These modes range from individual engine pulses (possibly for station keeping) to long-duration, steady-state thrusting (perhaps for interplanetary missions). In addition, if clusters of small spacecraft are used for missions requiring simultaneity of measurements, a propulsion system with very high accuracy and precision may be required for station keeping.

The smaller mass, moments of inertia, and volume of the small spacecraft drive the desired characteristics of the propulsion system. For on-orbit operations of small spacecraft, the thrust levels must be smaller than those on large spacecraft to keep the acceleration levels within the design limits. The impulse bits delivered for pulsed operation also must be smaller to allow the spacecraft to stay within the bounds of the stabilization control logic. Additionally, the propulsion system volume and weight must be minimized.

Spacecraft maneuvers are usually done with chemical propulsion systems. Past improvements of these systems, while impressive, have been incremental. In the future, dramatic improvements in propulsion technology for small spacecraft could be accomplished through other types of propulsion such as electric propulsion. For example, the low weight of the small spacecraft opens up the orbit-change operation to electric propulsion. The very low-thrust electric propulsion devices can be employed for payload placement in orbit or on interplanetary trajectories within reasonable time frames and can possibly reduce the size of the launch vehicle required. 


\section{CHEMICAL PROPULSION}

Chemical spacecraft propulsion devices, other than those used for orbit elevation or orbit insertion, usually employ liquid reactants as the energy source. The propellant might be a single reactant (monopropellant) or a combination of fuel and oxidizer (bipropellant).

The most common monopropellant is hydrazine. It is passed through a catalyst bed, where it decomposes into ammonia and nitrogen at a temperature of about $700^{\circ} \mathrm{C}$ with a delivered specific impulse ${ }^{1}$ of about 230 seconds. A monopropellant propulsion system is relatively simple and is amenable to short, pulsed operation, which is suitable for small spacecraft attitude control.

The most common bipropellant system utilizes a nitrogen tetroxide oxidizer and a fuel of either hydrazine or monomethyl hydrazine. The reactants are hypergolic, ${ }^{2}$ facilitating ignition under vacuum conditions and pulsed operation. Use of hypergolic reactants also provides the capability to restart the system when necessary. The delivered specific impulse of such systems is about 310 seconds.

A chemical energy propulsion system integrated into a typical spacecraft operating in Earth orbit can range from 10 to 20 percent of the total spacecraft weight; or up to 40 to 50 percent if significant parts of higher orbit insertion and circularization are included in its mission cycle. Technology advancements have therefore focused on achieving higher specific impulse since 90 percent of the propulsion system weight is usually propellant. Most thruster technology focuses on increasing the allowable operating temperature and duty cycle life of radiation-cooled combustion chambers, and on achievement of very small reproducible impulse bits without major degradation in specific impulse. In some special applications with minimal total impulse requirements, thruster weight may be an important factor and some research and development has been focused on thruster weight reduction.

For monopropellant systems using hydrazine, research has been focused on increasing the pulse duty-cycle life by reducing catalyst bed degradation, and on increasing the specific impulse by use of electric energy for raising the decomposition products temperature before expansion through the nozzle.

\section{NASA Chemical Propulsion Programs}

The Lewis Research Center (LeRC) is working with Aerojet General, TRW, Atlantic Research, and Ultramet to develop high-temperature, oxidation-resistant materials for small, bipropellant, high specific impulse rockets across a broad spectrum of thrust levels ( 22 to 550 newtons). The designs incorporate a rhenium-iridium thrust

${ }^{1}$ Specific impulse is the impulse delivered to the spacecraft per unit weight of expelled propellant.

${ }^{2}$ Hypergolic substances are ones that react spontaneously upon contact. 
chamber that can permit operation at temperatures up to $2200^{\circ} \mathrm{C}$. To date, LeRC has designed, fabricated, and tested four different rockets. One system has tentatively been baselined on an advanced commercial communication spacecraft. Specific goals of the project include attaining specific impulses greater than 350 seconds, a factor of three or greater reduction in rocket sizes and masses, and the ability to operate radiation-cooled rockets at arbitrary propellant mixture ratios with all on-board propellant options (Bennett, 1994). While not necessarily an enabling technology for small spacecraft in general, these thrusters offer a higher performance, chemical propulsion option for orbit raising, while retaining payload delivery time to orbit on the order of hours.

\section{Department of Defense Chemical Propulsion Programs}

Much of the recent, low-thrust, propulsion technology that has been developed within BMDO programs can be used as a technology base for small NASA spacecraft. The primary issues become those of capitalizing on the potential for large weight savings, extending the life of the propulsion system for scientific rather than military requirements, and tailoring the size of the system to small spacecraft applications. The issues also include finding techniques for increasing thrust chamber reliable lifetimes to permit the long operating times demanded by some scientific missions.

Technology advances and extensive reductions in weight and size of pulsed, bipropellant and monopropellant chemical propulsion units have been made with the recent work on kinetic-kill vehicles by BMDO under the Light Exo-Atmospheric Projectile program. Under this program, a 755-newton bipropellant thruster weighing 64 grams, developed by the Rocketdyne Division of Rockwell International, has been flown on a prototype kinetic-kill vehicle at the Air Force's National Hover Test Facility at Edwards Air Force Base, California. The thruster's rapid-response valving system makes it suitable for numerous spacecraft maneuvering functions. Concurrent with these developments, monopropellant attitude control thrusters (223 to 500 newtons) developed by Rocket Research Company with high pulsing rates and low weight (184 to 326 grams) have also been demonstrated on the kinetic-kill vehicle.

Advances in lightweight, piston-pump, propellant supply systems have been made by Lawrence Livermore National Laboratory in conjunction with Rocket Research Company and Moog Valve. These advances reduce feed system weight by about 50 percent while improving engine performance (Whitehead, 1993).

The Advanced Liquid Axial Stage program funded by BMDO has also made significant advances in reducing the propulsion system weight while demonstrating the practicality of using carbon composites for spacecraft structures. Carbon composites have been used as the high-temperature thrust chamber structure for high-performance small thrusters and in the construction of high-pressure, bipropellant propulsion tanks. Use of a carbon-fiber overwrap on a thin aluminum tank liner permits high-pressure tankage operation at one-half the weight of presently used tanks.

Under Air Force sponsorship through the U.S. Air Force Phillips Laboratory and the Space Systems Division, Aerojet General Corporation and Rocketdyne have 
demonstrated 16,680-newton orbit transfer engines that use a nitrogen tetroxide and monomethyl hydrazine bipropellant to deliver a specific impulse of 340 seconds at the time of this study. These engines, designated XLR-132s, represent a major upgrade in the technology and enhance payload delivery capability. At the time of this study, the Aerojet General Corporation engine has amassed 680 seconds of operating time at simulated altitude; the Rocketdyne version has accumulated 700 seconds of test time primarily at sea level.

\section{SOLAR PROPULSION}

Whereas chemical propulsion devices use the energy of chemical reactants, solar propulsion devices use the sun's energy to generate high-temperature gases that are expelled at high velocities from a thruster. There are two methods by which this is accomplished. First, a solar electric thruster can convert the solar energy to electrical energy by means of solar cells. This electrical energy is then used to power a thruster in which the electrical energy is converted to the kinetic energy of the expelled, hightemperature gases. The second method captures the solar energy in the cavity of a solar thermal thruster, where its thermal content is absorbed by a working fluid that, in turn, is expelled for thrusting purposes.

\section{Solar Electric Propulsion}

Solar electric propulsion is a near-term technology with considerable potential for reducing spacecraft mass and cost. Electric propulsion generally is characterized by low thrust and high specific impulse. While it cannot satisfy requirements for prompt deployment at high altitudes, it is well-suited for less urgent, anticipated demands. Electric propulsion can result in spacecraft weight reduction that could dramatically reduce costs by allowing the selection of a smaller launch vehicle. It also can reduce or eliminate the use of gravity assists in planetary missions by enabling direct trajectories, as well as shorter trip times. Even missions to the outer planets could utilize the solar electric propulsion for continuous thrusting out to perhaps three astronomical units before solar flux diminishes beyond a useful intensity. For surveillance or remote sensing missions that require frequent maneuvering or repositioning, the comparatively high efficiency of electric thrusters can substantially increase spacecraft lifetime or enhance versatility. Low-thrust, electric propulsion could also be well-suited for precision station keeping of clusters of small spacecraft.

The three basic types of electrically powered thrusters, in order of successively greater potential for higher specific impulse are arc jets, electromagnetic (plasma) thrusters, and ion engines. Arc jets can deliver a specific impulse from about 450 to 550 seconds, whereas electromagnetic thrusters can provide a specific impulse in the range of 1,000 to 2,000 seconds, and the xenon ion engine can deliver a specific impulse in the range of 2,500 to 3,500 seconds. The power required to be delivered to the propulsion 
system will be proportional to the operating specific impulse, the thrust profile required to satisfy the mission and the overall efficiency of the unit. Depending on the application and system, design, power levels for small spacecraft could range from ten's of watts to many kilowatts.

Power requirements for electric propulsion include both the power delivered to the spacecraft and to the energy residing in the ejected propellants. This total power is proportional to the thrust times the operating specific impulse. The optimization of any size spacecraft for various missions where electric propulsion may be advantageous requires careful trade offs between power level, specific impulse, and thrust profiles. These optimizations will usually determine the selection of arc jets, plasmas, or ion-type thrusters and their operating profiles during the mission. Such profiles can be very different for orbit-raising velocity increments versus station-keeping impulse bits or versus the energy input profile for interplanetary flights where trajectory plans would dominate. However, power requirements for orbit-change velocity increments and interplanetary flights generally will require higher power levels.

Recently U.S. private industry has begun to use small arc jet propulsion systems for station keeping of geostationary communications satellites (Aerospace America, 1993; Space Technology Innovation, 1994). However, there are no flight-qualified single thruster modules currently available at power levels of one kilowatt or more (note: the "desirable" power level is totally mission and device oriented).

The xenon ion engine has a higher specific impulse than the electromagnetic and arc jet thrusters. To date, no commercial spacecraft manufacturer has flown ion propulsion engines. However, Hughes has baselined a xenon ion propulsion system for the HS601 Galaxy large spacecraft scheduled for launch in 1995 which could be applicable to small spacecraft. The xenon thruster at the 1-kilowatt class power level for small spacecraft would require work to improve the ion optics of the thruster, which impacts thruster life. Ion thruster technology is well-suited for interplanetary science missions using Delta II-class launch vehicles, small spacecraft (100 to 300 kilograms), and short mission durations. This technology could also be directly applicable to commercial spacecraft for station keeping.

\section{NASA Programs for Solar Electric Propulsion}

Development of the arc jet and ion thruster technologies are underway at both NASA LeRC and the U.S. Air Force Phillips Laboratory. In addition, Boeing is currently exploring a solar electric propulsion option for the Pluto Fast Flyby mission with internal funds. While a variety of technical issues still need to be resolved, studies on the Pluto Fast Flyby mission indicate that a solar electric propulsion unit that utilizes three high voltage, 5-kilowatt-electric xenon ion thrusters may enable a Delta-class or Atlas-class launch vehicle to be used instead of a Titan IV. The electric power for these thrusters is generated by solar panels, which employ mini-dome concentrators to enhance electrical output of the solar (photovoltaic) cells. Such a unit would make trip times of less than 11 years possible through the use of Earth-gravity-assist maneuvers compared 
to the baselined 8-year direct flight without gravity assists. Use of solar electric propulsion for the Pluto Fast Flyby mission deliberately pushes technology and would require significant investments in design, development, test, and evaluation to reach acceptable levels of mission risk.

NASA is scheduled to flight qualify a 2.5-kilowatt xenon ion engine aboard the U.S. Air Force Phillips Laboratory's Electric Insertion Transfer Experiment, which is tentatively scheduled for launch in 1998.

\section{DoD Programs for Solar Electric Propulsion}

BMDO is sponsoring research and development work on the SPT-70 and SPT-100 electromagnetic Hall thrusters from Russia. Both devices are in the power range of interest for orbit raising and other functions for small spacecraft. Currently, tests are being conducted at LeRC and JPL to validate the performance and life of the thrusters and determine the radiation fields generated about the thruster during operation (Space News, 1993). Preliminary ground testing has produced mixed results due to the highly ionized exhaust plume, which can interfere with communications, and the wide plume divergence angle, which means the thrusters must be canted to avoid hitting delicate parts of the spacecraft. BMDO flew the SPT-70 electric thruster on the MSTI II spacecraft that was launched in May, 1994 (Matlock et al., 1993). The test flight of the SPT-100 device was planned in conjunction with the test flight of the Topaz reactor, which, at the time of this report, has been indefinitely deferred.

Ammonia arc jet thrusters are planned for use in the U.S. Air Force Phillips Laboratory's Electric Propulsion Space Experiment, scheduled for launch in 1995 and the Electric Insertion Transfer Experiment, scheduled for launch in 1998 (Avila, 1992; Sneegas et al., 1993).

\section{Solar Thermal Propulsion}

Solar thermal propulsion offers promise of a higher thrust capability than electric propulsion at lower specific impulse. Research indicates that these devices for propulsion may be able to deliver a specific impulse of about 850 seconds with higher thrust levels than solar electric thrusters (less than one newton), but they are less developed. The demonstrated specific impulse to date is on the order of 600 seconds. The solar collector (mirror) technology required is dependent upon successful demonstration of lightweight, deployable mirrors that can be easily packaged and then deployed in space. These mirrors must have concentration ratios on the order of 10,000:1 to produce the desired thrust levels for small spacecraft. Both the thruster required to absorb the radiated energy that is needed to heat the working fluid and the mirror collector technologies require significant development efforts before solar thermal propulsion can be fully demonstrated. 


\section{NASA Programs for Solar Thermal Propulsion}

NASA does not have any solar thermal propulsion programs.

\section{DoD Programs for Solar Thermal Propulsion}

Technology for solar thermal propulsion is being supported mainly through the DoD Small Business Innovative Research (SBIR) funds and company-funded efforts. Research and development of solar thermal devices has been underway at the U.S. Air Force Phillips Laboratory and in company-funded efforts in 0.22-newton thrust-level devices at Rocketdyne and Hercules (Pande, 1993). The solar collector technologies needed to implement a solar thermal device also are being pursued through the U.S. Air Force Phillips Laboratory.

\section{NUCLEAR PROPULSION}

Both nuclear electric propulsion and nuclear thermal propulsion have been considered by mission planners (e.g., for the Mars mission studies). These technologies are generally incompatible with the assumption in this report of 600 kilograms as the upper limit for small spacecraft. Nuclear propulsion does, however, have the potential of raising a 1,000-kilogram spacecraft from low Earth orbit to geosynchronous Earth orbit with Atlas-class boosters. The technology, therefore, may be addressed in future Aeronautics and Space Engineering Board studies.

\section{FINDINGS AND PRIORITIZED RECOMMENDATIONS}

The Panel on Small Spacecraft Technology believes that advanced propulsion technology can provide dramatic reductions in the cost of placing the payload in orbit. Specifically, electric propulsion can be an enabling technology for small spacecraft in that its use for orbit-raising functions can effect a reduction in launch vehicle size with an attendant reduction in launch costs. It can also be an enabling technology for small spacecraft cluster station keeping.

Miniaturization and weight reduction technologies have been demonstrated on chemical propulsion systems. In turn, these technologies lead to reductions in the mass and volume of propulsion systems aboard the spacecraft, which are necessary for on-orbit functions such as attitude control, repositioning, and station keeping. However, lifetimes of months to years are required for such applications and necessitate additional technology advancement to ensure suitability of the demonstrated technologies.

The panel recommends that NASA focus its technology development and integration resources, first, on solar electric propulsion technology for primary (orbit transfer stage or spacecraft) propulsion; second, on advanced chemical propulsion; and 
third, on solar thermal propulsion technology. Specific recommendations on propulsion technology are prioritized below.

1. An aggressive program should be established to demonstrate, in ground tests, the life of xenon ion propulsion systems that operate at power levels in the range from about 0.5 kilowatt to about 2.5 kilowatts for lifetimes of up to 8,000 hours. Arc jet thrusters for small spacecraft applications also should be evaluated. The systems demonstrated should be capable of being integrated into solar electric propulsion systems with total power levels in the range of 1 to 5 kilowatts. Both the ion thruster and the arc jet should then be demonstrated in space flight tests in the near term.

2. The propulsion system requirements should be determined for precision station keeping of clusters of small spacecraft, and the capability of currently available systems should be evaluated. If it is necessary, systems should be developed to meet specific mission requirements.

3. A technology program should be established to demonstrate the Light ExoAtmospheric Projectile propulsion technologies at mission duty cycles and lifetimes consistent with small spacecraft mission life and operational requirements.

4. The 445-newton rhenium-iridium thruster should be evaluated for application to an apogee kick stage for small spacecraft. This includes demonstration over a duty cycle typical of the missions envisioned for small spacecraft.

5. The suitability of the XLR-132 engine as an upper-stage propulsion system for launching small spacecraft with deep space propulsion needs should be evaluated.

6. Research and technology programs should be initiated to demonstrate fully the capability of solar thermal rockets, with emphasis on concentrator/mirror, absorberthruster, and feed-system technology. Space flight tests should be conducted to explore deployment mechanisms and dynamics, validate packaging techniques, and demonstrate the performance and durability of absorber-thruster operation with a deployable concentrator mirror. 


\section{4 \\ Spacecraft Electric Power}

\section{BACKGROUND AND STATUS}

A spacecraft's electrical power system generally consists of the primary power generating unit (solar or nuclear), the power management and distribution system, and an energy storage unit. The power system typically accounts for 25 to 35 percent of spacecraft dry mass (Herrera and Kuck, 1992; Larson and Wertz, 1992). In solar power systems, the energy storage unit represents about one-third of the mass of the power generating unit. Nuclear radioisotope power systems are independent of sunlight and require little or no energy storage. The choice of power system depends on such considerations as power level (average and peak), mission lifetime, and operating environment. In the vast majority of cases, solar power systems are preferred over nuclear power ones due to their lower cost and simpler launch approval procedures.

\section{POWER SOURCES}

\section{Solar Arrays}

For space missions that are sufficiently close to (and with an unobstructed view of) the sun, solar cell arrays can meet most near-term space power needs for small, lightweight spacecraft by converting solar energy to electrical power. Solar cells can be mounted directly on the external surface of the spacecraft or on panels that are deployed once the spacecraft achieves orbit. The performance of solar arrays is quantified by (1) the specific power, power delivered by solar array per unit weight (watts per kilogram); (2) the power density, the power delivered by a solar array per unit area (watts per square meter); and (3) the survivability level, the capability of an array to survive hostile attack (for DoD missions) and the space environment.

Solar array configurations are either (1) unconcentrated, in which case they operate on the as-received solar flux or (2) concentrated, where the solar cells' output is increased by the use of lenses in order to focus more solar radiation onto the cells. Unconcentrated arrays are not necessarily planar; they can also be cylindrical or spherical 
and can be subdivided into rigid and flexible arrays. The flexible arrays include blanket arrays and inflatables. Concentrated arrays are usually planar.

Silicon and gallium arsenide cells are currently used on spacecraft arrays. Of the two technologies, silicon solar cell technology is the more mature and has the lower cost per watt. However, gallium arsenide, first flown in 1983, has a higher energy conversion efficiency and is inherently more resistant to radiation (Larson and Wertz, 1992). Unfortunately, gallium arsenide costs approximately two to five times more than silicon and is 2.2 times as dense (Chetty, 1991). Other cell types, such as amorphous silicon, aluminum gallium arsenide, indium phosphide, copper indium diselenide, cadmium telluride, and multibandgap cells, are under development and have been flown experimentally, but have not yet been flight qualified for major U.S. operational spacecraft (Cooley, 1991). For example, although copper indium diselenide and amorphous silicon cells are both now flying on the LIPS-III satellite, and a new program has been funded by OACT for a flexible, indium phosphide, thin-film solar array experiment, neither of these systems has been qualified to an acceptable level for deployment in major U.S. flight systems (Landis and Hepp, 1991; NASA, 1993a).

NASA and DoD, both with industry support, are developing high specific power solar array systems for small spacecraft applications. The status of research within each organization is summarized below.

\section{NASA Programs}

NASA's research activities on solar cell and solar array technology are currently centered at the LeRC. Until recently, JPL also had a program for high-performance solar array technology, which was complementary to LeRC's program on high-efficiency, radiation-resistant solar cells.

LeRC. LeRC's power systems programs focus on Earth orbital applications. LeRC contributed to the large area silicon cell technologies (with strong contributions in cell technology from the European Space Agency) that were used on the Hubble Space Telescope and were scheduled for use on Space Station Freedom, prior to the latest redesign (Cooley, 1991). Flexible, roll-up arrays made from these silicon cells were initiated at LeRC and further developed by the U.S. Air Force at the Wright-Patterson Air Force Base. These flexible silicon cell arrays were eventually utilized on the Hubble Space Telescope.

LeRC is currently working on many advanced solar cells, such as copper indium diselenide cells, amorphous silicon cells, indium phosphide on germanium cells, cadmium telluride cells, and other multibandgap cells. ${ }^{1}$ LeRC is also performing research on

${ }^{1}$ The multijunction approach utilizes the solar spectrum more efficiently by stacking several bandgap cells (e.g., a thin gallium arsenide cell stacked on top of a silicon cell) in series such that successive junctions convert different frequency ranges of sunlight. 
ultralight flexible panels that could utilize many of these advanced cells in various flexible array designs.

One inflatable array design under development at LeRC utilizes flexible silicon cell panels, which can provide total power in the range of 200 to 500 watts at a specific power of 200 watts per kilogram. In the future, substitution of silicon cells with cells of 20 percent indium phosphide on germanium could result in a more radiation-tolerant array with approximately 1 percent degradation over 10 years and an efficiency of greater than 17 percent. Use of arrays with indium phosphide on germanium solar cells is expected to produce a specific power of 130 watts per kilogram and would enable long-life missions in polar orbits and other high-radiation environments (Budinger et al., 1993).

At a recent joint LeRC, JPL, GSFC workshop, the participants concluded that most of LeRC's advanced solar cell work could be ready for flight qualification within seven years (NASA/OACT, 1993).

$J P L$. JPL's research and technology programs generally focus on planetary exploration. Most of the solar array work at JPL has been carried out under the Advanced Photovoltaic Solar Array (APSA) program, which was cancelled due to funding limitations. A flexible, lightweight fold-up solar array with a mass of 1 kilogram per square meter of collecting area was developed by JPL under the APSA program, in conjunction with TRW's Space and Electronics Group. The array design incorporates both thin silicon cells and thin gallium arsenide on germanium substrate cells. The cells are attached to a flexible Kapton polyamide blanket. A fiberglass deployment mast is used. The complete array system produces 135 watts per kilogram (Scala, 1993). Although a full-size flexible blanket array was not flight tested, fabrication, integration, ground vibroacoustic testing, and ground deployment tests of a prototype 6-kilowatt APSA array were successfully completed (Kurland and Stella, 1992). The JPL/TRW APSA flexible solar cell blanket array technology is currently scheduled for use on two future missions: the NASA Earth Observing System AM-1 mission, using gallium arsenide on germanium solar cells, and a DoD mission supported by TRW, also using gallium arsenide on germanium solar cells.

Prior to program termination, the midterm goal of the APSA program was to implement cell fabrication methods and array assembly procedures for thin-film solar cells that could increase array specific power to 190 watts per kilogram. As an example, advanced thin-film gallium arsenide or aluminum gallium arsenide cells produced by Kopin Corporations's Cleaved Lateral Epitaxy Films for Transfer (CLEFT) process could have been utilized by 1996. Just prior to termination, lightweight flexible modules utilizing thin-film gallium arsenide solar cells from this process were fabricated for JPL and sent to LeRC for thermal cycling tests. The long-term APSA program goal was to develop flexible solar cell blanket array designs with array specific powers of 300 watts per kilogram (at 12 kilowatts total power) by the year 2000, and of 20 to 25 kilowatts total power ultimately.

JPL has been working with industry and universities to improve the performance of silicon cell arrays at distances from two to five astronomical units from the sun. These 
low-intensity, low-temperature conditions degrade the performance of conventional silicon cells due to metallization and silicon interactions. JPL hopes to solve the lowintensity, low-temperature technology problem by 1995 , but the program is likely to be terminated due to budget reductions.

\section{DoD Programs}

DoD, including the U.S. Air Force, BMDO, and the U.S. Navy has performed substantial work to increase the specific power in solar arrays for low-power, small spacecraft applications. Prior to the availability of flexible arrays analogous to those developed in the NASA APSA program, DoD platforms generally utilized planar silicon arrays with specific powers ranging from 40 to 60 watts per kilogram. These arrays have beginning-of-life efficiencies of 12 to 15 percent that drop to end-of-life efficiencies of 10 to 12 percent (Russell et al., 1992). For the same specific power, advanced technology for gallium arsenide on germanium cells could offer a nominal end-of-life efficiency as high as 18 percent (Russell et al., 1992).

In the past, DoD has supported research on concentrator arrays through various programs, such as the now-cancelled BMDO/Martin Marietta Survivable Power Subsystem Demonstration program and its predecessor, the Survivable Concentrator Photovoltaic Array program. These technology programs were supported by the Strategic Defense Initiative Organization with plans for future incorporation into the Brilliant Eyes program.

Although the design objectives for DoD concentrator technology generally focus on survivability rather than efficiency and high specfic power, there were several DoD technology advancements made in these programs that may hold promise for future NASA spacecraft. For example, the concentrator technology developed for the Survivable Concentrator Photovoltaic Array and the Survivable Power Subsystem Demonstration programs (mini-Cassagrainian arrays developed by TRW, minidome arrays developed by Boeing, and slats being developed by General Dynamics) has the potential to reduce by a factor of two the cost of planar arrays and to eventually provide specific power of around 80 watts per kilogram, at beginning-of-life overall efficiencies of 24 percent. However, with the formal dissolution of the Strategic Defense Initiative Organization into BMDO, and the termination of several programs such as the Survivable Power Subsystem Demonstration program, the advancement of the concentrator technology within DoD is uncertain.

Currently, the Air Force is trying to maintain work in multibandgap cells and thin-film cells despite the absence of funding from BMDO and overall DoD budget cuts. Production of cells with intermediate capability levels is within a year or two of completion.

BMDO, the Naval Research Laboratory, and NASA are jointly sponsoring the Deep Space Program Science Experiment (Clementine) program, which will demonstrate lightweight technology components with a lunar mapping and asteroid flyby mission that was launched in January 1994. The spacecraft is utilizing gallium arsenide on germanium 
cells that are 0.14 centimeters thick at 40 watts per kilogram. These are the thinnest gallium arsenide solar cells flown to date (Nozette, 1993).

\section{Nuclear Technology}

Nuclear radioisotope power systems convert the heat from a radioisotope heat source into electricity. Current radioisotope power systems are more compact than solar systems and are mass-competitive, but they are quite costly and require a complicated launch approval process. Therefore, solar power is always preferred over radioisotope power, except for deep space or sun-obscured missions, where there is too little sunlight for efficient photovoltaic conversion, and for missions near the sun, where the solar flux is too intense and too variable for practical solar powered systems. The use of nonrechargeable batteries for primary power has been proposed for some missions, but for the power levels and operating times required by those missions, batteries become prohibitively heavy for a small spacecraft. For such missions, radioisotope systems are enabling and are used in spite of their cost and complicated launch approval process.

In today's systems, thermoelectric unicouples are used to convert heat into electricity. These systems, while reliable and long-lived, are inefficient. Substantial reductions in cost and mass of radioisotope power systems can be achieved through development of more efficient power conversion technologies. Potential conversion technologies include advanced thermoelectric materials, Stirling engines, alkali metal thermoelectric converters, and thermophotovoltaic systems. The last three options offer the possibility of tripling or even quadrupling the efficiency of thermoelectric converters, with corresponding reductions in the cost and mass of the required radioisotope fuel.

Both NASA and the Department of Energy (DOE) have invested in conversion technologies for radioisotope power systems that could be used for small 'spacecraft. The status of research within each organization is summarized below.

\section{NASA Programs}

LeRC. LeRC and its contractors, Mechanical Technologies, Inc., Sunpower, STC, and others, have been working on free-piston Stirling engines internally coupled to linear alternators, to increase engine reliability and lifetime by eliminating the need for external seals on moving shafts. Mechanical Technologies, Inc., recently completed a large system of that type, possibly for a second-generation space station or as an alternative conversion system for the since-cancelled SP-100 reactor program. The engine produced an electrical output of 12 kilowatts at an overall system efficiency of over 23 percent. The system gave an initial performance that was in excellent agreement with analytical predictions, but it has not undergone life-cycle testing.

A scaled-down, Stirling engine was recently designed for possible use in NASA's proposed Pluto Fast Flyby mission. Analytical models showed that a 75 -watt engine would have an efficiency of 23 percent. 
JPL. For nearly twenty years, JPL and Advanced Modular Power Systems have been developing a highly efficient, static alkali metal thermal-to-electric converter for the direct conversion of heat to electricity. Alkali metal thermal-to-electric converter cells suitable for zero-gravity conditions were recently tested by Advanced Modular Power Systems and yielded an efficiency of 9.6 percent at $700^{\circ} \mathrm{C}$. Advanced Modular Power Systems predicts efficiencies of 15 to 20 percent through advanced cell designs and higher-temperature operation. Based on that prediction, JPL system studies estimate that an alkali metal thermal-to-electric converter-generator for the Pluto Fast Flyby mission that uses two standard radioisotope heat source modules would have a system mass of 9.7 kilograms. Such a system has not yet been demonstrated, and one major uncertainty about these devices is their ability to withstand launch vibration.

JPL is also working on thermophotovoltaic conversion systems, which are an outgrowth of recent advances in photovoltaic materials developed for high-efficiency solar cells. Instead of converting solar radiation to electricity, they convert infrared radiation emitted by the radioisotope heat source. Since infrared radiation has a very different spectral distribution than solar radiation, different photovoltaic conversion materials are required. One material under test by Boeing for JPL is gallium antimonide, whose bandgap is well matched to the infrared spectrum. Relatively high efficiencies have been demonstrated with this material, and extremely high efficiencies (greater than 30 percent) may be achievable through addition of reflective filters or mirrors to return the unconverted radiation to the heat source.

\section{DOE Programs}

DOE has extensive experience with nuclear power technology. In the late sixties and early seventies, thermoelectric unicouples employing silicon germanium materials were developed by RCA and General Electric for DOE. These unicouples were successfully flown in 200- to 300-watt radioisotope thermoelectric generators (RTG) on several NASA missions and are slated for use on the proposed Cassini mission. The RTGs, developed by DOE laboratories and contractors, with assistance from JPL, have rather low efficiencies (less than 7 percent) but have proved extremely reliable and longlived (approximately 150,000 hours). A typical small (70-watt) RTG for the Pluto Fast Flyby mission, based on silicon germanium unicouples, has a mass of 15 kilograms, with a cost of $\$ 51$ million estimated by DOE for three fueled flight units.

During the 1980s, a modular, radioisotope heat source module (the General Purpose Heat Source) was developed and safety qualified by DOE laboratories and contractors. Being modular, these heat sources are adaptable to a wide range of power levels and conversion systems. RTGs are flying on the Galileo and Ulysses missions and are slated to be flown on the proposed Cassini mission.

Thermoelectric multicouples employing silicon germanium materials with additives have been under development by DOE contractors for over ten years, but their development was recently suspended by the department. The multicouples were developed for use in modular RTGs, which are scalable over a wide range of power 
levels with minimal redesign. They are only a little more efficient than unicouple RTGs, but offer a significantly higher specific power. They also make it possible to generate high voltages from small RTGs ( 28 volts DC has become the accepted industry standard power bus voltage for small spacecraft). Multicouples have been successfully tested for up to 15,000 hours, but their measured degradation rates were about twice as high as those of unicouples. As of this writing, funding for continuing development has not been allocated.

DOE has also been involved in work on other conversion technologies, sponsoring Fairchild Space and Defense Corporation to prepare and analyze detailed system designs for integrating the advanced conversion systems (Stirling engines, thermophotovoltaic systems, and alkali metal thermoelectric converters) with a radioisotope heat source and a heat rejection radiator. A recently completed system design study showed that replacement of the RTG with a thermophotovoltaic generator for the proposed Pluto Fast Flyby mission would reduce the required number of costly heat source modules by 60 percent, reduce the power source mass by over 50 percent, and triple or quadruple the system efficiency.

\section{BATTERY TECHNOLOGY FOR ENERGY STORAGE}

\section{NASA Programs}

NASA's battery technology research and development activities are located at LeRC and JPL and have focused principally on the following systems.

Nickel Cadmium (NiCd) Batteries. Rechargeable NiCd batteries, which have been used in spacecraft for over 20 years, may be considered the currently available technology, although they are gradually being phased out, due in part to government restrictions on manufacturing processes involving cadmium and in part to the increasing availability of superior alternatives.

Individual Pressure Vessel (IPV) Nickel Hydrogen ( $\left.\mathrm{NiH}_{2}\right)$ Batteries. In an IPV $\mathrm{NiH}_{2}$ battery, each cell (cathode-anode pair) is individually contained in its own pressure vessel. (Pressure vessels are needed to contain the cell's hydrogen gas at high pressures of $6.2 \times 10^{6}$ pascals to $6.9 \times 10^{6}$ pascals.) $\mathrm{A} \mathrm{NiH}_{2}$ battery is typically composed of 22 cells.

The first such battery was flown in 1977 by the Naval Research Laboratory. Today, it has replaced the NiCd battery for defense applications in geosynchronous orbit, and it is quickly becoming the preferred battery technology in low Earth orbit as well. IPV $\mathrm{NiH}_{2}$ batteries are more voluminous than $\mathrm{NiCd}$ batteries due to individual cell containment in rounded vessels, but they offer substantially longer cycle (charge/discharge) lifetime, greater depth of discharge, and improved tolerance of abuse (e.g., overcharging). 
LeRC has developed a new, lightweight nickel electrode that is usable in IPV $\mathrm{NiH}_{2}$ batteries as well as in other nickel-based ones and that will increase specific power.

Nickel Metal Hydride (NiMH) Batteries. NiMH batteries, which are being studied by LeRC and JPL, would be about 10 percent lighter than $\mathrm{NiH}_{2}$ batteries and could provide up to about 50 watt-hours per kilogram. They also offer a longer shelf life, lower cost, and higher power density in a reduced volume.

NiMH batteries have not yet been flown, and some development work remains to be done, but they represent an attractive near-term option to replace NiCd batteries on the low-power end of the small spacecraft spectrum.

Lithium Batteries. Lithium batteries are a highly promising mid- to far-term technology. Lithium titanium disulfide $\left(\mathrm{LiTiS}_{2}\right)$ batteries, for example, are being studied at JPL for low-power (less than 1-kilowatt-electric) applications. These batteries have a high power density (100 watt-hours per kilogram), a lifetime of 1,000 cycles at 50 percent depth of discharge, a 10-year shelf life, and low volume, all of which would make these batteries well-suited for long-duration planetary missions.

Lithium polymer batteries are being investigated by LeRC and JPL to achieve a specific power goal of 150 to 200 watt-hours per kilogram. Substantial effort is still needed in electrolyte research, but the ultralight weight and small size of these batteries would provide important benefits.

In the far term, lithium primary (i.e., nonrechargeable) batteries may present an alternative to radioisotope power systems for outer planetary missions, but such batteries would have much lower specific energies than RTGs or other radioisotope systems. High energies are required not only for extended survey or exploration missions but also for brief flybys like Pluto Fast Flyby. The mission's power requirements are determined not by the length of the flyby but by the amount of stored data to be transmitted back to Earth from deep space. In the case of the proposed Pluto Fast Flyby mission, the power demand stipulated by the current design would have to be reduced by orders of magnitude to lower the battery mass to that of the radioisotope power system. Clearly, that would be a very different mission, with a much smaller scientific return.

\section{Other Government Programs}

DoD, particularly the U.S. Air Force Phillips Laboratory, BMDO, and the Naval Research Laboratory, and DOE have several advanced battery concepts that complement NASA's work.

Common Pressure Vessel (CPV) $\mathrm{NiH}_{2}$. The CPV $\mathrm{NiH}_{2}$ battery is a logical near-term follow-on system to the individual pressure vessel $\mathrm{NiH}_{2}$ battery. The containment of all cells in a single pressure vessel allows for a significant reduction in battery volume as compared with the IPV battery concept. As currently designed, 
however, the CPV battery does not permit monitoring of individual cell performance and the ability to switch defective cells off-line.

However, the CPV battery offers significantly higher specific power (nearly 50 watt-hours per kilogram), lower cost, and simplified electrical and thermal interfacing. It is a strong candidate for use in the "larger members" of the small spacecraft family. CPV battery technology development is centered at the Naval Research Laboratory. Additional work is underway at U.S. Air Force Phillips Laboratory.

A CPV $\mathrm{NiH}_{2}$ battery has been scheduled to fly within a year on a DoD spacecraft as part of a joint effort between the Naval Research Laboratory and industry under a Cooperative Research and Development Agreement. A second CPV battery is being used on the BMDO Clementine mission, launched in January 1994. CPV battery technology is currently planned for use in the IRIDIUM ${ }^{\mathrm{TM} / \mathrm{SM}}$ spacecraft being developed by Lockheed (AuClair et al., 1993).

Sodium Sulfur (NaS) Batteries. NaS batteries have the potential for a further doubling of specific power up to 100 watt-hours per kilogram, but they require additional development work and a flight experiment in order to complete qualification. This appears to be a promising technology, but predominantly for larger spacecraft.

LeRC had planned a NaS cell flight experiment in 1995, but this has been cancelled due to funding limitations. (This decision may be subject to reconsideration by NASA.) The U.S. Air Force Phillips Laboratory remains committed to the technology, but it also has only limited resources available.

Lithium Batteries. The U. S. Air Force and BMDO are conducting early work on solid-state batteries (including lithium titanium disulfide and lithium polymer), with a long-term performance goal of 200 watt-hours per kilogram.

DOE has produced tiny, bench-scale thin-film lithium batteries to power individual chips. Preliminary work is underway to increase production rates and to develop larger rechargeable lithium batteries with a calculated specific power of more than 300 watt-hours per kilogram.

The Lawrence Livermore National Laboratory has performed life-cycle testing on a lithium ion battery that may be suitable for low-Earth-orbit applications in the near term.

\section{FINDINGS AND PRIORITIZED RECOMMENDATIONS}

Improvements in power generation and storage technology would be beneficial to virtually all classes of small spacecraft missions, reducing mass and cost, as well as enhancing performance.

The Panel on Small Spacecraft Technology believes that developments in lowweight, high-efficiency solar cells and arrays would enhance not only the power generation capability of small spacecraft but also that of solar electric propulsion. The panel also found that advanced, high specific power battery technologies for space 
applications have received insufficient attention and lag considerably behind developments in terrestrial power storage. Successful development of compact, long-lived, high specific power battery systems, coupled with improvements in power generation and management, will significantly enhance the utility and affordability of small spacecraft by offering reductions in mass and launch costs and improved performance.

The use of currently available radioisotope power system technology for interplanetary missions and others where the sun is obscured results in higher-thandesired cost or mass. Technologies that would enable more efficient, lighter-weight systems have shown promise in research and development programs at NASA and DOE. Development times are probably too long to permit use in near-term planned programs such as the proposed Pluto Fast Flyby and Mars Pathfinder missions. However, for future deep space missions and Martian planetary surface investigations with small spacecraft and microrovers, especially at high latitudes, these technologies are enabling. Future developments in the radioisotope power technology require the active involvement of DOE as mandated by the Atomic Energy Act of 1954, which is still in effect.

In considering the use of radioisotope power generation systems in future spacecraft, special attention must be paid to ensuring that there is a source of plutonium-238. The U.S. reactors capable of its production have been shut down. Arrangements should be made to ensure the availability of a foreign source (e.g., Russia, France, or the United Kingdom).

Considering that investments in this technology area will produce returns across the entire spectrum of missions, the panel recommends the following, in priority order:

1. An advanced solar array program should be initiated at a funding level that will allow reaching a goal of 200 watts per kilogram with 5 to 10 kilowatts of total power within the next five years.

2. The development, characterization, and testing of NiMH batteries for lowpower small spacecraft should be completed.

3. Building on the work already completed for the Clementine mission, the characterization and testing of CPV $\mathrm{NiH}_{2}$ batteries for mid- to high-power small spacecraft should be completed.

4. The development of lithium alloy $\left(\mathrm{LiTiS}_{2}\right)$ batteries, particularly for lowenergy-demand planetary missions, should be continued.

5. The application of lithium ion batteries developed by DOE should be evaluated for possible use in low-Earth-orbit spacecraft. If found promising, the technology should be adapted for small spacecraft.

6. For mid- to far-term applications, the development of lithium polymer batteries should be accelerated. 
7. In the long-term, work on other advanced solar cell and solar array technology, including thin-film cell development, inflatable arrays, and flexible blanket wing APSA arrays, should continue at an increased funding level, with the goal of achieving a specific power of 300 watts per kilogram.

8. There is a small but important subset of small spacecraft missions that cannot use solar power or batteries and that are enabled by radioisotope power systems. For those missions, development of more efficient conversion systems to reduce heat source mass and cost would be beneficial. Radioisotope power system designs using Stirling, thermophotovoltaic, and alkali metal thermal-to-electric converter conversion techniques should be jointly evaluated by NASA and DOE, and the ability of these techniques to satisfy various NASA missions should be assessed. Based on the evaluation, NASA and DOE should select one or more of these systems for experimental demonstrations of its performance against specific pre-determined criteria that are peculiar to the approach selected. NASA and DOE should then select the most promising approach for further development. A decision about flight demonstrations should be made contingent on future NASA planning of missions that would utilize the technology.

9. Research on concentrator arrays, with a goal of reaching power densities in excess of 300 watts per kilogram at one-half the cost of existing arrays, should be increased. 


\section{5 \\ Spacecraft Structures and Materials}

\section{BACKGROUND AND STATUS}

Spacecraft structures-small or large-must be made of materials that resist, without failure or excessive distortion, the static, dynamic, and thermal stresses that occur during launch, deployment, and service. Payloads and ancillary equipment also must be protected from undesirable distortion, vibration, and temperature changes. Appendages such as antennas and reflectors that are too big to fit into the spacecraft in their operational configurations have to be packaged in collapsed states during launch and subsequently deployed. These design requirements should be met within guidelines for weight, cost, and reliability-conditions that are always inextricably coupled and have to be reassessed in the context of the small spacecraft philosophy. Structural weight of spacecraft has historically been only about 20 percent of the total dry weight. However, structural weight saving may assume accentuated importance for many small spacecraft missions, where each kilogram shaved from the structure is precious, and may provide increased capacity for additional payload, autonomous control devices, or auxiliary equipment. However, this emphasis on low weight may be tempered in some small spacecraft applications that involve demands for low cost, easy adaptability, and growth capability.

Although the spacecraft structure and the material of which it is composed are inextricably linked entities in their influences on cost, strength, stiffness, weight, reliability, and adaptability to change, it is nevertheless convenient to discuss separately issues that may be regarded as being predominately in either the structures or materials category.

\section{STRUCTURES}

Currently, in most small spacecraft, a simple truss structure provides the primary resistance to static and dynamic loads, and flat panels (often of sandwich construction) support the payload and associated spacecraft contents. While it does not appear that much attention has been paid to optimizing the spacecraft structural configuration, future missions will require more efficient design of the central bus structure. Fortunately, past 
research and flight application in airplanes and large space buses have made available proven, high-efficiency configurations such as stiffened shell structures and skin-stiffener panels. In addition to conventional bus structures, there is a need for deployable and special-purpose structures on most spacecraft, whatever the size. The status of these enhanced spacecraft structures is discussed below.

\section{Deployable Structures}

In order to accomplish its mission, a small spacecraft may require an appendage, such as a boom or a surface, that is very large relative to the size of the spacecraft. Such appendages must be packaged in collapsed states during launch and subsequently deployed prior to operation. Past and present spacecraft have used a variety of articulated deployable structures as booms supporting instruments or solar cell blankets or as area structures forming antennas or solar arrays. Some of these deployable structures were developed during the 1960s and early 1970s for use on the small spacecraft of that time, but during the past two decades, advanced development at NASA and DoD in the area of deployable structures has been directed almost entirely toward large antennas and platforms, particularly those for which precision is a dominant requirement. Nevertheless, the technologies developed may be useful for small spacecraft, particularly if high accuracy is required.

Most existing deployable structures are deemed reliable only by virtue of being thoroughly tested by repeated ground-based deployments, which is complicated and expensive because of the need to counteract the effects of gravity on configurations that are designed to operate in the gravity-free space environment. Even so, recent flight experience has involved a distressing number of deployment hangups. Inexpensive small spacecraft may require new and simpler reliable deployable designs. One of the present thrusts of development efforts involves the use of inflatables, which are possibly cheaper and more dependable than articulated structures.

\section{Control-Structures Interaction and Smart Structures}

The age of control-structures interaction ${ }^{1}$ is well underway, and that of its offspring, smart structures, ${ }^{2}$ has dawned. These technologies have particular relevance to small spacecraft designs. Counteracting the dynamic load environment during launch by the provision of sufficiently stiff structural packaging alone may not make sense in a small spacecraft if active vibration suppression could achieve the required isolation

1 Control-structures interaction refers to the coupling between the displacements of deformable structures and the performance of control systems.

${ }^{2}$ A smart structure has sensors and actuators as integral parts along with a control computer that is required to actively control vibrations and shape. 
(from dynamic stress and acceleration) with lower mass. In addition, after launch, control-structures interaction and smart-structure design play an important part in the suppression of jitter. ${ }^{3}$ The jitter problem may actually be accentuated in small spacecraft by the effects of scale. Although most current small spacecraft are being designed without the use of control-structures interaction and smart structures, these advanced techniques will become essential as scientific and other payloads become more sensitive and as pointing requirements and dimensional precision constraints become more severe. Experimental smart structures developed by NASA, by DoD, and elsewhere consist of composite material plies containing piezoelectric ${ }^{4}$ sensors and actuators to control mechanical behavior. Other possible actuator technologies are based on shape-memory materials (e.g., Nitinol), electrostrictive ${ }^{5}$ and magnetostrictive effects, ${ }^{6}$ and micromotors. The U.S. Air Force Phillips Laboratory has demonstrated an increase in spacecraft structural damping by two orders of magnitude and has provided on-orbit demonstrations of the use of embedded sensors and actuators for both active and passive vibration suppression.

\section{MATERIALS}

Aluminum is the conventional material for flight structures of all types. In addition, graphite-fiber/polymer-matrix composite materials having much higher strength to density ratios and stiffness to density ratios are finding substantial use in aircraft and spacecraft, more in commercial satellites than in NASA spacecraft, and even less in military spacecraft. For early small spacecraft, the tendency has been to use aluminum solely and to avoid the perceived extra costs of more advanced materials. Future small spacecraft with requirements for higher performance and lighter weight will necessarily use the advanced materials. The status of these candidate advanced materials is discussed below.

${ }^{3}$ Jitter is the unacceptable disturbance-induced vibrations during critical performance time windows.

${ }^{4}$ A piezoelectric device undergoes reversible change in dimension when an electric force is applied. The change in dimension is dependent on the polarity of the field.

${ }^{5}$ An electrostrictive effect is a reversible dimensional change in a material when the material is subjected to an electric field. The direction of dimensional change is independent of electric field polarity.

6 A magnetostrictive effect is a reversible dimensional change in a material when the material is subjected to electric or magnetic fields. 


\section{Aluminum-Lithium Alloys}

A weight-saving alternative to the use of conventional aluminum alloys in spacecraft design could be the use of aluminum-lithium alloys. The lower density of aluminum-lithium alloys, coupled with their somewhat increased stiffness and, in specific alloys, higher strength, could provide immediate weight savings of 7 to 20 percent with few required changes in fabrication and design. Moreover, specific aluminum-lithium and magnesium-aluminum-lithium alloys show markedly increased toughness at cryogenic temperatures, an important property for liquid oxygen and liquid hydrogen fuel tanks. With respect to space structures, these characteristics can be particularly important, as the failure of most structures will be associated with buckling or stress fractures. Based on buckling and yield strength, an increase in the elastic modulus and yield strength or tensile strength should produce a corresponding decrease in the structural weight. Aluminum-lithium alloys can provide up to 12 percent higher elastic stiffness and, in the case of Alcoa alloy 2090, an increase of almost 20 percent in tensile strength over conventional aluminum alloys such as 2219 and 2014. Moreover, processing and fabrication techniques (e.g., machining, chemical milling, gas tungsten arc welding, shot peen forming, etc.) similar to those employed for conventional alloys can be utilized for aluminum-lithium alloys. In addition, studies (e.g., at General Dynamics and NASA) suggest that techniques for low-cost, near net-shape processing ${ }^{7}$ of aluminum-lithium alloys that are under development may lead to cost savings of 20 to 30 percent compared with integral machined structures. However, although substitution of aluminum-lithium alloys for conventional alloys can essentially be achieved with no redesign, and several alloys are becoming "flight tested" as commercial aircraft components, care must be exercised with the use of forgings of certain aluminum-lithium alloys due to their low through-thickness (short-transverse) toughness.

The following aluminum-lithium alloys are currently available.

- Weldalite $e^{\mathrm{TM}}$ is an aluminum-lithium alloy developed by Martin Marietta, which has excellent welding characteristics, strength, comparable toughness to aluminum, and stress corrosion resistance. Two variants of Weldalite are Reynolds Metals alloys 2195 and MD345.

- Alloy 2090 was developed by Alcoa to replace the conventional alloy 7075-T6, and for some applications, to replace alloy 2024-T3. Alloy 2090 has the highest strength of all aluminum-lithium alloys.

- $\quad$ Alloy 8090 was developed by Alcan, with approximately 15 percent to 20 percent lower strength than alloy 2090, but improved damage tolerance and short-transverse toughness (Venkateswara Rao and Ritchie, 1992).

${ }^{7}$ Near net-shape processing produces a part that requires little machining of the finished product. 
To date, aluminum-lithium alloys have not been used in small spacecraft structures, although they have appeared in launch vehicle designs.

\section{Polymer-Matrix Composites}

In currently planned small spacecraft programs, there is a trend toward considerable exploitation of organic-matrix composites in structural truss members, in propellant tanks (or as overwraps on metal tanks), and in flat panel components. Very significant weight savings (perhaps 25 to 50 percent) could be achieved in the spacecraft structure through use of polymer-matrix composites. However, the question of the cost of such composites cannot be divorced from the engineering effort needed to establish confidence in their use, which varies as a function of the expertise available to individual agencies and companies. Nevertheless, the overall level of accumulated experience in design with composites in the United States, especially in the aircraft industry and large spacecraft prime contractors, should be high enough to counteract residual tendencies to accept the weight penalties associated with designs based on the exclusive use of conventional aluminum alloys. Further, industry estimates suggest that the costs of graphite epoxy or similar composite materials may actually, in the long run, be less than those of monolithic metals in the same application. Although polymer-matrix composites are subject to space environment degradation effects that must be considered, there are no indications so far that their structural performance would be seriously threatened by the three-to-five year exposures currently contemplated for most small spacecraft missions. Several contractors and government laboratories including Space Systems/Loral, Lockheed Missiles and Space Company, Martin Marietta Astro Space, and Lawrence Livermore National Laboratory are developing techniques for the economical production of composite structures for spacecraft.

The most commonly used polymer-matrix composite for primary spacecraft structures is graphite epoxy. Structural forms, such as tubes, can be obtained at varying cost from several commercial suppliers, which range from fabricators of golf club shafts to the aerospace prime contractors. Other well-used polymer-matrix composite fibers are glass and Kevlar, ${ }^{\mathrm{TM}}$ which are processed similarly to graphite fibers. Fiberglass, particularly the S-glass variant, can be subjected to 3 percent strain without harm and is useful for applications requiring large strain capability, but its strength and stiffness is unremarkable. Kevlar fiber, on the other hand, has high specific tensile strength and stiffness and is useful where electrical or dielectric properties are of concern. Kevlar, however, has a relatively low compressive crushing strength.

\section{Metal-Matrix Composites}

Metal-matrix composites are becoming available with possible applications to spacecraft frames and components. As spacecraft frame materials, aluminum alloys reinforced with silicon carbide, alumina, or boron particulates or fibers may offer 
advantages of increased stiffness and strength; however, these materials may be an order of magnitude more expensive than conventional aluminum alloys and have certain mechanical property disadvantages (e.g., the particulate-reinforced alloys have, until recently, shown poor ductility and toughness properties). In addition, specific metalmatrix composites, such as graphite-reinforced magnesium alloys, can offer increased stiffness at coefficients of thermal expansion (for dimensional stability) comparable with those of graphite-resin composites. Such metal-matrix composites can be designed with tailored physical and mechanical properties and do not have the outgassing characteristic of graphite epoxy.

NASA is considering boron-aluminum metal-matrix composites for selected applications in primary structures for its space transfer vehicles and silicon-carbide particulate-aluminum alloys for cryogenic tanks. Titanium and titanium-matrix composites are generally applicable for higher-temperature environments. For example, the siliconcarbide reinforced Timetal $21 \mathrm{~S}$ alloy is useful at temperatures up to $800^{\circ} \mathrm{C}$ and has excellent resistance to corrosion and oxidation in elevated temperatures.

Metal-matrix composites have also found application as lightweight, strong, and highly conductive materials for high-temperature thermal management systems. For example, Rockwell has developed copper-matrix composites with fiber reinforcements of graphite, molybdenum, or tungsten for actively cooled structures in hypersonic aircraft and rocket nozzles and in radiator fins for space power systems. These composites are stable in high heat flux and in thermal cycling applications, and they offer improved creep resistance compared with conventional conductive alloys. Fairchild Space and Defense Corporation is working on electro-emissive panels for thermal management of small spacecraft.

\section{Carbon-Carbon Composites}

Carbon-carbon composites are generally used in applications requiring extreme temperatures, typically up to about $1650^{\circ} \mathrm{C}$. In fact, combined with active cooling, they can be used for the leading edges of nose, wings, and tails of airframes exposed to temperatures as high as $3300^{\circ} \mathrm{C}$. For the National Aerospace Plane vehicle, for example, carbon-carbon composites were being used as thin panels mechanically attached to the underlying titanium-matrix composite structure over parts of the fuselage. However, despite their very high thermal resistance, carbon-carbon composites are highly susceptible to oxidation; on the National Aerospace Plane, they needed to be protected by thin multilayer coatings of silicon carbide. For spacecraft, carbon-carbon composites may offer significantly reduced time and cost for fabricating structures through rapid densification processes. NASA is developing continuous and batch processing techniques for carbon-carbon spacecraft tubular frames and precision reflector, antenna, radiator, and aerobrake panels with appropriate thermal, reflective, and radiator coatings. 


\section{STRUCTURE/MATERIALS SYSTEMS}

The challenge to imaginative designers in the age of small spacecraft will be to meld the technologies of advanced materials, structures, deployable appendages, and control-structures interaction into small and inexpensive configurations. There exists a large body of structures and materials technology pertinent to aircraft and large spacecraft (and the small spacecraft of the early space decades) that can provide a serviceable springboard for the design of present and future small spacecraft, but, in various technical areas and their synthesis, there is a wide range of needs for further research and development. The aforementioned substitution of aluminum-lithium alloys for aluminum in traditional structural metal designs would provide immediate, if modest, weight savings. But the current knowledge base for the production of, and design with, composite materials-polymer-matrix composites in particular-has to be not only thoroughly absorbed but may have to be substantially enhanced by the emerging small spacecraft community in order to meet demands of low cost as well as the promise of low weight.

Composite materials and components explicitly configured to fulfill multiple requirements (such as those of strength and thermal conductivity) clearly offer scope for weight savings. The design of simple, reliable, and cheap joints and attachments in composite structures is a structure/materials systems problem that never goes away, as is the related requirement for easy design and fabrication modification to accommodate unforeseen (but inevitable) changes in payload configurations. Although some existing concepts and technologies for the compact storage and reliable deployment of appendages may find continued applicability to small spacecraft, there is considerable potential for new invention and development in this area, given the inevitable conflict between the smallness of the structure and the desirability of large appendages. Finally, against a background of considerable existing theoretical and laboratory research, but with little established flight experience available, small spacecraft engineers will have to be heavily involved with the nascent technologies of control-structures interaction and smart structures and their exciting promise, including their integration into the overall spacecraft system as cost-cutting and weight-saving elements.

\section{FINDINGS AND PRIORITIZED RECOMMENDATIONS}

NASA has potentially important roles to play in the creation, enhancement, and application of structures and materials technology for small spacecraft, both in its traditional capacity as an agency for frontier, generic engineering-science research focused on particular relevant topics and as a leader in joint projects with industry intended to demonstrate the design, fabrication, and deployment of high-performance, reliable, and adaptable small spacecraft in accordance with the central guidelines of low cost and low weight. As always, vigilance is essential to ensure that these activities nourish each other. 
The following explicit recommendations for NASA action are listed in a priority order that reflects the integrated judgment of the Panel on Small Spacecraft Technology, after considering the state of development of new technology and potential payoffs that can reasonably be expected.

1. Research on simple, low-cost deployable booms and surfaces should be emphasized. The objectives should include high deployment reliability, compact stowage, and adequate precision. Ground-test proof of successful deployment in space is essential.

2. A joint NASA-industry program should be initiated to demonstrate developments of advanced small spacecraft designs that are based on polymer-composite components, exploiting available as well as novel technology as appropriate to meet the paramount demands of low cost, low weight, reliability, and adaptability. The NASA Small Spacecraft Technology Initiative may fulfill this objective.

3. In coordination with ongoing research at universities and other government agencies, research efforts should be intensified in the area of smart structures and control-structures interaction. Research should be generic in character as well as focused on specific needs for small spacecraft.

4. A short-term demonstration program with industry should be undertaken to design, construct, and qualify a small spacecraft structure based primarily on current structural design configurations that exploit aluminum-lithium alloys in lieu of aluminum in order to determine the feasibility of rapid weight savings with minimal effort and cost.

5. Sufficient expertise in polymer-matrix composite technology should be maintained within NASA to identify and pursue opportunities for research aimed at improving strength, stiffness, thermal properties, and economy of fabrication, with explicit attention to the possibilities of multiple-use components and the engineering of modular attachments and joints. 


\section{6 \\ Small Spacecraft Communications Technology}

\section{BACKGROUND AND STATUS}

The present infrastructure for command, control, communications, and data recovery from NASA spacecraft consists of a number of facilities, such as the Tracking and Data Relay Satellite System (TDRSS); the Deep Space Network; and others, including commercially available services. This infrastructure is old and has been developed over many years. It is massive and costly in proportion to its presently envisioned uses with low-cost small spacecraft systems. Several studies examining ways to update these facilities have been performed in the past, but these study concepts did not consider the use of small spacecraft in conjunction with these facilities. The development of low-cost enabling technologies can greatly contribute to the overall effort in using small spacecraft for future NASA missions. The infrastructure is discussed further in Chapter 2 of this report.

A second important area in communications covers application of commercial spacecraft to normal, every day, high-capacity voice and data communications in conjunction with the national and international public-switching networks. All aspects of every day life have developed a dependence on these communications services. Computer-dependent services, manufacturing facilities, financial institutions, health care services, entertainment, TV, etc., are utilizing today's spacecraft communications that have become an integral part of the national and international communications and data transmission infrastructure. Spacecraft communication systems also have been utilized for dedicated, specialized services as well as for government and military use. A multibillion dollar segment of private and government-owned industry has been developed, which is of vital importance in the overall economic structure of every nation, including the United States.

With the rapid expansion of the wireless communications networks and cellular systems, and the initiation of worldwide personal communications networks, a number of innovative approaches recently have been proposed utilizing constellations of lightweight spacecraft. These proposed new systems utilize both low Earth orbit and higher-altitude orbits. Table 6-1 lists a few of the recently proposed mobile systems.

In recent years, with the exception of the Advanced Communications Technology Satellite (ACTS) spacecraft, NASA has not been involved in the new developments in 
satellite communications. Private industry and DoD, however, have invested substantially in this field, in both technology as well as operational capabilities. Still, there are several areas where NASA could provide unique technological and operational contributions to enhance the private-sector efforts. Launch vehicles and launch operations technology is an area where industry could benefit from NASA operations. Command, control, and tracking of space assets is another area where NASA experience could be very useful.

TABLE 6-1 Some Recently Proposed Mobile Satellite Systems

\begin{tabular}{ll}
\hline COMPANY & SYSTEM \\
\hline Iridium, Inc. (Motorola) & IRIDIUM $^{\mathrm{TM} / \mathrm{SM}}$ \\
Loral/Qualcomm & Globalstar \\
Constellation Communications & Aires \\
Ellipsat & Ellipso \\
Orbital Sciences Corporation & Orbcomm \\
Starsys Global Positioning & Starsys \\
\hline
\end{tabular}

One of the more important NASA contributions to industry will be the experimental development and evaluation of advanced technologies for use by modern high-capacity voice and data satellite communications systems. Examples of technologies that can contribute to future, low-cost small spacecraft missions are as follows:

- $\quad$ satellite-to-satellite communication technology;

- new multiple access techniques such as Code Division Multiple Access;

- signal interference and other effects (channelization, error correction techniques, bandwidth compression, rain attenuation at higher frequencies, etc.) on quality of transmission;

- effects on communications and data transmission due to nonstationary spacecraft (handover from one Earth station to the next Earth station, Doppler frequency shift, etc.);

- efficient utilization of the radio spectrum for mobile low-Earth-orbit satellite constellations;

- $\quad$ spacecraft antennas; and

- optical communications. 


\section{NASA PROGRAMS}

Since NASA has not been active in communications technology development in recent years, while industry and DoD have been very aggressive in promoting new systems and new technology, the opportunities for NASA to contribute significantly to small spacecraft communications technology in the near term are limited. For example, the NASA ACTS program for developing and space testing advanced communications concepts was initiated in the 1970s and was only recently launched aboard the Space Shuttle to flight test the technologies that were proposed at the beginning of the program. Meanwhile new concepts and new needs have been developed.

OACT, in conjunction with JPL and LeRC, is overseeing the NASA communications technology program. The program addresses the following areas:

- $\quad$ ACTS experiments;

- commercial fixed and broadcast satellite communications;

- commercial mobile and personal satellite communications;

- $\quad$ NASA near-Earth missions communications; and

- $\quad$ NASA deep-space mission communications.

The ACTS spacecraft is now operating in orbit and performing a variety of tests, such as spot-beam tests, on-board switching, and propagation at 20 and $30 \mathrm{GHz}$. Both JPL and LeRC are involved in this activity. Among other functions, ACTS serves as a testbed for mobile satellite communications technology programs, which also involves both fixed and mobile terminals at the Ka-frequency band which is being used more often since most of the lower frequencies are allocated. The direct utility of the ACTS technologies to near-term, small spacecraft systems is modest.

The JPL communications technology program addresses both the technology needs for planetary space communication and the critical technologies for commercial satellite communications (such as optical [laser] communications and power amplifiers), which could be used for small spacecraft. JPL, in addition to identifying needs for future NASA missions, is envisioning the use of industry partnerships for identifying future commercial applications and for technology development and demonstration, including ground test programs for technology verification.

The LeRC program, besides the ACTS involvement, addresses space communications technologies. In fiscal year 1994, LeRC has budgeted \$2 million for work on traveling wave tubes and on solid-state, gallium arsenide/indium phosphide power amplifiers (Giffin, 1993).

NASA also has a number of relatively modest development programs in place to support its optical communications technology needs at both GSFC and JPL, and those are aimed at some future generation of TDRSS. These systems could be useful for small spacecraft systems that require intersatellite links, but there is little likelihood that they will reach technological readiness in time for decisions on, for example, the commercial IRIDIUM $^{\mathrm{TM} / \mathrm{SM}}$ system. 
Recently, an intercenter (JPL, LeRC, Langley Research Center, GSFC) systemsanalysis team performed a study to identify priorities for technology development in support of OACT's small spacecraft technology program (Budinger et al., 1993). The team prepared a communications technology summary indicating that: electronically steered, (phased array) Ka-band antennas; Ka-band solid-state amplifiers; and Ka-band power modules were the highest priority, followed by source/channel coding, optical communications, and low-mass antennas. On-board processing was categorized as the next highest priority.

\section{DoD PROGRAMS}

DoD programs for lightweight communications subsystems and components are mainly directed toward the development of space defense systems. Developments are concentrated in the extremely high radio (EHF, $60 \mathrm{GHz}$ ) and laser frequencies, where over $\$ 550$ million has been spent over the past 11 years on military optical communications technology (Munro, 1993).

In the $60 \mathrm{GHz}$ range, both transmitters and receivers have been developed and demonstrated in a working link. Substantial work has been directed toward the application of millimeter-wave integrated circuit components to solid-state power amplifiers. In addition, work on 40-watt traveling wave tube power amplifiers is sponsored by the Navy. Work on electronically steerable, phased array antennas for use on spacecraft remains to be completed. Work in digital programmable modems has been sponsored by BMDO.

In the laser area, work on laser sources, beam formation and control, and other components is underway. Two types of laser systems are under development, heterodyne systems and laser diode systems. Heterodyne systems require much less power than other laser systems for the same performance. The above technologies are applicable in spacecraft-to-spacecraft crosslinks. Work on these technologies is performed by the U.S. Air Force Phillips Laboratory with industry support. Some of these technologies will be very useful for small spacecraft programs of NASA and industry.

\section{INDUSTRY PROGRAMS}

Industry has extensively supported both the DoD and NASA programs. Starting with the ACTS program and continuing in the Military Satellite (MilSat) program and the BMDO work, a large number of major contractors, as well as small ones, have made substantial contributions to communications technology. In addition, industry has carried out proprietary company developments for application in commercial programs. A substantial effort has been expended in developing small spacecraft low-Earth-orbit systems concepts for commercial communication purposes. The technology utilized is a mix of the results from the government-sponsored developments and corporate proprietary efforts. 


\section{SPACECRAFT-TO-SPACECRAFT COMMUNICATIONS}

TDRSS is the first operational system to utilize spacecraft-to-spacecraft crosslinks. Each geostationary TDRSS spacecraft has the capability to communicate with as many as 22 spacecraft. Ground tracking and computation determines the position in space of each of the spacecraft. This information is transmitted to the TDRSS spacecraft and through the spacecraft's multi-element, electronically controlled antenna, the proper beam is formed in order to establish a link with the other spacecraft. Due to the relative motion between the two communicating spacecraft, a Doppler frequency shift takes place, which must be recognized and compensated for.

In the general case, the frequency shift and the establishment of the communications link result in complexities and difficulties that limit the capabilities of a system. These problems are more complex in systems with constellations of many spacecraft in a nonstationary orbit, especially if there is a requirement for each spacecraft to communicate with several others simultaneously.

The utilization of optical communications is expected to be very beneficial for the space crosslinks, since lasers are highly directive and can accommodate high data rates. Development of laser technology for spacecraft-to-spacecraft communications is currently underway by NASA and DoD.

In addition, technology utilizing radio frequency communications is currently available commercially for the most simple cases. The effort has been concentrated in direct digital synthesizers, solid-state amplifiers, and low-weight antennas. In addition to the industry-sponsored developments, the U.S. Air Force Phillips Laboratory has also been active in these technologies.

\section{MULTIPLE ACCESS}

When simultaneous transmissions from a number of transmitters are received by the same receiver, a protocol is required in order for the receiver to reconstruct each message correctly. There are two multiple access protocols frequently in use in satellite communications systems: Frequency Division Multiple Access and Time Division Multiple Access. For security and radiation-hardening purposes or in case of lack of adequate bandwidth or for other reasons, other multiple access schemes have been devised. For example, some of the proposed low-Earth-orbit wireless telephone systems plan to use Code Division Multiple Access techniques. With radio frequency bandwidths becoming scarce due to overcrowding, and with the need for low-power, lightweight, mobile receive/transmit hand sets, the need for proven, efficient, multiple access techniques becomes pressing. This is another area in which advanced technology could have a high payoff for small spacecraft. 


\section{COMMUNICATIONS COMPONENT TECHNOLOGY}

Both spacecraft-to-TDRSS and spacecraft-to-ground links require nearhemispherically steerable, efficient antennas. Flat-plate, phased array antennas with a 10$\mathrm{dB}$ antenna gain appear readily available. NASA is developing a three-dimensional phased array that can be electronically steered approximately 60 degrees off perpendicular and with a $24-\mathrm{dB}$ on-axis gain. The projected weight is 4.5 kilograms, which could be excessive for some small spacecraft missions but may be amenable to weight reduction through additional research and development.

On-board spacecraft computers have often lagged behind the state of the art. As a part of the GSFC Small Explorer program, an 80386/80387 processor has been qualified and flight tested on the Solar Anomalous and Magnetospheric Particle Explorer spacecraft. Data storage is provided by a high-density solid-state recorder. Technology developed by ARPA has been adopted and modified by NASA to produce a 1.4 gigabitper-card solid-state recorder with latch-up protection. Error-detection codes and correction codes are employed to eliminate other errors with approximately a 12 percent coding burden. Military Standard 1553 and 1773 data buses are available. Programming is done in $\mathrm{C}$ language.

Cabling occupies a significant part of a spacecraft's mass budget. GSFC is working with DoD on the Fiber Optics Data Bus project to reduce this burden. NASA is responsible for low-data-rate systems, while DoD is addressing high-data-rate systems.

The base of expertise for the development of solid-state spacecraft transmitters rests with industry. NASA has in the past contributed to the development of high-power traveling-wave tubes and has internally built a number of solid-state amplifiers. The laboratories associated with DoD have been a source of space-qualified parts for NASA. Currently, however, all high electron mobility transistors made of gallium arsenide/indium phosphide for use in solid-state amplifiers, are supplied by one of two Japanese companies: NEC or Fujitsu. A core problem has been the lack of an economic incentive for private semiconductor and electronics firms to maintain the capability to provide space-qualified parts and systems, which are only purchased in small lot sizes. Other less demanding opportunities exist in the commercial market, where lot sizes are many orders of magnitude larger.

\section{SPECTRUM UTILIZATION}

With the explosive growth of the communication needs, which demand more and more transmission bandwidth, the available radio spectrum has become overcrowded. The increasing need for transmission of data at very high speeds and very low bit-error rates has aggravated this problem. In addition, the need for low-power, low-weight transmitters adds to the problems. Several existing techniques are being continuously improved, while new ones are being invented for the solution of this problem. Examples of these techniques are (1) new, more spectrum-efficient modulation and multiple access 
technologies; (2) new multiplexing techniques; (3) frequency reuse; (4) signal coding techniques and forward error correction; and (5) more efficient antennas.

The rapid growth of optical communications will have significant impact on this area by freeing radio frequency spectrum from the present demands. The panel expects that by freeing up the radio frequency spectrum, substantial new opportunities will present themselves for mobile and remote area telecommunications. NASA should become the technical leader in this expected future re-apportionment of frequencies and open new possibilities for space communications.

\section{FINDINGS AND PRIORITIZED RECOMMENDATIONS}

Communications technology is fundamental to the global economic infrastructure. Except for the ACTS program, NASA has not significantly invested in communications technology or monitored industry developments. Small spacecraft technology could play a substantial role in the development of the global communications infrastructure as well as the economic development of many geographical areas.

In order to enhance communications technology for small spacecraft, the panel makes the following recommendations for NASA:

1. Development of the following technologies should be supported:

- $\quad$ an electronically steered Ka-band phased array antenna;

- a Ka-band solid-state amplifier; and

- a Ka-band power module.

2. Optical frequency (laser) communications systems and components (e.g., electronically controlled antennas and signal processing) should be developed for spaceto-space links.

3. Radio frequency space-to-space links, the associated components, and spacecraft antenna systems for complex spacecraft constellations in both low Earth orbit or other orbits should be developed.

4. New, multiple access schemes and the associated critical components should be developed, as well as optimization of bandwidth utilization in the mobile satellite frequencies for low-Earth-orbit systems.

5. NASA should be the technical leader in developing the rationale for radio frequency reassignments in view of the new optical communications developments. 


\section{7 \\ Guidance and Control Technology}

\section{BACKGROUND AND STATUS}

The function of the guidance and control system is to determine and control a spacecraft's position, attitude, and directional and angular velocity. A guidance and control system consists of sensors to measure required parameters, signal transducers and transmission circuitry to connect elements of the system, processors, storage devices, and electronics and actuators to effect control.

As a result of significant investments by ARPA, BMDO, and corporate independent research and development, near-term NASA space missions are unlikely to be precluded or seriously inhibited by shortcomings in guidance and control devices, components, or subsystems. Fortunately, by leveraging the past research and development by DoD and industry, NASA has brought many key devices, components, and subsystems appropriate for small spacecraft to a level where they could be ready for use in a short time and at reasonable cost. Some equipment will be flown, essentially in commercial form, within the next two years. Pertinent designs of key devices, components, and subsystems should be completed, documented, and appropriately prooftested. In this regard, the panel considers the proposed TIMED program to be critical; it should be augmented with sufficient funds to ensure adequate "validation" and full documentation of hardware and software. However, for NASA to take full advantage of these developments, additional funding for space qualification; radiation hardening; adaptation; and, in some cases, further refinement, is required. In the present austere funding environment, NASA cannot depend on DoD technology as it has in the past. If existing components and subsystems are not qualified for space use, in the future, payload size and performance will be limited on small spacecraft.

In addition to a short-term program to capitalize on existing guidance and control designs and developments, the panel considers it important to maintain some level of effort on longer-term, high-potential developments to ensure that breakthrough opportunities are not overlooked. Also, and most important, attention needs be paid to ongoing development in other arenas (defense, commercial, Federal Aviation Administration) that may be of value to NASA if properly qualified. 
Component requirements and system considerations vary with mission; however, many key guidance and control elements are common to many missions and are discussed below.

\section{GUIDANCE AND CONTROL COMPONENTS}

\section{Gyroscopes}

Gyroscopes are used to determine a spacecraft's attitude. Conventional mechanical (rotating mass) gyroscopes have been employed in most spacecraft flown to date. However, as the size of these gyroscopes is reduced, performance is limited. Gyroscopes based on optical techniques have been advanced in Air Force and corporate-sponsored programs to a level where they have displaced mechanical gyroscope-based systems in many applications, for example, commercial aircraft navigation.

Two types of optical gyroscopes are gaining acceptance for space missions: ring laser gyroscopes and fiber-optic gyroscopes. Each is based on measuring the difference in time taken for two beams of light to complete a circular path when the beams are moving in opposite directions, and the medium in which they are moving is rotating.

Ring laser gyroscopes were developed first. They are offered commercially by various companies, such as Litton, Kearfott, and Honeywell. A ring laser gyroscope is flying on the Clementine spacecraft and is scheduled for the proposed TIMED mission (see Appendix D). The NASA effort on ring laser gyroscopes has been limited largely to procurement and testing. The primary shortcomings of these gyroscopes are the difficulty and cost of achieving and maintaining the necessary mechanical alignment.

Interferometric fiber-optic gyroscopes (also called fiber-optic-rotation-sensor gyroscopes), while not as fully developed as ring laser units, are considered to have greater promise than ring laser gyroscopes. Interferometric fiber-optic gyroscopes do not have the severe mechanical tolerances of ring laser gyroscopes. Design and fabrication are relatively simple and readily adaptable for different levels of performance. Interfaces for interferometric fiber-optic gyroscopes also can benefit from the ongoing development in optical communication. Interferometric fiber-optic gyroscopes employ optical fibers and electro-optical transducers similar to those used in optical communication links and, hence, will continue to benefit from ongoing developments in commercial communications. Developers believe that necessary performance and radiation resistance in interferometric fiber-optic gyroscopes are readily achievable with further effort. Company-sponsored development programs are underway at several locations, such as the Charles Stark Draper Laboratory, Litton, and Honeywell. JPL, with U.S. Air Force sponsorship, is conducting a developmental program in-house and at Lawrence Livermore Laboratory. GSFC has an experimental program and has scheduled an interferometric fiber-optic gyroscope to fly on the proposed NASA TIMED spacecraft. Interferometric fiber-optic gyroscopes are flying on the BMDO Clementine mission and on the 
ARPA/U.S. Air Force Technology for Autonomous Operational Survivability (TAOS) spacecraft (see Appendix D).

A quartz hemispherical vibrating gyroscope has been developed by Hughes that appears simple, rugged, and inexpensive. Evaluation for space applications would be worthwhile. Micromechanical (vibrating) gyroscopes, fabricated with semiconductor manufacturing techniques, offer longer-term potential. A modest development and qualification effort on such devices could result in a major breakthrough in size, weight, and cost. Small programs are currently underway at the Charles Stark Draper Laboratory and JPL on in-house funds.

\section{Trackers}

Trackers, like gyroscopes, are used to determine spacecraft attitude. Sun and horizon trackers are being used extensively in space missions with modest attitude accuracy requirements. Star trackers employing focal plane arrays have proven successful in simultaneously tracking a number of stars and establishing attitude to a high degree of accuracy.

Focal plane array star trackers have a wide field of view and can track a target body as well as reference stars, thereby eliminating transmission errors between the attitude reference and the target sensor. Since detector arrays are important for commercial applications, continued development and improvement is ensured. As a result of U.S. Air Force support and in-house-funded research and development at companies such as Ball Aerospace and Hughes, trackers of a size suitable for small spacecraft are now available. While current performance falls short of that which is desired for many applications, the commercial effort on detector arrays is almost certain to improve the discrimination and accuracy achievable in the near future. Even though flight tests of these devices are currently scheduled on the proposed NASA TIMED and the ongoing BMDO Clementine missions, the panel considers it desirable to thoroughly test and document the designs to assure future availability (NRL/NCST, 1993; Ryschkewitsch and Plotkin, 1993).

\section{Accelerometers}

Accelerometers for small spacecraft do not appear to be a limiting item in the foreseeable future. Developments for other markets should satisfy space requirements.

\section{Reaction Wheels and Control Moment Gyroscopes}

Reaction wheels and control moment gyroscopes provide torque to correct and maintain spacecraft attitude. Since reaction wheels and control moment gyroscopes are heavy and have a short life, redundant wheels are frequently used to improve reliability, 
thereby intensifying the weight problem. Several small programs are underway to introduce magnetic bearings to increase the lifetime, but this adds complexity, cost, and weight. A number of smaller and lighter-weight reaction wheels are becoming available (e.g., from Ball Aerospace and Bendix) that have potential for use on small NASA spacecraft. The panel believes that conventional bearings, when properly designed, are adequate and superior for most applications. Advantage should be taken of the conventional-bearing design skills in industry and in the Charles Stark Draper Laboratory, and the development of magnetic-bearing reaction wheels should be limited to those programs requiring the special properties of such bearings, namely, very long life and lower level of vibration. Magnetic bearings could become important, but the complexity of associated electronics, the added power requirements, and the increased cost and weight are disadvantages, particularly if properly designed conventional bearings can satisfy the requirements.

\section{Thrusters}

Thrusters are employed to correct and maintain the position and attitude of a spacecraft. They are discussed in Chapter 3 of this report.

\section{Control Electronics}

System architecture and spacecraft and data collection control electronics are largely mission/spacecraft specific, although some software, some electronics standards, and the general system approach carries over from spacecraft to spacecraft. As a result, system design and control electronics development for NASA scientific spacecraft are largely done at NASA centers like JPL and GSFC. Designs reflect advances in the commercial world; they employ current microelectronics, packaging techniques, and automated design aids but recognize the special environmental, weight, and power requirements of space. With the exception of radiation hardening, NASA should be able to depend on industry for advancing the state of the art in control electronics.

\section{Hardened Solid-State Processor and Recorder}

Processors and recorders are used for controlling the spacecraft and for storing and processing data. Computers and recorders of large capacity are advantageous, if not necessary, for control, storage, and processing of data; spacecraft health monitoring; and autonomous operation. Although impressive advances in processing capability and storage capacity have been made for terrestrial uses, for space-based application these devices must be hardened against radiation. Several reasonably modern, solid-state recorders and 32-bit computers have been hardened; the level of hardening and the missions for which this equipment is suitable should be established and designs documented. 
Commercial requirements will ensure continued progress in capacity and speed. With the exception of radiation hardening, NASA can depend on industry for advancing the state of the art. However, since the processor/memory field is changing so rapidly and computer hardening has proven to be a major effort in the past, it is critical that an ongoing effort in processor/memory technology be ensured to develop means for simplifying hardening of new designs.

\section{Global Positioning System (GPS)}

Although developed for military use, current orbital-based guidance and navigation systems such as GPS and its Russian counterpart (GLONASS) provide extremely precise positional information for spacecraft within the operating range of the GPS constellation and now are available for civilian use. When viewed as position sensors, GPS receivers working in differential mode offer about 1-meter accuracy for low-Earth-orbit spacecraft. Current JPL results suggest accuracies better than 10 centimeters under ideal circumstances. Since the GPS constellation is in a 20,000kilometer orbit, precision is degraded for spacecraft with orbits significantly higher than 2,000 kilometers, although precision of a few tens of meters can be obtained even at geosynchronous Earth orbit.

Relative positional precision can be further extended to the centimeter level by a variety of differential techniques. These include such schemes as combining GPS receivers and ground-based (or other spacecraft-based) GPS transmitters with known locations, the use of antenna arrays, and relative measurements using GPS carrier waves. With this technique, the system is referred to as Differential Global Positioning System (DGPS). The information obtained using the various differential techniques can then be used to develop velocity, attitude, and even attitude rate signals, as well as extremely precise relative position data.

Several specific schemes yielding position, velocity, and attitude information have been demonstrated experimentally with aircraft and ground vehicles. In fact, such uses are now being seriously considered for future low-Earth-orbit spacecraft. GPS could be applicable to several aspects of a mission. Combining GPS and an inertial measurement unit (with gyroscopes, accelerometers, or trackers) offers major advantages by bounding errors of the inertial set, providing exceptionally good long-term references and thereby ensuring precise, on-board navigation and, with appropriate complimentary techniques, providing a higher level of redundancy and/or accuracy for position, velocity, and attitude. GPS systems may enable a combination of several small spacecraft to serve as a surrogate for one very large spacecraft by providing time and position connections between sets of data gathered by the different small spacecraft. GPS could be used to simplify range safety during launch by eliminating the ground-based radar systems, or it could be used to assist in the maintenance of orbit position by determining orbit.

The search for GPS applications has become an enormously fertile and expansive area. Receivers are already sufficiently compact and inexpensive to be applied to all manner of visionary systems, and they promise to become even more available as 
production levels soar. Because of the enormous market potential, transmitter and receiver technologies for GPS are advancing rapidly on many fronts. Unquestionably, commercial and additional military developments will serve to further advance the component technology. Consequently, no NASA assistance is needed at the component level. On the other hand, the application of this technology to small spacecraft will require novel systems engineering developments. Accordingly, it is recommended that funding emphasize system considerations, many of which will be unique to NASA, rather than emphasizing component technologies. The potential payoffs in weight, volume, and power savings from utilizing GPS can be substantial. GPS can, in fact, conceivably eliminate the need for components such as star trackers, Earth sensors, sun sensors, accelerometers, and rate gyroscopes in some spacecraft system arrangements.

\section{AUTONOMOUS SYSTEMS}

Advances in computing and data storage make possible on-board processing of data and instructions, which reduces the communication load and increases the opportunity for risk reduction through bit checking, redundancy, and backup systems. Technologies for autonomous operations are discussed in Chapter 2 of this report.

\section{RADIATION HARDENING}

The requirement for radiation hard and tolerant systems presents the major complication in adapting commercial products for spacecraft use and, hence, limits the opportunity for designers to use currently available hardware and software. Further, the uncertainties associated with radiation effects have, in the past, resulted in space flight being a necessary part of a test program. It is understood that some space flight testing will always be required, but hopefully not the extended space testing that was necessary in the past.

Considerable progress has been made in predicting radiation effects and in ground testing, enabling radiation hard and tolerant design and reducing the need for flight tests. Funding for expanding and documenting these techniques and making design tools readily available could result in earlier technology insertion and substantially reduced program costs. The cooperative effort of GSFC and JPL in this field should be encouraged and expanded.

\section{ELECTRONICS PACKAGING}

Two trends are having a profound influence on the size and capacity of electronic circuitry: the combining of functions on individual semiconductor chips and the dense packaging of chips on stacked boards. A number of packaging designs are being pursued by both government and industry and should be continued. One design, employed by the 
Charles Stark Draper Laboratory and others, appears to offer major advantages and development should be encouraged. This technique employs uncased chips; provides embedded electrical and electro-optical interconnecting circuitry; and results in a rugged, dense, easily tested package. Development is being funded largely on corporate independent research and development, with a small program underway at GSFC.

\section{INTERFACES}

Considerable emphasis has been placed on spacecraft bus standards by industry and government. The proliferation of bus standards suggests that standardization at this level may involve unacceptable compromise, except by class of application (e.g., satellite communications). Alternately, standardization of components and system architecture offers greater opportunity for time and cost savings and should be pursued. However, even at this level, differences such as level of radiation exposure will necessitate deviation.

Standardization at the interface level, with the resultant reduction in interface negotiation and documentation; integration; checkout effort and time; and cabling will produce the majority of cost savings (Krueger, 1993). The broad acceptance of Military Standards 1553 and 1773, indicates what can be accomplished. The many advantages of fiber optics for a data bus dictate that emphasis should be on this approach. An existing standard electro-optical bus Military Standard 1773, has demonstrated weight and power savings and reduced radio frequency/electromagnetic interference. Simple redundancy and fault tolerance have been achieved. Further, electro-optical transceivers and fiberoptic cables stand to benefit from new developments in commercial communications, a rapidly evolving field.

\section{FINDINGS AND PRIORITIZED RECOMMENDATIONS}

In the recent past, DoD, through ARPA and BMDO, has funded major efforts on spacecraft and their guidance and control systems and components. This not only provided direct support to activities of interest to NASA but also promised a significant market in which industry was willing to invest. NASA has accordingly been in the enviable position of being able to procure equipment that could, with modest effort, be tested and qualified for its applications. This has had two effects. On the positive side, NASA's requirement for development funds was reduced. The negative side is that the development efforts have generally been funded as part of specific programs, where the natural tendency of a project manager to avoid risk and limit the cost and schedule impact of new technology often results in use of obsolete technology. Also, new technology, when accepted, tends to be mission specific. As DoD and corporate independent research and development activities are reduced, NASA's technology development requirements also are changing. If the goal of smaller, less expensive, and 
more frequent spacecraft is to be achieved, NASA must now assume a larger role in research and development.

To circumvent the problems inherent in the introduction of new technology or the use of older mission-specific, but adaptable, hardware, some of the NASA funding necessitated by the changed environment should be applied to the development and qualification of components and subsystems suitable for multimission applications and independent of specific programs. To maintain the focus on timeliness and requirements, some funding might be provided to other than NASA research centers.

The full implications or the potential impact of GPS have not yet been completely recognized. The availability of GPS and the rapidly developing capability of associated products will have a profound influence on the applications and effectiveness of small spacecraft and, hence, deserve special attention. GPS, used in various combinations with other guidance components, will afford drastic reduction in size and weight and improvement of performance over current systems. GPS is likely to revolutionize guidance and control equipment and capability, at least for low Earth orbit. Further, GPS in differential modes can possibly enable the use of several small spacecraft instead of a large spacecraft for some missions.

Products based on current technology are frequently excluded from critical roles in missions because radiation effects on the technology are undefined, which leads to fear that failure will occur in the flight environment. Even items that have been flown may be excluded because of longer mission duration or a different radiation environment. Potential small spacecraft applications are compromised by the size and weight of spacequalified hardware. Smaller, lighter models exist and in some cases have been flown, but final design and proofing have not been completed.

Investment in high-risk, high-payoff technology is limited. With reduced spending for DoD and corporate independent research and development, additional funding for NASA will be required. In order for NASA to enhance small spacecraft systems for guidance and control, the Panel on Small Spacecraft Technology makes the following prioritized recommendations.

1. A high-priority program to realize the potential of GPS on small spacecraft should be established. The unique combination of capability and small size made possible by integrating GPS receivers/processors with other existing and emerging guidance components should be assessed.

2. The design, documentation, and appropriate qualification of the following components and subsystems should be completed:

\footnotetext{
- fiber-optic interferometric gyroscope;

- miniature focal plane array star tracker;

- $\quad$ space-hardened GPS receiver/processor with attitude capability;

- advanced, miniaturized small reaction wheel;

- hardened 32-bit processor; and

- hardened solid-state recorder.
} 
Advantage should be taken of work in programs such as the proposed NASA TIMED and BMDO Clementine missions. A small amount of funding could significantly advance the capability of small spacecraft.

3. Design and ground-testing techniques should be developed that ensure acceptable performance in the space radiation environment. Additional support should be provided for the work in this field. The payoff in reduced flight-test time and funding will more than compensate for the investment in this effort. Further, the added assurance will encourage project managers to use more current technology. These techniques could be applicable to a broad range of electronic components and systems.

4. The advantages and disadvantages of applying standardization to specific interfaces for electronic and electro-optical components and subsystems (e.g., Military Standards 1553 and 1773) to simplify integration activities should be evaluated, and standardization should be implemented as indicated by the evaluation. 


\section{8 \\ Sensors for Small Spacecraft}

\section{BACKGROUND AND STATUS}

In the past, the NASA budget for science missions was allocated primarily for medium and large spacecraft (Delta class or larger). Since volume or weight was not usually a constraint, the instruments that were developed to support the scientific missions were also quite large. While the capability of NASA's instruments have advanced over the years, little investment was made in instrument miniaturization.

Prior to BMDO's Brilliant Eyes and Brilliant Pebbles programs and ARPA's (formerly DARPA) Advanced Spacecraft Technology Program in the mid 1980s, the same philosophy of using large spacecraft also existed in DoD, and resources were focused on improving instrument capability rather than on miniaturization. The BMDO and ARPA program requirements for small spacecraft resulted in a large investment (hundreds of millions of dollars) on the development of lightweight, low-power instruments and components. Although impressive advancements were made in miniaturization, many of the instruments were tailored toward specific military requirements and are not directly applicable to NASA scientific missions. While NASA can build on BMDO and ARPA technology advances, NASA must invest in smaller scientific instruments that are compatible with small scientific spacecraft.

\section{NASA PROGRAMS}

NASA has a long history of successful space science missions carried out with large and small spacecraft. It continues to have ambitious plans for the future, with emphasis on doing more with small, less expensive spacecraft. For this approach to yield the maximum return of scientific data, the mission sensors must be capable of providing more return for less weight and less electric power consumption. NASA's current major emphasis is on Mission to Planet Earth, a multidecade examination of the Earth as a coupled, interacting system. As currently planned, Mission to Planet Earth will be carried out with both intermediate and small spacecraft. The long-term nature of the program provides the opportunity to employ small spacecraft to a greater degree later in the program if a vigorous technology program supporting small spacecraft and sensors 
is conducted. Because of the high-weight and large-power requirements of many of the instruments, and the need to acquire data simultaneously with several different sensors, the current state of instrument technology necessitates the use of intermediate-sized spacecraft for the majority of the mission requirements.

In support of the Mission to Planet Earth program, a wide variety of sensors, both active and passive, has been, and is being, developed for use on numerous instruments. The sensors range in weight from as low as 19 kilograms to as high as 1,300 kilograms (for a planned synthetic aperture radar). In electric power requirements, they range from 18 watts to 2.2 kilowatts (for a planned Laser Atmospheric Wind Sounder).

A listing of the Mission to Planet Earth instruments with their weight and power requirements is given in Appendix F. Although Appendix F covers only Mission to Planet Earth, the technology discussed is representative of currently available NASA instrument technology. Several of the instruments were scheduled for flight on the joint ARPA/NASA Collaboration on Advanced Multispectral Earth Observation (CAMEO) spacecraft, which did not receive funding for fiscal year 1994. This spacecraft was intended to provide a demonstration of multispectral remote sensing to meet DoD's tactical wide-area surveillance needs while also supporting civilian climate research and environmental monitoring. It had the technical objective of demonstrating a multispectral imaging system compatible with small spacecraft (Nicastri, 1993).

Although much of NASA's sensor development has been for larger instruments, a significant amount of work in sensor miniaturization is being conducted at the Center for Space Microelectronics Technology at JPL. The Center for Space Microelectronics Technology was founded by NASA and several DoD agencies in 1987. It concentrates on innovative high-risk, high-payoff concepts and devices for future space missions (JPL, 1993). For example, the Mars Pathfinder rover (Rocky) utilizes a microseismometer developed by the Center for Space Microelectronics Technology (Space Microelectronics, 1993).

\section{DoD PROGRAMS}

DoD and associated agencies have been long-standing users of remote sensing information and, as a result, have made significant investments in sensor technology. Although in some instances the technology developed is directly applicable to civilian applications (e.g., the preparation of accurate maps and the imagery of snow and ice cover), in other instances the uses are tied to the particular tactical and strategic needs of defense forces.

In the past several years, BMDO and other defense agencies have invested sizable funds in the development of advanced sensors and instruments for acquiring and tracking ballistic missiles and for remote sensing. Several technologies under development by ARPA include a multispectral sensor, which detects a broad range of frequencies simultaneously, and superconducting materials. In support of the Brilliant Eyes program and the now-cancelled Brilliant Pebbles program, a sensors program was initiated by BMDO to develop advanced sensor technologies under a large number of separate 
projects. When these technologies are combined, they will produce a highly capable tracking and measurement system. The projects include work on passive and active sensors, on laser radar and interactive discrimination, on signal processing, and on radar and optical discrimination. A long-term development program in indium antimonide for midwave infrared sensors and arsenic-doped silicon for long-wave infrared sensors for use in passive infrared cameras has been funded by BMDO and may offer alternatives to the sensor developers in both the defense and civil sectors in the future. Many of the technologies developed under the BMDO sensor programs have been combined to develop lightweight and low-power star trackers; infrared cameras; ultraviolet and visible wavelength cameras; and laser radar and interactive discrimination capabilities. These instruments have been tested under a variety of programs, such as the Midcourse Space Program Space Experiment and the Infrared Background Signature Survey (Katz, 1993).

Advances in miniature devices such as the tunneling transducer, electron tunneling accelerometer, magnetometers, and infrared sensors have been made by BMDO-funded research at the Center for Space Microelectronics Technology (The Update, 1993). Many of these devices have the potential to significantly reduce the weight of small spacecraft.

In the near future, many of the instruments developed by BMDO will be flown on several spacecraft. The Deep Space Program Science Experiment, usually known as the Clementine program, launched in January 1994, is testing instruments during its orbit of the moon and subsequent rendezvous with an asteroid. Another activity is the MSTI program, where the objective is to test BMDO-developed miniature sensor technology. As noted above, JPL is developing a number of the Mission to Planet Earth sensors inhouse and has a long record in both the planetary and Earth sciences. The MSTI program, however, was carried out independently of JPL's Earth sciences activities, and the focus was on the fastest possible, lowest-feasible-cost launch of available experimental hardware, with emphasis on the management techniques necessary to make this possible.

Several sensors currently are flying aboard DOE's Array of Low-Energy X-Ray Imaging Sensors (ALEXIS), including six x-ray telescopes and a device to measure the effect of the Earth's ionosphere on radio signals.

\section{FINDINGS AND PRIORITIZED RECOMMENDATIONS}

For essentially all of the NASA instruments described above, technology currently exists to conduct research and operational Earth observation measurements to a precision that satisfies the concerned science and applications communities. Although there will always be a desire for better capabilities, the current environment of limited budgets requires that a drive toward less expensive missions is necessary. Thus, in the near term, the most desirable advances are those that would permit high-quality measurements to be made with smaller, lighter, less-power-demanding systems. These would enable more frequent missions, perhaps with higher risk, and the financial ability to provide for a backup launch in the event of a failure of the first. The NASA technology program for sensors and instruments should be directed toward that objective. 
Technology advances in guidance and control and in orbit location accuracy through use of GPS and low-thrust, high-response thrusters could enable the use of multiple small spacecraft flown in clusters to take sensor measurements where simultaneity is required. This technique could allow more scientific missions to be conducted with small spacecraft.

In order to enhance sensor technology for small spacecraft, the panel makes the following recommendations:

1. The feasibility of achieving the required simultaneity of measurements of different instruments using a cluster of small spacecraft should be evaluated, and, if feasible, technology should be developed. The employment of GPS and very low-thrust and high-response attitude-control thrusters might enable this technique.

2. A research and development program should be directed toward the development of miniaturized, power-efficient, high-performance instruments in the following areas:

- $\quad$ multifrequency radar altimeter and scatterometer systems;

- $\quad$ advanced coherent lidar systems;

- multispectral Earth observation systems operating in the ultraviolet, visible, and infrared wavelengths, employing lightweight optics and advanced detector-array technology;

- $\quad$ advanced, passive, larger-aperture, high-sensitivity, low-weight, microwave radiometry employing lightweight deployable antennas, room-temperature superconducting sensors, and advanced on-board processors; and

- lightweight, deployable-mirror optical systems with deformable mirrors correctable to the diffraction limit, for ultraviolet, infrared, and visible long baseline interferometry using several small spacecraft, ultimately resulting in an extremely largeaperture phased array for astronomical observations.

3. A continuous research and development program should be conducted to improve the performance and reduce the weight and power required for infrared detector arrays; cryogenic detector coolers; and deployable antennas for radiometry and radar. 


\section{9}

\section{Robotics, Automation, and Artificial Intelligence}

\section{BACKGROUND AND STATUS}

In 1987, the National Research Council report Space Technology to Meet Future Needs stated that "the time has come to add a new technology, automation and robotics, to the other major technologies-propulsion and power, materials, and information management-that are considered essential to U.S. capability to operate effectively in space. There are three reasons: affordability, achievability, and need" (NRC, 1987). Since that report, the technology is no longer "new." Much has been done, but it is still young relative to other space technologies. However, the reasons for its application are becoming even stronger.

The application of automation and robotics to NASA's mission is in a state of transition. NASA is increasingly moving toward the use of small spacecraft and associated systems and technology that may minimize the need for robot-assisted servicing. At the same time, the servicing and maintenance of major projects such as the Hubble Space Telescope and the Space Station are being planned using teleoperated robotic arms.

This section is directed toward the following applications for robotics, automation, and artificial intelligence as they relate to small spacecraft applications that the panel believes offer great potential payoffs:

- small microrovers capable of rapid deployment and numerous operations, for robotic exploration of Mars; and

- $\quad$ small robotic spacecraft and intravehicular robotics, which can contribute to crew productivity and the health and maintenance of major space assets such as the Space Station and the Hubble Space Telescope.

In addition, the panel believes that increased applications of computer-based systems will benefit all aspects of mission operations, including training and simulations. These systems are discussed in Chapter 2 of this report. 


\section{SMALL ROBOTIC PLANETARY EXPLORERS}

In the area of planetary exploration, small spacecraft systems are already being developed. For example, the NASA Mars Pathfinder project scheduled for launch in 1996 will employ an innovative microrover (termed "Rocky") operating in the vicinity of a Mars landing craft. This craft serves as a science base and as the communications center with Earth. With the ability to operate somewhat autonomously in the vicinity of the lander craft, Rocky can significantly increase the total returned knowledge. The Mars Pathfinder baseline is for remote task control, where an Earth-based operator can observe the three-dimensional environment of Rocky and program in the next sequence of maneuvers.

Rocky's perceptive ability is based on a laser line-striping scanner. However, its task-control ability is limited by an 8-bit processor and the associated limited memory. Rocky has sensors for operation as well as limited spectral-analysis capability for rock samples.

The potential for limited autonomous operation after the completion of the principal mission objectives is being considered for Mars Pathfinder. However, there is concern that the microrovers will prove to be limited in overall performance due to technological deficiencies identified in this report.

The NASA Mars Pathfinder project is the focal point for all on-going rover technology development. Currently, fully autonomous rovers for future missions are being developed, but due to limited resources, the work has not reached a stage of maturity where it can confidently be included in the next flight project. Technology for autonomous mobility exists at various locations, including several NASA Centers, ARPA, and Carnegie Mellon University.

Overall, the development of small automated science instruments and of micromanipulators with capabilities similar to Flight Telerobotic Servicer-class systems and suitable for use in small rovers is lagging behind the rest of the spacecraft systems. Small, capable stereo-vision systems do not exist. Unless technology advances are made, the capability of future, proposed programs such as the Mars Surveyor program consisting of orbiters, ground stations, and microrovers, will be limited by the inability of the rovers to perform important exploration tasks, such as sample collection, preparation, and even limited analysis.

Major enhancements in the ability of microrovers can be made by investing in the development of small calibrated science instruments and small robotic manipulators capable of extended operations and improved analytical skills on the planets. Fully autonomous microrovers capable of independent exploration and reporting could turn a network of small rovers into a powerful research tool. This would minimize the impact of the time delay between the Earth and Mars on mission planning and scientific results. The ultimate long-term success of these remote explorers will result from the aggressive application of autonomous operation in an unstructured environment.

Since current rover designs use solar arrays to generate power, the ability to fully implement a truly productive, planetary microrover exploration system is now directly related to the amount of sunlight available at the planet to be explored. For the Mars 
Pathfinder program, the limited power available to Rocky from its solar power generation system seriously limits its effectiveness, especially at higher latitudes of Mars. In the future, lightweight, low-cost radioisotope power systems could be enabling technologies for planetary exploration with microrovers. Other technology developments recommended throughout this report, such as miniaturized guidance and control and communication components; high-capacity, lightweight computers; and advanced materials and structures, could also contribute to the effectiveness of these small robotic spacecraft.

One way to achieve planetary surface technology development objectives in the near term while accomplishing significant scientific objectives, would be to conduct experimental work on the surface of the moon. This could be done with much shorter flight times than those required to travel to Mars, provide higher solar power, and permit greatly expanded communications.

\section{SMALL ROBOTS IN LOW EARTH ORBIT}

The Space Station is a major investment in space infrastructure, in which a limited number of humans must be provided with systems that will help improve their efficiency. The proper application of automation and robotics can improve the return on this investment by freeing the crew from repetitious tasks and allowing for more direct involvement of ground-based researchers in mission execution via teleoperations. Within the research environment of the Space Shuttle and the Space Station, small intravehicular activity robots such as the German ROTEX on the 1993 Space Laboratory mission can turn a limited flight opportunity into a productive research project. The automation of human-tended teleoperated space-based investigations is within the technical capability of university and industry investigators. To date only the Germans have demonstrated its utility in space.

Small robotic spacecraft could reduce, and in some cases eliminate, the need for extravehicular activity and Shuttle-related operations. In the vicinity of the Space Station, small, free-flying robots could be programmed for autonomous or teleoperated inspection of critical Space Station systems as an integral part of repair and maintenance. The concepts and technology base exist within NASA, the universities, and industry to develop autonomous systems that are efficient and fault-tolerant with respect to human safety needs. These new, small space robots can become unique, relatively low-cost tools for the crews of the Space Station, and they could help bring research productivity more in line with earlier (1980) expectations involving larger crew complements.

Perception research is needed for recognizing robot tasks and positioning, controlling, and safeguarding devices used in extravehicular and intravehicular activities. Task-control research to achieve robotic competence via task-control techniques, task diagnostics, and fault recovery strategies should be conducted. In addition, research on mechanical systems is needed to create miniaturized, low-power, reliable robot components and complete servicing robots. Finally, flight opportunities to evolve competent servicing robots should be made available. Several NASA centers, including Ames Research Center, GSFC, JPL, and the Johnson Space Center, are working on task- 
control techniques such as robot task planners, sequence safeguards, user displays, and interfaces. Much progress has been made in this area since the 1987 National Research Council report (NRC, 1987).

Small, robotic free flyers capable of performing autonomous, as well as teleoperated, inspection and maintenance are being researched at the University of Maryland, Johnson Space Center, and JPL. The only project with a planned launch is the University of Maryland's Ranger Robot, which is not scheduled to interact with a manned spacecraft during its flight. Such robotic systems employ single-string designs and software. The integration of autonomous inspection and maintenance into the manned program has not occurred. Work to date is limited to concepts and laboratory demonstrations.

Initiating the required research and development now could make systems available for insertion incrementally during the projected 10-year life of the Space Station.

\section{OTHER AGENCY PROGRAMS}

Beyond NASA, there is much automation and robotic work supported by DOE, DoD, ARPA, BMDO, the National Science Foundation, and industry. For the most part, these programs are focused on point solutions for repetitive problems such as manufacturing or hazardous-waste cleanup, rather than on changing tasks and space environments that are characteristic of most NASA applications. ARPA is supporting an unmanned ground vehicle development for teleoperated and autonomous vehicle navigation for the U.S. Army and U.S. Marine Corps. The current support of spacebased automation and robotics research and development is almost entirely funded by NASA. Much of this development can apply to small space systems.

\section{FINDINGS AND PRIORITIZED RECOMMENDATIONS}

Recommendations for NASA technology development for spacecraft subsystems that are also applicable to small robotic spacecraft are addressed in other sections of this report. The recommendations included here apply to technologies specific to small robotic spacecraft or peculiar to the robotic technology.

1. Technology work related to autonomous operations in unstructured environments should be supported and expanded.

2. Autonomous systems and artificial intelligence should be developed for application to microrovers.

3. A research and development program focused on miniaturizing robotic devices, science instruments, and associated computing power should be developed. 
4. Robotic spacecraft systems incorporating the most advanced autonomous systems and artificial intelligence technology currently available should be developed for demonstration in space on small spacecraft and on the Space Shuttle. The technology should be applied to the development of a free-flying robotic spacecraft for inspection, maintenance, and research support on the Space Station.

Beyond the NASA-unique advantages, the continued investment in automation, artificial intelligence, and robotics is in the broader national interest. Such systems have already changed the way we work and how goods are manufactured. 


\section{0 \\ Launch Vehicle Technology for Small Spacecraft}

\section{BACKGROUND AND STATUS}

It is well recognized that a credible space launch capability is the cornerstone of the U.S. space program. This capability must provide the ability to deliver payloads in a reliable, safe, and flexible manner at low cost. For small spacecraft, the launch cost is a significant portion of the total life-cycle cost. Therefore, as the emphasis on smaller and less expensive missions increases, attention must be given to reducing the cost to deliver small systems to space.

Today, the United States possesses a mixed fleet of launch vehicles that could be used to launch small spacecraft. These include expendable launch vehicles; a manned, partially reusable transportation system; and a newer class of small payload launch vehicles. With the exception of a few of the small payload launch vehicle concepts, most of the existing fleet of vehicles are either variants of military ballistic missiles upgraded into versions capable of space launch or use technologies that date back to the 1970s. All current launch vehicle systems are expensive to build and operate. Moreover, even though some of the new, small payload launch vehicles have potential for operational flexibility (i.e., the ability to change payloads in minimum time before launch), the majority of the launch vehicles lack this attribute.

In addition, recent policies issued by DoD and the Administration to allow a limited use of excess ballistic missile assets for space launch vehicles and the more aggressive entry of foreign competition, have raised new, but mixed, reactions among U.S. producers of launch vehicles and launch services (DoD, 1993a; DoD, 1993b; DoD, 1993c).

\section{SMALL LAUNCH VEHICLES}

Several U.S. launch vehicles are listed in Table 10-1. These vehicles are well suited to launch small spacecraft (600 kilograms or less), but are in various states of design, development, and use. Specific information on availability and capabilities of the launch vehicles can be obtained from the companies involved. 
TABLE 10-1 Representative U.S. Launch Vehicles

\begin{tabular}{ll}
\hline \multicolumn{1}{c}{ COMPANY } & \multicolumn{1}{c}{ LAUNCH VEHICLE } \\
\hline Orbital Sciences Corporation & Pegasus, Taurus \\
EER Systems & Conestoga \\
E-Prime Aerospace & Eagle \\
Lockheed Missiles \& Space Company & LLV1, LLV2, LLV3 \\
CTA Launch Vehicle Services & Orbex \\
(formerly International Microspace Inc.) & \\
PacAstro & PA \\
American Rocket Company & Aquilla \\
\hline
\end{tabular}

Many of the vehicles have several variants. Although there are exceptions, most of these vehicle designs incorporate a combination of stages previously used for ballistic missiles, orbit insertion, or sounding rockets. They are heavily oriented to the use of solid rocket propulsion rather than the mix of solid and liquid propellant stages usually used for medium- and heavy-lift launch vehicles. Most of the small launch vehicles have been developed as innovative commercial ventures with some government investment. In some cases, the government has provided minimal support and then served as an "anchor customer," allocating a limited number of launches for the government payloads. In this sense, the government has played a key role in encouraging development of a commercial launch industry for the small launch vehicle market.

Orbital Sciences Corporation is the only company that has actually launched payloads to orbit (using Pegasus and Taurus), and, at this writing, only Orbital Sciences Corporation and PacAstro have firm contracts for future launches. Lockheed Missiles and Space Company has scheduled the first launch of the LLV1 for November 1994. American Rocket Company uses a hybrid-rocket approach with a solid fuel and liquid oxidizer and has successfully conducted several short-duration, static firing tests of a motor producing 112,500 kilograms of thrust (Boyer, 1993).

Because of several attractive operational, safety, environmental, and cost benefits associated with hybrid rockets, there is interest within both DoD and NASA in carrying hybrid-motor technology to a point of maturity to assess its true potential. The American Rocket Company was one of the companies recently selected by DoD to receive Technology Reinvestment Project Funds over 24 months to further develop a 112,500kilogram thrust hybrid-rocket motor. The other companies involved in the Technology Reinvestment Project award includes Martin Marietta, United Technologies Corporation, U.S. Air Force Phillips Laboratory, U.S. Air Force/30th Space Wing, and U.S. Air Force/6595 Test and Evaluation Group. The 1994 NASA Appropriation Bill also contained language specifying continued investment in hybrid-rocket technology (U.S. Congress, 1993). 
There are many entries in the small launch vehicle market by international competitors, such as Australia's ALV; Israel's Shavit; China's Long March (1D); India's ASLV; Brazil's ELV; Italy's SMS; Japan's M-5 and J-1; Spain's Capricornio; and Russia's START-1, KOSMOS, and Surf (a vehicle built by the U.S./Russian company, Sea Launch Investors). Currently, only China and Russia are actively marketing their launch vehicles, but other countries are becoming more aggressive internationally.

Today, the United States has a minimally demonstrated launch capability for spacecraft under 600 kilograms, with the promise of significant improvement. If many of the proposed U.S. vehicles become operational, then the capability and availability would significantly increase. However, it is still unclear whether the cost would decrease as a result of increased competition. In addition, the fate of domestic suppliers in the U.S. small spacecraft market is even more unclear when considering the number of potential international competitors.

\section{LOWERING COST OF LAUNCHING SMALL SPACECRAFT}

If there is to be an expanded small spacecraft market, there needs to be a lowercost means of launching the spacecraft than exists today. A total launch cost of $\$ 5$ million to $\$ 7$ million was frequently cited by industry representatives and government officials during panel briefings as a threshold considered critical for an expanded market. This cost appears affordable for experimenters, innovators, and commercial and university users. However, none of the launch services listed above is close to the target of $\$ 5$ million to $\$ 7$ million. Although spacecraft can be built for $\$ 2$ to $\$ 5$ million each, total launch costs, including the vehicle and flight operations, for existing small launch vehicles cost between $\$ 10$ million and $\$ 25$ million (Seitz, 1993c).

\section{Use of Excess Missile Assets}

One approach under consideration by the Clinton Administration that will result in lowering launch costs for small payloads is to allow the use of excess missile assets. Although they are not technology issues, decisions regarding the authorization of the use of U.S. and Russian excess missile assets will have an impact on the pace of advanced technology development to reduce launch costs for small spacecraft. Some contractors contend that the goal of a total cost per launch of $\$ 5$ million to $\$ 7$ million could be achieved using excess missiles. The current U.S. Air Force/Martin Marietta multiservice launch system program using excess Minuteman assets should provide the basis for a reliable cost estimate. Policy recommended by DoD allows the general use of the existing missiles for suborbital requirements. Use for orbital requirements is highly restricted, and permission for use is controlled by DoD (DoD, 1993a; DoD, 1993b; DoD 1993c). In spite of the potential to make launch more affordable for small payloads, there are some in the U.S. industry that believe such an action would have a negative impact on domestic commercial suppliers. The DoD-recommended policy is now under 
consideration by the National Security Council and the Office of Science and Technology Policy for recommendation to the President as a national policy.

This study assumes that the goal of lowering the cost of space launches using systems developed specifically for that purpose will continue even if excess missile assets are used to support some portion of the requirements.

\section{Technology Improvements}

Given the launch vehicle options discussed earlier, the problem is being able to provide launch services at a price that users are willing to pay. This appears to be in the range of $\$ 5$ million to $\$ 7$ million. With the exception of excess missile assets, today's market price appears to be about twice this desired range. Thus, a significant technology challenge exists to find ways to reach the desired price. Even with a new design based on currently available technologies and those projected to be available in the next few years, the Panel on Small Spacecraft Technology concludes that the likelihood of reaching this goal is very small. Also, little can be done from a technology perspective, to significantly reduce costs of existing small spacecraft launch vehicles except in operations as discussed in Chapter 2 of this report.

Assuming a new launch vehicle approach, there are technologies that could be developed that can lower costs well below today's level. The following sections list technology recommendations to reduce the cost for future (1) expendable launch vehicles and (2) reusable launch vehicles.

\section{Technologies to Reduce the Cost of Future, Expendable Launch Vehicles}

Since propulsion and structures can account for 60 to 80 percent of the vehicle cost, it is not surprising to see attention for technology improvements focused in those areas. The majority of those addressing the panel emphasized that propulsion was a key area for technology investment. ${ }^{1}$ It was suggested that future systems be designed for low cost, not high performance. This included component developments that use fewer parts and improved manufacturing processes, while still maintaining sufficient margins. In this regard, hybrid propulsion appears attractive from the view of safety and environmental compatibility.

NASA and DoD have each been sponsoring several efforts to apply advanced manufacturing methods (e.g., precision investment casting, laser drilling, stereo lithography) to the manufacture of rocket components. The NASA Solid Propellant

1 This was also the finding in the 1987 Aeronautics and Space Engineering Board report Space Technology to Meet Future Needs and in its 1992 report From Earth to Orbit (NRC, 1987, 1992). 
Integrity Program (SPIP) is funding industry programs to study manufacturing for reliability of nozzles, bond lines, and propellant. NASA and industry (notably McDonnell Douglas and TRW) have been jointly funding a low-cost, low-pressure propulsion approach that has the potential to lower production unit costs significantly. However, work is needed of sufficient scale to demonstrate the potential cost savings associated with advanced manufacturing techniques for a low-cost and highly reliable design.

Except for solid rocket motors, launch vehicle structures have been fabricated, for the most part, from conventional aluminum materials. The higher strength composite materials have been avoided because of perceived higher cost. Advanced manufacturing technologies could overcome this concern and perhaps result in reduced cost when compared with conventional metal structures.

A large body of applicable launch vehicle technology has been developed by several aircraft and spacecraft companies. For example, LTV, Boeing, Hughes Aircraft, and others have developed advanced manufacturing techniques for structural components made from high-performance composite materials. Some government laboratories (Naval Research Laboratory and U.S. Air Force Phillips Laboratory) have developed composite structural components for spacecraft applications. These techniques may have application to launch vehicle structures. However, during this study the panel identified no program for application of advanced composites to launch vehicle structures other than propellant tanks. For example, NASA has proposed the use of aluminum-lithium alloys for the Space Shuttle's external tank. Proposals to use an aluminum-lithium alloy in launch vehicle structures have been made for some time, and tanks up to 45 inches in diameter have even been fabricated in technology programs.

Another factor that tends to increase launch vehicle costs is the fact that the vehicles and their subsystems are manufactured from an extensive number of components that are inherently less reliable and more expensive than integrated components.

\section{Technologies to Enable Future Recoverable, Reusable Launch Vehicles}

The improvements in technology and operational approaches described earlier can drive costs down and deserve attention. However, the panel believes that the desired range for launch cost ( $\$ 5$ million to $\$ 7$ million) is not achievable with current and nearterm systems. Even with newly designed expendable systems, the low costs desired will be difficult to attain. For cost reductions that are substantial, new systems must be considered that force a fundamental change in launch system design and operational culture.

An approach, which long has been supported by space enthusiasts, is the fully reusable single-stage-to-orbit launch vehicle or some variant like a reusable two-stage-toorbit launch vehicle. In the long term, the ability to decrease recurring costs via reuse and the introduction of appropriate aircraft industry-like operations to reduce infrastructure costs have a potential to offer a competitively low-cost launch service, especially for the small-payload portion of the market. It is not apparent that it would be economically feasible to develop a single-stage-to-orbit vehicle specifically to support the 
small spacecraft market. However, the potential for a very low-cost launch system is sufficiently high that the enabling technology program should be supported.

The technology required to support fully reusable single-stage-to-orbit or twostage-to-orbit concepts is generally not very mature. Without the development of several enabling technologies, recoverable, single-stage-to-orbit launch vehicles are not possible. Some enabling technologies are

- lightweight, high-temperature composite structures; aluminum-lithium alloy or composite cryogenic tankage; and thermal protection system materials with good moisture resistance;

- high specific impulse, low-weight, high thrust-to-weight tripropellant propulsion systems;

- flexible, lightweight guidance and control systems for launch and landing;

- on-board health-monitoring systems; and

- automated mission planning systems.

Achievement of a reusable single-stage-to-orbit vehicle will require a substantial investment in these enabling technologies before a system development program can be initiated. However, because of the high potential payoff of a successful development, some level of technology support, especially in propulsion and materials, is advisable.

The launch and recovery operational aspects were being addressed in the McDonnell Douglas/BMDO Single-Stage-to-Orbit DC-X project. At the time of this report, announcements indicate the single-stage-to-orbit technology efforts will be continued under the auspices of NASA.

\section{ENVIRONMENTAL CONSIDERATIONS}

The preponderance of the launch vehicles being developed commercially to service the small payload market use existing solid propellant stages. Larger launch vehicles often have strap-on solid propellant booster stages. At the same time, environmental regulations are increasing, and more ingredients, compounds, and substances have been restricted under various clean air acts. The exhaust product of most solid propellant rockets is hydrogen chloride, which is converted to hydrochloric acid in the presence of moisture and can prove toxic to ground vegetation and wildlife. Since the total quantity being emitted by current launches is small, this concern is not currently significant. But, if launch frequency increases, or regulations become more stringent, then it is possible that launch vehicles using today's varieties of solid propellant could be tightly controlled or stopped altogether in the future. 
Technology programs are currently sponsored by the U.S. Air Force Phillips Laboratory with Thiokol and Aerojet to develop solid propellants using scavengers ${ }^{2}$ or using solution-propellant processing to eliminate or minimize hydrogen chloride exhaust compounds. These propellants are referred to as clean propellants.

Currently, ammonium nitrate-based clean propellants that contain no chlorine are available, but severe manufacturing problems exist, because the propellants are hygroscopic. ${ }^{3}$ Rocket-motor manufacturing must be in a controlled, low-humidity environment, and the motor system must be hermetically sealed through the entire storage life of the rocket motors. Ammonium dinitramide propellant eliminates the problem of hydrogen chloride from the combustion products. However, the ammonium dinitramide manufactured in the United States is extremely expensive and has not been manufactured on a large scale (Pak, 1993). The Office of Naval Research has funded Thiokol and Chemical Systems Division of United Technologies Corporation to manufacture ammonium dinitramide and evaluate the product. Additionally, the solid propellant industry is doing small-scale, corporate independent research and developmentsponsored work on ammonium nitrate and ammonium dinitramide propellants. The ammonium dinitramide technology is in the very early research phase.

The hybrid-rocket system described earlier has the added advantage of producing environmentally acceptable propellant exhaust inherently. Unlike a conventional solid propellant, the hybrid fuel does not contain any ingredients that will form environmentally harmful exhaust products. These systems have the potential for providing a new, low-cost technology approach coupled with operational safety and environmental features.

\section{PRIORITIZED RECOMMENDATIONS}

In order to enhance technology for small spacecraft launch vehicles, the panel makes the following recommendations.

1. Hybrid rocket motors that simulate operational requirements, thrust level, and burn duration for small launch vehicles should be manufactured and tested to demonstrate readiness for application.

2. Although the Panel on Small Spacecraft Technology believes it has identified several areas with potential for reducing small spacecraft launch vehicle costs, the panel was not able to identify a technology program that would achieve the desired cost of $\$ 5$ million to $\$ 7$ million per launch. The panel, therefore, recommends that NASA conduct a study of proposed, new launch vehicles targeted for the small payload

2 A scavenger is a propellant additive that will continue with chlorine to reduce or eliminate hydrogen chloride.

3 "Hygroscopic" means readily taking up or retaining water. 
market; with a goal of $\$ 5$ million to $\$ 7$ million per launch; to determine the cost benefits associated with the introduction of new technology, including unique concepts, new hardware designs, new materials, and manufacturing methods. This study should also include consideration of support for launch and mission operations. NASA should initiate advanced demonstration programs for promising concepts identified in the study, especially in propulsion technology. These demonstrations should be carried to the point that will allow decisions for system development to be made by either the government or commercial ventures.

3. The ongoing Solid Propellant Integrity Program should be supported with increased consideration toward those solid propulsion units used in commercial small launch vehicles. Such action will help the commercial sector maintain or improve reliability.

4. Development of advanced manufacturing methods directed toward producibility and cost reduction of small spacecraft launch vehicles should be continued. This should include potential application of advanced composites.

5. Scavenged and solution propellants are possible near-term solutions to potential environmental limitations of propellants and should be scaled up and qualified for use.

6. A program to characterize the ammonium dinitramide-based clean propellants should be funded. If the results are positive, a program to develop a pilot plant to scale-up the manufacture of ammonium dinitramide should be funded.

7. NASA should initiate technology efforts in support of a reusable singlestage-to-orbit vehicle for small spacecraft where appropriate, to ensure the availability of the enabling technologies on a realistic time scale. 


\section{1 \\ Overall Findings and Recommendations}

\section{CURRENT EMPHASIS AND JUSTIFICATION}

NASA currently is focusing on more frequent use of smaller, more technically advanced, and less expensive scientific spacecraft to replace large, expensive, one-of-akind spacecraft. This approach is intended to promote not simply a specific category of technologies and missions with a lower cost, faster development and launch time, and higher tolerance for risk but also a space program that enhances productivity and economic competitiveness.

Small spacecraft already have served a long-standing role in space physics, astrophysics, and planetary missions, notably at GSFC and at JPL, which predates the recent enthusiasm for small spacecraft. With decreasing NASA budgets projected for at least the next five years and with over 50 percent of NASA's overall budget allocated for the Space Station, the Space Shuttle, and Mission to Planet Earth, the Panel on Small Spacecraft Technology believes the increased emphasis on small spacecraft is well placed if NASA is to have a meaningful science program in the future (Goldin, 1993). Although small, less-expensive spacecraft cannot satisfy all potential mission requirements, such as manned exploration and more demanding science missions, the panel believes they can contribute to the revitalization of the space program. Further, more-frequent and lessexpensive missions can help to promote structural and cultural changes that are vital to the future of the space program considering the current budgetary and political environment. These changes include increased opportunities for infusion of new technology in ongoing programs, along with an increased tolerance for technological risk; overall improvements in program responsiveness, versatility, and cost-effectiveness; and economic competitiveness in both aerospace and nonaerospace industries.

\section{SMALL SPACECRAFT CAPABILITIES}

While the panel believes that for many missions small spacecraft have the potential to achieve the mission requirements with capability approaching that of today's large spacecraft, it must acknowledge that even with the application of currently available technology, today's small NASA spacecraft have limitations. Furthermore, not all small 
spacecraft missions are simultaneously faster and less expensive, since technology research and development for miniaturization can be expensive. However, the panel believes that with a vigorous technology-development and miniaturization program that focuses on areas that provide the highest payoff, small spacecraft, either singular or in constellations, can be used to achieve increasingly significant mission requirements.

\section{RESPONSE TO TASK STATEMENT}

The task statement for this study asked the panel to

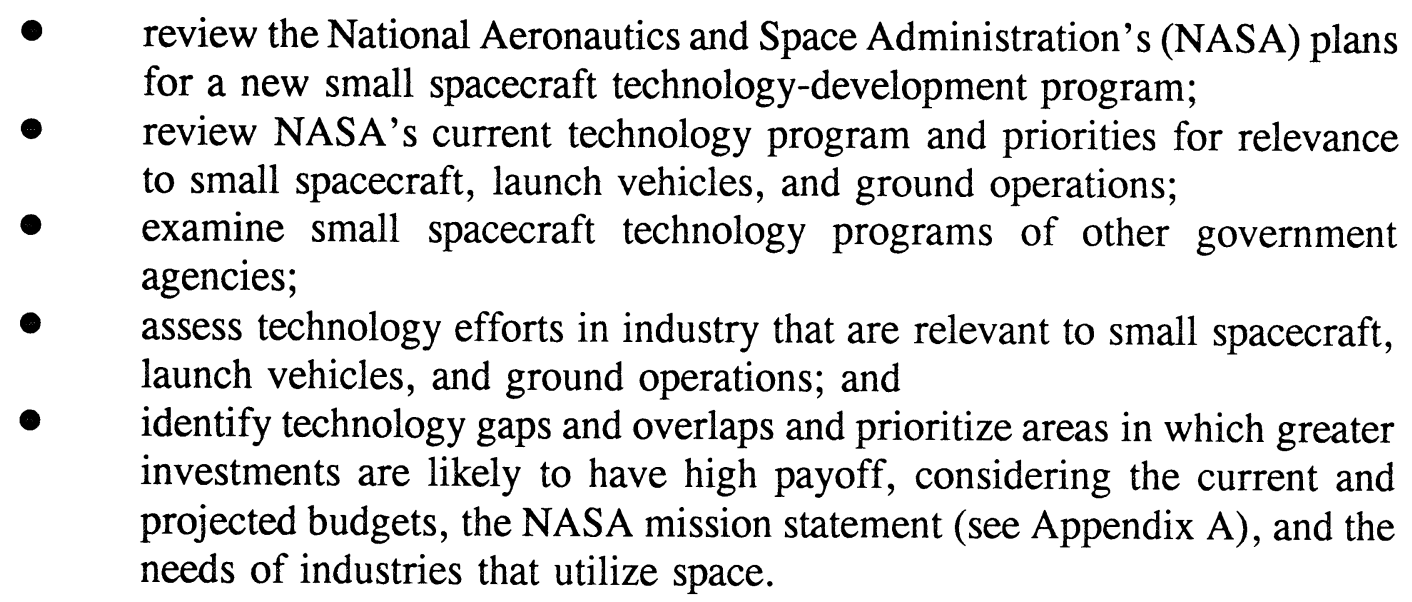

\section{Review of NASA's Small Spacecraft Technology Program}

While NASA's technology program has not, until recently, been focused on small spacecraft, NASA has had several development programs for small scientific spacecraft in the past, which used advanced technology that was developed, to a significant degree, by DoD and industry. The current NASA development programs for small scientific spacecraft include the ongoing Small Explorer program at GSFC and NASA activities in support of small DoD spacecraft, such as Clementine and MSTI.

In addition to the existing activities, OACT recently established the Small Spacecraft Technology Initiative and the Office of Space Science initiated the Discovery program to develop a series of smaller scientific spacecraft. The first two Discovery missions, which are both scheduled for launch in 1996 are JPL's Mars Pathfinder and the Applied Physics Laboratory's Near Earth Asteroid Rendezvous. Appendix D gives a more complete summary of NASA small spacecraft programs.

The goals of the OACT Small Spacecraft Technology Initiative are to develop and infuse technology into planned missions and to demonstrate a new approach to small spacecraft technology integration through development and flight of several small spacecraft. Because of the recent establishment of OACT's Small Spacecraft Technology 
Initiative, small spacecraft technology-development activities may receive greater emphasis in the future.

It is the intent of OACT to infuse technology into proposed internal NASA development programs for small spacecraft. A new ethos of technology infusion should be actively promoted by NASA, and project managers should be encouraged to incorporate new technology into all future small spacecraft missions. The panel believes that every space mission could contribute substantially to the achievement of NASA's larger mission if every mission were also, to one degree or another, a flight test of new technology.

The project management philosophies utilized for the GSFC and JPL small spacecraft development programs and the one proposed for the OACT Small Spacecraft Technology Initiative and the Office of Space Science's Discovery program are markedly different. In the case of GSFC and JPL programs, spacecraft design and integration and, in many cases, the manufacturing effort, are largely kept within NASA centers, while industry's role is limited to that of support contractors and subsystem suppliers. Project managers of the Discovery missions and the OACT Small Spacecraft Technology Initiative propose to place responsibility for spacecraft concept, design, and integration with a prime contractor and utilize NASA in a support and oversight role.

The panel believes that each approach has merit. The internal NASA "prime contractor" role provides NASA a means for conducting special missions where a NASA lead is considered necessary and also provides an excellent training ground for future NASA project managers. However, it tends to impede the transfer of technology to industry, where it can be used in support of future NASA programs, and, perhaps more importantly, to commercial initiatives and to programs of other agencies. Having an industry prime contractor lead with support from other industry partners, universities, and NASA, places the technology in the hands of industry where it is more likely to be applied commercially. The panel believes that NASA should continue an active internal technology development program for small spacecraft, as discussed in the following section, independent of the project management approach.

\section{Assessment of the NASA Technology Priorities for Relevance to Small Spacecraft, Launch Vehicles, and Ground Operations}

The establishment of the Small Spacecraft Technology Initiative appears to have heightened emphasis, in NASA technology planning circles, on team operations involving industry, university, and NASA interaction on specific space missions, with accentuated industry leadership. "Customer needs," "user needs," and technology transfer capability have received considerable emphasis from NASA management as the primary drivers of NASA's research and development efforts. While this emphasis is certainly healthy in establishing relevant foci for NASA's technological activities and providing a vital framework for intensive efforts, the panel is concerned that overemphasis on this approach may lead NASA to overlook its responsibility to the long-term development of generic space technology. A mix of direct mission support, especially for NASA's own 
space-science projects, and generic research on a variety of advanced technology special topics should be pursued. Adequate funding for technology development is required for NASA to successfully implement this approach. Especially since the defense budgets are decreasing, NASA must be able to support its own requirements for technology research and development.

The specific technology recommendations of this report are generally of a relatively short-term nature and do not address the need for a more generic research and development program that will support future generations of small spacecraft systems. It is the opinion of the panel that the recommendations of this report, coupled with such a generic technology-development activity would, over both the short and long term, enable the execution of meaningful space-science programs and economically attractive commercial space ventures using small spacecraft.

In recent years, several high-level study groups have been very critical of the level of funding committed to NASA's technology development program. The groups have recommended funding levels that range from a level of 7 to 10 percent of NASA's total budget (NRC, 1987) to a factor of three increase of the 1990 technology budget (NASA, 1990).

This panel recognizes that the level of expenditure for technology development should be related to NASA's long-range plans for future programs. As of this writing, several elements of NASA's overall plan are apparent to the panel:

- an international space station that uses existing systems for placement in orbit;

- Mission to Planet Earth, which uses existing systems for orbit placement;

- use of small spacecraft for future Earth and planetary science programs;

- technology to support the commercial industry; and

- technology development to support a later decision for manned exploration of space.

As can be seen from this list, several different types of programs must compete for technology development funds within NASA. The panel notes that although the NASA Administrator strongly supports using small spacecraft for scientific missions, the same support was not reflected in Congress' fiscal year 1994 budget, where the Small Spacecraft Technology Initiative received only $\$ 12.5$ million of the $\$ 30$ million requested. Since the fiscal year 1995 budget only recently was submitted to Congress, it was not clear at the time of this report whether Congress would support NASA's $\$ 47.9$ million request for the Small Spacecraft Technology Initiative. While small spacecraft based on currently available technology have significant capability, their ability to conduct more-meaningful science programs at affordable cost could be greatly enhanced through technology development. Recognizing the great potential to be derived from research and development of advanced technology for small spacecraft, the panel recommends that an adequate level of funding be provided to ensure the achievement of that potential. 
The panel has not made specific cost estimates for each of its recommendations. This was considered to be beyond the panel's capability in the time it was able to dedicate to the study. It is the panel's belief that each of the recommendations that has survived its critical review and appears in this report should be funded and carried to the point where it is completed and the technology is ready for use or to the point where it is apparent that there is a better course to follow.

The panel leaves it to NASA to determine the cost of the recommended technology program for small spacecraft, and to make evaluations of the potential contributions of the recommendations to the health and vigor of the future NASA and commercial space programs. In the event that it is determined that a substantial increase in the NASA research and development budget is indicated in order to conduct the program in a timely manner, NASA should rearrange its budget priorities to accommodate the required level of funding for research and development and make the case with the Administration and the Congress for the substantial increase.

\section{Small Spacecraft Technologies of Other Government Agencies and Technology Efforts in Industry that are Relevant to Small Spacecraft, Launch Vehicles, and Ground Operations}

The panel was briefed by numerous government agencies and companies regarding the activities of these groups in small spacecraft, launch-vehicle, and groundoperations technology programs. While the survey of technology was not all inclusive, due primarily to time constraints, the panel believes that it developed a comprehensive understanding of the small spacecraft technology development activities. A summary of the panel's findings and recommendations is provided below. In brief, it was apparent that the DoD agencies, in particular the Naval Research Laboratory, BMDO, and ARPA, have had, in the past, very active programs in small spacecraft technology development. These programs were supported by industry, both in contractual efforts for the DoD agencies and with company-funded research and development projects.

Table 11-1 is a summary of the technologies that were identified by the panel as being currently available, that is, those technologies that could be used by small spacecraft designers today with minimal risk, but with the understanding that some degree of further development and flight qualification may be required. The availability was based on the experienced judgment of the panel members. Table 11-1 includes, in addition to DoD and industry technologies, those technologies developed in the NASA technology program, primarily at GSFC, JPL, and LeRC. Many of these technologies currently are being used in ongoing programs such as in the Clementine spacecraft, in the Small Explorer program, and in the Lockheed commercial spacecraft being developed for the IRIDIUM ${ }^{\mathrm{TM} / \mathrm{SM}}$ program. 
TABLE 11-1 Currently Available Technologies for Small Spacecraft within NASA, Other Government Agencies, and Industry

\begin{tabular}{|c|c|c|}
\hline $\begin{array}{c}\text { TECHNOLOGY } \\
\text { AREA } \\
\end{array}$ & TECHNOLOGY & LOCATION* \\
\hline \multirow{3}{*}{$\begin{array}{l}\text { SYSTEMS } \\
\text { ENGINEERING AND } \\
\text { OPERATIONS }\end{array}$} & $\begin{array}{l}\text { Phase-change memory materials to replace } \\
\text { explosive devices on the spacecraft }\end{array}$ & $\begin{array}{l}\text { U.S. Air Force Phillips Laboratory, } \\
\text { Industry, Naval Research Laboratory }\end{array}$ \\
\hline & $\begin{array}{l}\text { Autonomous, on-board health monitoring of } \\
\text { launch vehicle and spacecraft }\end{array}$ & $\begin{array}{l}\text { U.S. Air Force, NASA, Industry, U.S. } \\
\text { Army }\end{array}$ \\
\hline & $\begin{array}{l}\text { Autonomous determination of orbit } \\
\text { parameters and autonomous station keeping }\end{array}$ & BMDO, JPL \\
\hline \multirow[t]{5}{*}{ PROPULSION } & $\begin{array}{l}\text { Bipropellant thruster ( } 756 \text { newtons) with } \\
\text { high response valving and low weight ( } 64 \\
\text { grams) }\end{array}$ & $\begin{array}{l}\text { BMDO, U.S. Air Force Phillips } \\
\text { Laboratory, Industry }\end{array}$ \\
\hline & $\begin{array}{l}\text { Monopropellant thruster }(223-500 \\
\text { newtons) with high pulse rate, low weight } \\
(184-326 \text { grams })\end{array}$ & $\begin{array}{l}\text { BMDO, U.S. Air Force Phillips } \\
\text { Laboratory, Industry }\end{array}$ \\
\hline & $\begin{array}{l}\text { Carbon composites and fiber overwraps on } \\
\text { aluminum propulsion tanks for reduced } \\
\text { weight }\end{array}$ & $\begin{array}{l}\text { BMDO, U.S. Air Force Phillips } \\
\text { Laboratory, Industry }\end{array}$ \\
\hline & $\begin{array}{l}\text { Arc jets for station keeping (less than 1- } \\
\text { kilowatt power levels) }\end{array}$ & $\begin{array}{l}\text { NASA, U.S. Air Force Phillips } \\
\text { Laboratory }\end{array}$ \\
\hline & SPT-70 electromagnetic Hall thruster & $\begin{array}{l}\text { BMDO, JPL, U.S. Air Force Phillips } \\
\text { Laboratory, Industry }\end{array}$ \\
\hline \multirow[t]{3}{*}{ POWER } & $\begin{array}{l}\text { Silicon, Gallium Arsenide, and Gallium } \\
\text { Arsenide/Germanium solar arrays }\end{array}$ & NASA, BMDO, DoD, Industry \\
\hline & Radioisotope thermoelectric generators & DOE, NASA \\
\hline & $\begin{array}{l}\text { Individual and common pressure vessel } \\
\text { nickel hydrogen batteries }\end{array}$ & Naval Research Laboratory \\
\hline \multirow{3}{*}{$\begin{array}{l}\text { MATERIALS AND } \\
\text { STRUCTURES }\end{array}$} & Smart structures for jitter suppression & U.S. Air Force Phillips Laboratory \\
\hline & $\begin{array}{l}\text { Aluminum-lithium alloys for primary } \\
\text { structures }\end{array}$ & NASA, Industry \\
\hline & $\begin{array}{l}\text { Polymer matrix composites for primary } \\
\text { structures }\end{array}$ & Industry \\
\hline \multirow[t]{4}{*}{ COMMUNICATIONS } & $\begin{array}{l}\text { High speed switching from the Advanced } \\
\text { Communications Technology Satellite (Ka- } \\
\text { band) }\end{array}$ & NASA, Industry \\
\hline & Radio frequency satellite link components & NASA, Industry \\
\hline & Radio frequency phased array antennas & NASA, Industry \\
\hline & Solid-state amplifiers & NASA, Industry \\
\hline
\end{tabular}


TABLE 11-1 Currently Available Technologies for Small Spacecraft within NASA, Other Government Agencies, and Industry (Continued)

\begin{tabular}{|c|c|c|}
\hline $\begin{array}{c}\text { TECHNOLOGY } \\
\text { AREA } \\
\end{array}$ & TECHNOLOGY & LOCATION* \\
\hline \multirow{7}{*}{$\begin{array}{l}\text { GUIDANCE AND } \\
\text { CONTROL }\end{array}$} & Ring laser gyroscopes & Industry \\
\hline & Focal-plane-array star trackers & BMDO, Industry \\
\hline & $\begin{array}{l}\text { Small, lightweight reaction wheels using } \\
\text { conventional bearings }\end{array}$ & Industry \\
\hline & GPS receivers for position determination & Industry, Naval Research Laboratory \\
\hline & Solid-state recorders, radiation hardened & Industry \\
\hline & 32-bit computers, radiation hardened & Industry \\
\hline & $\begin{array}{l}\text { Standard electro-optical bus (e.g., Military } \\
\text { Standard 1773) }\end{array}$ & $\begin{array}{l}\text { U.S. Air Force Phillips Laboratory, } \\
\text { Industry, NASA }\end{array}$ \\
\hline \multirow[t]{2}{*}{ SENSORS } & $\begin{array}{l}\text { BMDO-developed instruments using passive } \\
\text { and/or active sensors: star trackers, near- } \\
\text { infrared camera, long-wavelength infrared } \\
\text { camera, ultraviolet/visible infrared camera, } \\
\text { laser imaging and detection ranger }\end{array}$ & BMDO \\
\hline & $\begin{array}{l}\text { NASA-developed instruments for the } \\
\text { Mission to Planet Earth program }\end{array}$ & NASA \\
\hline \multirow[t]{2}{*}{ LAUNCH VEHICLES } & $\begin{array}{l}\text { Aluminum-lithium alloys for propellant } \\
\text { tanks and other structures }\end{array}$ & NASA, Industry \\
\hline & $\begin{array}{l}\text { Graphite epoxy for propellant tanks and } \\
\text { other structures }\end{array}$ & Industry \\
\hline
\end{tabular}

* The location indicated is intended to be representative and may not include all sources. In addition, since the panel was tasked to survey small spacecraft technology in NASA, industry, and other government agencies, work at universities was not thoroughly assessed by the panel. 
TABLE 11-2 Technologies Under Development within NASA, Other Government Agencies, and Industry

\begin{tabular}{|c|c|c|}
\hline $\begin{array}{c}\text { TECHNOLOGY } \\
\text { AREA }\end{array}$ & TECHNOLOGY & LOCATION* \\
\hline \multirow{3}{*}{$\begin{array}{l}\text { SYSTEMS } \\
\text { ENGINEERING AND } \\
\text { OPERATIONS }\end{array}$} & Capability to use factory-to-launch sequencing & BMDO, JPL \\
\hline & $\begin{array}{l}\text { Processors that enable significant on-board } \\
\text { data processing to relieve ground data- } \\
\text { processing requirements }\end{array}$ & NASA, JPL \\
\hline & Automated preparation of flight software & Industry, BMDO, JPL \\
\hline \multirow[t]{7}{*}{ PROPULSION } & $\begin{array}{l}\text { XLR-132, advanced bipropellant orbit transfer } \\
\text { engine }\end{array}$ & $\begin{array}{l}\text { U.S. Air Force Phillips Laboratory, } \\
\text { Industry }\end{array}$ \\
\hline & Iridium-rhenium thrusters, 445 newtons & LeRC, Industry \\
\hline & Piston-pump propellant supply systems & $\begin{array}{l}\text { Lawrence Livermore Laboratory, } \\
\text { Industry }\end{array}$ \\
\hline & $\begin{array}{l}\text { Weight reduction and miniaturization of } \\
\text { propulsion system components }\end{array}$ & $\begin{array}{l}\text { U.S. Air Force Phillips Laboratory, } \\
\text { NASA, Industry }\end{array}$ \\
\hline & $\begin{array}{l}\text { Carbon composites for thrust-chamber } \\
\text { structure and high-pressure propellant tanks }\end{array}$ & $\begin{array}{l}\text { BMDO, U.S. Air Force Phillips } \\
\text { Laboratory, Industry }\end{array}$ \\
\hline & Xenon ion thrusters, $1-5$ kilowatts & NASA, JPL, Industry \\
\hline & Solar thermal propulsion & $\begin{array}{l}\text { U.S. Air Force Phillips Laboratory, } \\
\text { Industry }\end{array}$ \\
\hline \multirow[t]{6}{*}{ POWER } & $\begin{array}{l}\text { Amorphous silicon, copper indium diselenide, } \\
\text { cadmium telluride, indium phosphide on } \\
\text { germanium, and multibandgap cells }\end{array}$ & LeRC, U.S. Air Force, Industry \\
\hline & Thin-film cells & $\begin{array}{l}\text { BMDO, U.S. Air Force, JPL, } \\
\text { Industry }\end{array}$ \\
\hline & Ultra-light flexible panels and flexible arrays & LeRC \\
\hline & Nickel metal hydride batteries & LeRC, JPL \\
\hline & Lithium batteries & $\begin{array}{l}\text { JPL, LeRC, DOE, BMDO, U.S. Air } \\
\text { Force }\end{array}$ \\
\hline & $\begin{array}{l}\text { Advanced energy conversion systems (Stirling, } \\
\text { thermophotovoltaic, and alkali metal } \\
\text { thermoelectric converters) }\end{array}$ & NASA, DOE, Industry \\
\hline \multirow[t]{3}{*}{$\begin{array}{l}\text { MATERIALS AND } \\
\text { STRUCTURES }\end{array}$} & Inflatable structures & $\begin{array}{l}\text { Lawrence Livermore National } \\
\text { Laboratory, Industry, U.S. Air Force } \\
\text { Phillips Laboratory }\end{array}$ \\
\hline & Smart structures for vibration and jitter control & U.S. Air Force Phillips Laboratory \\
\hline & Embedded sensors & U.S. Air Force Phillips Laboratory \\
\hline
\end{tabular}


TABLE 11-2 Technologies Under Development within NASA, Other Government Agencies, and Industry (Continued)

\begin{tabular}{|c|c|c|}
\hline $\begin{array}{c}\text { TECHNOLOGY } \\
\text { AREA } \\
\end{array}$ & TECHNOLOGY & LOCATION* \\
\hline \multirow{3}{*}{$\begin{array}{l}\text { MATERIALS AND } \\
\text { STRUCTURES } \\
\text { (continued) }\end{array}$} & $\begin{array}{l}\text { Advanced composite materials and } \\
\text { manufacturing methods }\end{array}$ & Industry \\
\hline & Metal-matrix composites for structures & Industry, NASA, U.S. Air Force \\
\hline & Electro-emissive panels & Industry \\
\hline \multirow[t]{5}{*}{ COMMUNICATIONS } & Transponders & Industry, NASA \\
\hline & Superconducting communications components & Industry \\
\hline & Optical communications & $\begin{array}{l}\text { NASA/GSFC, JPL, U.S. Air Force, } \\
\text { BMDO, U.S. Navy, Industry }\end{array}$ \\
\hline & $\begin{array}{l}\text { Radio frequency space-to-space links and } \\
\text { associated components and antenna systems }\end{array}$ & U.S. Air Force Phillips Laboratory \\
\hline & New multiple-access schemes & Industry \\
\hline \multirow{7}{*}{$\begin{array}{l}\text { GUIDANCE AND } \\
\text { CONTROL }\end{array}$} & Interferometric fiber-optic gyroscopes & JPL, DOE, Industry \\
\hline & Advanced, miniaturized small reaction wheel & Industry \\
\hline & GPS for three-axis control of spacecraft & NASA, Naval Research Laboratory \\
\hline & Radiation-hardened, fault-tolerant electronics & Industry, NASA \\
\hline & Advanced electronics packaging techniques & Industry, Naval Research Laboratory \\
\hline & GPS receivers for attitude determination & Industry, NASA, Universities \\
\hline & $\begin{array}{l}\text { Advanced inertial measurement unit based on } \\
\text { emerging technologies }\end{array}$ & Industry, Universities \\
\hline \multirow[t]{8}{*}{ SENSORS } & $\begin{array}{l}\text { Technologies being developed for Mission to } \\
\text { Planet Earth (see Appendix F) }\end{array}$ & NASA \\
\hline & $\begin{array}{l}\text { Technology being developed for BMDO } \\
\text { programs }\end{array}$ & $\begin{array}{l}\text { BMDO, Industry, Lawrence } \\
\text { Livermore National Laboratory }\end{array}$ \\
\hline & $\begin{array}{l}\text { Indium antimonide detectors for midwave } \\
\text { infrared sensors }\end{array}$ & BMDO, Industry \\
\hline & $\begin{array}{l}\text { Arsenic-doped silicon for long-wave infrared } \\
\text { sensors }\end{array}$ & BMDO, Industry \\
\hline & Multispectral imager & ARPA \\
\hline & Superconducting materials & ARPA, Industry \\
\hline & Solar-blind ultraviolet detectors & $\begin{array}{l}\text { Applied Physics Laboratory, Naval } \\
\text { Research Laboratory }\end{array}$ \\
\hline & Analog processor & Applied Physics Laboratory \\
\hline
\end{tabular}


TABLE 11-2 Technologies Under Development within NASA, Other Government Agencies, and Industry (Continued)

\begin{tabular}{|c|c|c|}
\hline $\begin{array}{c}\text { TECHNOLOGY } \\
\text { AREA }\end{array}$ & TECHNOLOGY & LOCATION* \\
\hline $\begin{array}{l}\text { SENSORS } \\
\text { (continued) }\end{array}$ & Laser radar & Industry, BMDO \\
\hline \multirow[t]{3}{*}{ ROBOTICS } & Remotely programmed microrovers & JPL \\
\hline & $\begin{array}{l}\text { Tools for autonomous operation of } \\
\text { microrovers }\end{array}$ & NASA, ARPA, Industry \\
\hline & Spaceborne geophysical sampling device & NASA, Applied Physics Laboratory \\
\hline \multirow[t]{6}{*}{ LAUNCH VEHICLES } & $\begin{array}{l}\text { Advanced composite materials for fabrication } \\
\text { of intertank structure, skirts, and payload } \\
\text { shrouds }\end{array}$ & Industry \\
\hline & $\begin{array}{l}\text { Lower-cost solid- and liquid-rocket motor } \\
\text { components through use of advanced } \\
\text { manufacturing methods }\end{array}$ & $\begin{array}{l}\text { U.S. Air Force Phillips Laboratory, } \\
\text { Industry }\end{array}$ \\
\hline & Hybrid propellant motors and stages & Industry, NASA, U.S. Air Force \\
\hline & $\begin{array}{l}\text { Reusable cryogenic and tripropellant } \\
\text { propulsion components (injectors, thrust } \\
\text { chambers, pumps) for application to single- } \\
\text { stage-to-orbit }\end{array}$ & $\begin{array}{l}\text { U.S. Air Force Phillips Laboratory, } \\
\text { NASA, Industry }\end{array}$ \\
\hline & $\begin{array}{l}\text { Clean propellants using higher-performance } \\
\text { ingredients such as ammonium dinitramide }\end{array}$ & $\begin{array}{l}\text { U.S. Air Force Phillips Laboratory, } \\
\text { Industry, U.S. Navy }\end{array}$ \\
\hline & $\begin{array}{l}\text { Clean solid propellants exploiting ammonium } \\
\text { nitrate, solution propellant, and scavenged } \\
\text { approaches }\end{array}$ & $\begin{array}{l}\text { Industry, U.S. Air Force Phillips } \\
\text { Laboratory }\end{array}$ \\
\hline
\end{tabular}

* The location indicated is intended to be representative and may not include all sources. In addition, since the panel was tasked to survey small spacecraft technology in NASA, industry, and other government agencies, work at universities was not thoroughly assessed by the panel.

It should be noted that some technologies listed as being currently available in Table 11-1 may also appear in Table 11-2 as technology under development. The available technologies in Table 11-1 currently possess a specific level of capability that can be useful for small spacecraft, but the technology may also be under development to expand its mission capability or to complete the flight qualification. Recommendations for future work on many of the technology areas noted in Table 11-1 and Table 11-2 are presented in the last section of this chapter.

Based on its review, the Panel on Small Spacecraft Technology believes that the technologies noted in Table 11-1 can be used, with an acceptable risk level, in current NASA development programs for small spacecraft. 
Technologies currently under development in government and in industry are shown in Table 11-2. Table 11-2 was intended to serve two purposes: (1) to identify ongoing technology programs that, if continued, are likely to result in available technology that could be applied to future small spacecraft programs, and (2) to identify ongoing developments in industry and government agencies to assist NASA in avoiding duplication in their small spacecraft technology development program.

The Panel on Small Spacecraft Technology recommends that NASA monitor the progress being made in the technology programs listed in Table 11-2 and that the programs be evaluated to avoid possible duplication. It is further recommended that, in the event that the sponsoring agency is other than NASA, and decides to discontinue the development activity, NASA should consider completing the technology development.

Again, the panel does not intend the technology lists in Tables 11-1 and 11-2 to be all inclusive. The tables do, however, reflect the results of the panel's fairly extensive review.

\section{Technology Gaps and Overlaps}

The panel's review did not identify any overlaps of NASA's research and development with that of DoD and industry that were considered to be serious. On the contrary, the panel believes that the level of technology development underway in the United States is deficient, considering the NASA objective of widely expanded use of small spacecraft.

Although gaps in technology are difficult to define, the panel believes that there is a significant gap between the technology that is now available and that which is being used in the NASA small spacecraft programs. This may be a result of the conservatism of the NASA project managers, which is understandable because of the dire consequences of failure engendered by the current, very costly large space programs. In addition, the panel believes that there are gaps relating to the technology needed to achieve the maximum return from small spacecraft in the future. These gaps are addressed in the recommendations for technology development in the following section.

\section{Prioritized Areas in Which Greater Investments are Likely to Have High Payoff Considering Current and Projected Budgets, the NASA Mission Statement, and the Needs of Industries That Utilize Space}

As stated in Chapter 1, the principal deterrent to an expanded space program, both in NASA and commercially, is high cost. This is true for NASA because of today's budgetary and political climate and for industry because of the high cost in providing a 
potential service to a buyer, along with increasing international competition. If technology can be developed that will enable small spacecraft to achieve increasingly capable missions while maintaining the ability to produce the spacecraft at reasonable cost, the utilization of space by both NASA and industry could expand.

The panel believes that there are numerous opportunities in the development of technology related to small spacecraft systems. The difficulty is in how to prioritize and invest in technologies to achieve the greatest reduction in cost. In this section, the panel has assigned priority levels to the technology recommendations contained in the body of the report. Three priority levels were chosen: high, higher, and highest. The panel applied criteria (not in priority order) that included the following:

- the potential to reduce mission cost;

- the cost to develop the technology;

- the potential to reduce weight (permitting a higher payload mass fraction or use of a smaller launch vehicle);

- the likelihood of a successful development; and

- the potential to enable key mission goals.

Since hard data regarding these criteria are not available, the qualitative judgment of the panel members, based upon their experience and background, was the determining factor. In order to balance differences in judgments, the priority selections were made independently by two separate groups of panel members, and then a consensus was reached by the entire panel.

The recommendations, in general, address applied research programs rather than generic research activities. As discussed earlier, generic research also is an essential part of a total technology program. Such programs not only continue to extend the state of the art but also provide an opportunity for NASA to attract talented college graduates to work in NASA's laboratories and to engage universities, graduate students, and industry in stimulating research and development activity under contract to NASA.

In addition, since many of the technologies that can be used on small spacecraft have been developed by DoD and industry, the panel believes that:

A normal part of NASA's research and development activity should include the continual monitoring by NASA of research and development activities of other government agencies, foreign governments and organizations, and industry.

The panel believes that each recommendation is worthy of implementation. However, recognizing the uncertainty of NASA funding for technology development, the panel has identified those areas as highest priority, which in its judgement, offer the greatest potential for enhancing the mission capability and reducing the cost of small spacecraft. The remaining areas were identified as either high or higher priority. The assumption is that all of the recommended areas will be pursued at some point, with those in the highest priority level being funded first. The fact that the development of a 
particular technology may not come to fruition for several years should not bias a decision regarding early funding.

The panel believes that advanced technology has the potential to greatly enhance the ability of small spacecraft to perform meaningful missions at low cost. It is the opinion of the panel that the totality of the recommendations, if executed, would enable an important part of the United States' space-science program to be accomplished very economically with small spacecraft. It would also provide a very strong technology base for the emerging small spacecraft commercial industry.

The technology recommendations were assigned priority levels as discussed above and are listed at the end of this chapter. Discussions of the specific technologies can be found in the appropriate sections of the body of the report. Some technologies that have a particularly high potential to make a large impact on the cost and capability of small spacecraft are

- technologies to reduce cost and improve efficiency of up-front systems engineering, launch, and mission operations;

- GPS for precision guidance and control;

- high-efficiency solar electric power generation and electric propulsion;

- hybrid propulsion for launch vehicles; and

- miniaturization of electronic devices.

Many launch and mission operations functions that now are performed by ground personnel can be automated with lightweight, low-cost, on-board systems. For example, on-board vehicle monitoring and, in some cases, defect correction can be automated, enabling factory-to-launch operations without the requirement for extensive intermediate ground testing. On-board launch trajectory monitoring for range safety purposes is achievable using GPS on board the spacecraft, eliminating the need for ground-based radar tracking during launch. Automated, on-board orbit determination and station keeping is also possible using GPS, which simplifies the mission operations task. Highdensity computers and memory devices combined with advanced software techniques enable extensive on-board data processing and screening, reducing the amount of data to be stored and transmitted to Earth. The compact memory devices reduce the requirement for numerous data-reception locations on the ground. Communication systems can be developed that will permit direct delivery of data, partially processed on board, to researchers in their own laboratories, where they have powerful computing capability at their desks. Chapter 2 provides more detail on these and other technologies that could be applied to make substantial reductions in the personnel required to launch and operate a space mission using a small spacecraft.

Two potential applications of GPS to small spacecraft, as noted above, are launch trajectory monitoring and automated on-board orbit determination. The panel believes that GPS also has great potential in other applications. Use of GPS in various combinations with other guidance components can determine position and attitude accurately, probably at significantly reduced weight and cost. GPS also provides the 
capability to precisely fly clusters of small spacecraft in close proximity to one another, simulating a much larger spacecraft.

Electric propulsion is a very promising technology that can enable more ambitious missions in high-altitude orbits and at interplanetary distances. Such missions, however, must be able to tolerate orbit transfer times of several days or even months. Small, lightweight spacecraft are particularly suited to this technology because of the relatively higher thrust-to-weight ratios achievable with these very-low-thrust electric propulsion systems. In order to gain maximum potential from these high-specific-impulse systems, a high electric power level is required. Advanced technology in solar-generated power could supply the required power levels with array sizes and weights compatible with small spacecraft. Extensive development work on both the solar power and electric propulsion technologies has been conducted in the past, but a concentrated, well-funded, development activity is needed to bring these technologies to fruition.

Hybrid propulsion is a technology that has great potential for application to small spacecraft launch vehicles and has been under development for some time. Hybrid propulsion systems offer unique advantages over conventional solid-propulsion systems during manufacturing and shipping because of their inherent inertness and over both solid and liquid systems during launch operations. The reduction in special safety requirements should translate into reduced cost. Hybrid propulsion systems have the added advantage of an environmentally acceptable exhaust product, which could be an important factor if environmental restrictions increase.

Advances in miniaturization of electronic devices have the potential to increase the payload mass fraction, lower the spacecraft weight, reduce the power requirements, and reduce overall cost. These devices can be combined to form highly-capable systems for remote sensing, guidance and control, communications, and on-board operations. Continued investment in advanced design and ground testing techniques for adapting commercial products for the space environment can assure the availability of up-to-date technology for space application.

Table 11-2 lists those technology development programs currently underway that were identified by the panel during its review activity. Before NASA initiates programs responsive to the recommendations in Table 11-3, it should review development currently underway in other agencies and industry. 


\section{TABLE 11-3 Prioritized Technology Recommendations}

\section{HIGHEST}

\section{Systems Engineering and Operations}

Capabilities and design tools should be developed that facilitate improved up-front concept development for low-cost small spacecraft missions. These capabilities and tools should facilitate in-depth trades that result in improving the ability to estimate and in lowering overall life-cycle costs. Key trades include:

- $\quad$ operational mission concepts;

- many small spacecraft versus larger, fully integrated systems;

- the degree of autonomy on the spacecraft and on the ground;

- the effect of launch strategy and vehicle selection;

- the degree of acceptable risk and approach to reliability; and

- dedicated versus shared mission operations facilities.

Tools that would be useful are

- data bases and cost estimating software that address life-cycle cost of small missions; and

- nationally available data bases for existing parts, components, and new technologies.

Technologies and techniques should be developed that would reduce the required number of mission operations personnel. These techniques include:

- autonomous orbit determination and correction;

- on-board data screening to reduce the amount of data to be transmitted to the ground; and

- communication systems for distribution of mission data directly from the spacecraft to the data users.

Technologies and practices required to enable a factory-to-launch sequence with minimum checkout at the launch site should be developed and demonstrated. These should utilize expert systems when appropriate, including, as a minimum, the following:

- on-board health monitoring and checkout and, where economical, fault correction, for both the launch vehicle and the spacecraft;

- techniques for remote system checkout;

- automated preparation of flight software for guidance and control of both the launch vehicle and spacecraft;

- a set of standard hardware interfaces for small launch vehicles and spacecraft;

- on-board launch trajectory determination for range safety tracking;

- $\quad$ spacecraft accessibility late in the countdown; and

- reduction of launch pad safety requirements through use of technologies such as hybrid propulsion and nonexplosive separation devices.

\section{Propulsion}

An aggressive program should be established to demonstrate, in ground tests, the life of xenon ion propulsion systems that operate at power levels in the range from about 0.5 kilowatt to about 2.5 kilowatts for lifetimes of up to 8,000 hours. Arc jet thrusters for small spacecraft applications also should be evaluated. The systems demonstrated should be capable of being integrated into solar electric propulsion systems with total power levels in the range of 1 to 5 kilowatts. Both the ion thruster and the arc jet should then be demonstrated in space flight tests in the near term.

The propulsion system requirements should be determined for precision station keeping of clusters of small spacecraft, and the capability of currently available systems should be evaluated. If it is necessary, systems should be developed to meet specific mission requirements. 
TABLE 11-3 Prioritized Technology Recommendations (Continued)

\section{HIGHEST (Continued)}

\section{Power}

An advanced solar array program should be initiated at a funding level that will allow reaching a goal of 200 watts per kilogram with 5 to 10 kilowatts of total power within the next five years.

The development, characterization, and testing of NiMH batteries for low-power small spacecraft should be completed.

Building on the work already completed for the Clementine mission, the characterization and testing of $\mathrm{CPV} \mathrm{NiH}_{2}$ batteries for mid- to high-power small spacecraft should be completed.

\section{Communications}

Development of the following technologies should be supported:

$$
\begin{aligned}
& \text { an electronically steered Ka-band phased array antenna; } \\
& \text { a Ka-band solid-state amplifier; and } \\
& \text { a Ka-band power module. }
\end{aligned}
$$

\section{Guidance and Control}

A high-priority program to realize the potential of GPS on small spacecraft should be established. The unique combination of capability and small size made possible by integrating GPS receivers/processors with other existing and emerging guidance components should be assessed.

The design, documentation, and appropriate qualification of the following components and subsystems should be completed:

$$
\begin{aligned}
& \text { fiber-optic interferometric gyroscope; } \\
& \text { miniature focal plane array star tracker; } \\
& \text { space-hardened GPS receiver/processor with attitude capability; } \\
& \text { advanced, miniaturized small reaction wheel; } \\
& \text { hardened 32-bit processor; and } \\
& \text { hardened solid-state recorder. }
\end{aligned}
$$

\section{Sensors}

The feasibility of achieving the required simultaneity of measurements of different instruments using a cluster of small spacecraft should be evaluated, and, if feasible, technology should be developed. The employment of GPS and very lowthrust and high-response attitude control thrusters might enable this technique.

\section{Robotics and Automation}

Technology work related to autonomous operations in unstructured environments should be supported and expanded.

\section{Launch Vehicle Technology}

Hybrid rocket motors that simulate operational requirements, thrust level, and burn duration for small launch vehicles should be manufactured and tested to demonstrate readiness for application. 


\section{TABLE 11-3 Prioritized Technology Recommendations (Continued)}

\section{HIGHER}

\section{Systems Engineering and Operations}

Data storage and transmission techniques should be developed that meet the needs unique to small spacecraft. These techniques should utilize:

- low-cost, miniaturized, high-capacity, reliable data storage devices;

- efficient, high-data-rate transmission techniques;

- better forward error-correction codes; and

- efficient protocols for high-speed-data interactive transactions.

Standardized communications interfaces for mission control functions should be developed. Areas for standardization include:

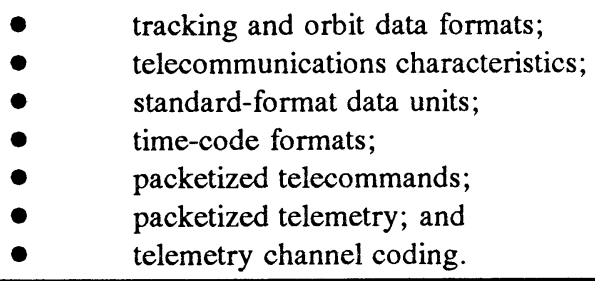

\section{Propulsion}

A technology program should be established to demonstrate the Light Exo-Atmospheric Projectile propulsion technologies at mission duty cycles and lifetimes consistent with small spacecraft mission life and operational requirements.

The 445-newton rhenium-iridium thruster should be evaluated for application to an apogee kick stage for small spacecraft. This includes demonstration over a duty cycle typical of the missions envisioned for small spacecraft.

The suitability of the XLR-132 engine as an upper-stage propulsion system for launching small spacecraft with deepspace propulsion needs should be evaluated.

\section{Power}

The development of lithium alloy $\left(\mathrm{LiTiS}_{2}\right)$ batteries, particularly for low-energy-demand planetary missions, should be continued.

The application of lithium ion batteries developed by the DOE should be evaluated for possible use in low-Earth-orbit spacecraft. If found promising, the technology should be adapted for small spacecraft.

For mid- to far-term applications, the development of lithium polymer batteries should be accelerated.

In the long-term, work on other advanced solar cell and solar array technology, including thin-film cell development, inflatable arrays, and flexible blanket wing APSA arrays, should continue at an increased funding level, with the goal of achieving a specific power of 300 watts per kilogram.

\section{Structures and Materials}

Research on simple, low-cost deployable booms and surfaces should be emphasized. The objectives should include high deployment reliability, compact stowage, and adequate precision. Ground-test proof of successful deployment in space is essential. 


\section{TABLE 11-3 Prioritized Technology Recommendations (Continued)}

\section{HIGHER (Continued)}

\section{Structures and Materials (continued)}

A joint NASA-industry program should be initiated to demonstrate developments of advanced small-spacecraft designs that are based on polymer-composite components, exploiting available as well as novel technology as appropriate to meet the paramount demands of low cost, low weight, reliability, and adaptability. The NASA Small Spacecraft Technology Initiative may fulfill this objective.

In coordination with ongoing research at universities and other government agencies, research efforts should be intensified in the area of smart structures and control-structures interaction. Research should be generic in character as well as focused on specific needs for small spacecraft.

\section{Communications}

Optical frequency (laser) communications systems and components (e.g., electronically controlled antennas and signal processing) should be developed for space-to-space links.

Radio frequency space-to-space links, the associated components, and spacecraft antenna systems for complex spacecraft constellations in both low Earth orbit or other orbits should be developed.

New, multiple access schemes and the associated critical components should be developed, as well as optimization of bandwidth utilization in the mobile satellite frequencies for low-Earth-orbit systems.

\section{Guidance and Control}

Design and ground-testing techniques should be developed that ensure acceptable performance in the space radiation environment. Additional support should be provided for the work in this field. The payoff in reduced flight-test time and funding will more than compensate for the investment in this effort. Further, the added assurance will encourage project managers to use more current technology. These techniques could be applicable to a broad range of electronic components and systems.

\section{Sensors}

A research and development program should be directed toward the development of miniaturized, power-efficient, highperformance instruments in the following areas:

- multifrequency radar altimeter and scatterometer systems;

- advanced coherent lidar systems;

- multispectral Earth observation systems operating in the ultraviolet, visible, and infrared wavelengths, employing lightweight optics and advanced detector array technology; advanced, passive, larger-aperture, high-sensitivity, low-weight, microwave radiometry employing lightweight deployable antennas, room-temperature superconducting sensors, and advanced on-board processors; and

- lightweight, deployable-mirror optical systems with deformable mirrors correctable to the diffraction limit, for ultraviolet, infrared, and visible long baseline interferometry using several small spacecraft, ultimately resulting in an extremely large-aperture phased array for astronomical observations.

\section{Robotics and Automation}

Autonomous systems and artificial intelligence should be developed for application to microrovers. 


\section{TABLE 11-3 Prioritized Technology Recommendations (Continued)}

\section{HIGHER (Continued)}

\section{Launch Vehicle Technology}

Although the Panel on Small Spacecraft Technology believes it has identified several areas with potential for reducing small spacecraft launch vehicle costs, the panel was not able to identify a technology program that would achieve the desired cost of $\$ 5$ million to $\$ 7$ million per launch. The panel, therefore, recommends that NASA conduct a study of proposed, new launch vehicles targeted for the small payload market; with a goal of $\$ 5$ million to $\$ 7$ million per launch; to determine the cost benefits associated with the introduction of new technology, including unique concepts, new hardware designs, new materials, and manufacturing methods. This study should also include consideration of support for launch and mission operations. NASA should initiate advanced demonstration programs for promising concepts identified in the study, especially in propulsion technology. These demonstrations should be carried to the point that will allow decisions for system development to be made by either the government or commercial ventures.

\section{HIGH}

\section{Propulsion}

Research and technology programs should be initiated to demonstrate fully the capability of solar thermal rockets, with emphasis on concentrator/mirror, absorber-thruster, and feed-system technology. Space flight tests should be conducted to explore deployment mechanisms and dynamics, validate packaging techniques, and demonstrate the performance and durability of absorber-thruster operation with a deployable concentrator mirror.

\section{Power}

There is a small but important subset of small spacecraft missions that cannot use solar power or batteries and that are enabled by radioisotope power systems. For those missions, development of more efficient conversion systems to reduce heat source mass and cost would be beneficial. Radioisotope power system designs using Stirling, thermophotovoltaic, and alkali metal thermal-to-electric converter conversion techniques should be jointly evaluated by NASA and DOE, and the ability of these techniques to satisfy various NASA missions should be assessed. Based on the evaluation, NASA and DOE should select one or more of these systems for experimental demonstrations of its performance against specific pre-determined criteria that are peculiar to the approach selected. NASA and DOE should then select the most promising approach for further development. A decision about flight demonstrations should be made contingent on future NASA planning of missions that would utilize the technology.

Research on concentrator arrays, with a goal of reaching power densities in excess of 300 watts per kilogram at one-half the cost of existing arrays, should be increased.

\section{Structures and Materials}

A short-term demonstration program with industry should be undertaken to design, construct, and qualify a small spacecraft structure based primarily on current structural design configurations that exploit aluminum-lithium alloys in lieu of aluminum in order to determine the feasibility of rapid weight savings with minimal effort and cost.

Sufficient expertise in polymer-matrix composite technology should be maintained within NASA to identify and pursue opportunities for research aimed at improving strength, stiffness, thermal properties, and economy of fabrication, with explicit attention to the possibilities of multiple-use components and the engineering of modular attachments and joints.

\section{Communications}

NASA should be the technical leader in developing the rationale for radio frequency reassignments in view of the new optical communications developments. 


\section{TABLE 11-3 Prioritized Technology Recommendations (Continued)}

\section{HIGH (Continued)}

\section{Guidance and Control}

The advantages and disadvantages of applying standardization to specific interfaces for electronic and electro-optical components and subsystems (e.g., Military Standards 1553 and 1773) to simplify integration activities should be evaluated, and standardization should be implemented as indicated by the evaluation.

\section{Sensors}

A continuous research and development program should be conducted to improve the performance and reduce the weight and power required for infrared detector arrays; cryogenic detector coolers; and deployable antennas for radiometry and radar.

\section{Robotics and Automation}

A research and development program focused on miniaturizing robotic devices, science instruments, and associated computing power should be developed.

Robotic spacecraft systems incorporating the most advanced autonomous systems and artificial intelligence technology currently available should be developed for demonstration in space on small spacecraft and on the Space Shuttle. The technology should be applied to the development of a free-flying robotic spacecraft for inspection, maintenance, and research support on the Space Station.

\section{Launch Vehicles}

The ongoing Solid Propellant Integrity Program should be supported with increased consideration toward those solid propulsion units used in commercial small launch vehicles. Such action will help the commercial sector maintain or improve reliability.

Development of advanced manufacturing methods directed toward producibility and cost reduction of small spacecraft launch vehicles should be continued. This should include potential application of advanced composites.

Scavenged and solution propellants are possible near-term solutions to potential environmental limitations of propellants and should be scaled-up and qualified for use.

A program to characterize the ammonium dinitramide-based clean propellants should be funded. If the results are positive, a program to develop a pilot plant to scale-up the manufacture of ammonium dinitramide should be funded.

NASA should initiate technology efforts in support of a reusable single-stage-to-orbit vehicle for small spacecraft where appropriate, to ensure the availability of the enabling technologies on a realistic time scale. 


\section{List of References}

Aerospace America. 1993. Electric propulsion. Aerospace America, December 1993, Vol. 31 (No. 12): pp. 52. American Institute of Aeronautics and Astronautics. Washington, D.C.

American Rocket Company, 1994. HyTOP consortium and NASA MSFC sign cooperative agreement for hybrid technology option project under the President's technology reinvestment project. American Rocket Company Press Release issued April 8, 1994. American Rocket Company. Ventura, CA.

Asrar, G. and D.J. Dokken. 1993. 1993 Earth Observing System Reference Handbook. NASA Earth Science Support Office. National Astronautics and Space Administration. Washington, D.C.

Auclair, G., M. Dimiceli, M. Gerbasi, and D. Damon. 1993. Lockheed Small Satellites. Presentation to the Panel on Small Spacecraft Technology, September 29, 1993. Lockheed Missiles and Space Company. Sunnyvale, CA.

Avila, E. 1992. Elite Program Overview. Space Programs and Technologies Conference and Exhibits, March 24-26, 1992. AIAA-92-1559. American Institute of Aeronautics and Astronautics. Washington, D.C.

Bennett, G. 1994. On-board propulsion reaches new heights. Space Technology Innovation, January/February 1994. Vol. 2 (No. 1): pp. 4.

Boden, D. and W. Larson. Undated. Cost Effective Space Mission Operations. Kluwer Academic Publishers. Norwell. MA.

Boyer, W. 1993. American Rocket Co. touts hybrid's future after test. Space News, February 15-21, 1993. Vol. 4 (No. 7): pp. 11.

Budinger, J., L. Deutsch, H. Hendricks, B. Howell, C. Raquet, D. Rascoe, L. Riley, B. Seery, and W. White. 1993. Miniature Spacecraft Communications Technology Program. System Team Analysis Report to OACT, February 9, 1993. 
National Aeronautics and Space Administration/Office of Advanced Concepts and Technology. Washington, D.C.

Chetty, P.R.K. 1991. Satellite Technology and Its Application. 2nd Edition. TAB Books. Division of McGraw-Hill, Inc. Blue Ridge Summit, PA.

Cooley, W.T. 1991. Air Force Photovoltaic Array Alternatives. Proceedings of the 26th Intersociety Energy Conversion Engineering Conference, August 4-9, 1991. Vol. 2 IECEC-91. American Nuclear Society. LaGrange Park, IL.

David, L. 1993. NASA culls discovery missions while seeking program funds. Space News, February 22-28, 1993. Vol. 4 (No. 8): pp. 17.

Davis, T.M. 1993. Space Technologies for Small Satellites. Presentation to the Panel on Small Spacecraft Technology, April 8, 1993. U.S. Air Force Phillips Laboratory. Kirtland AFB, NM.

Davis, T.M., and T. Imler. 1993. Enabling Space and Missiles Technologies and Small Satellite Initiatives. Presentation to the Panel on Small Spacecraft Technology, April 8, 1993. U.S. Air Force Phillips Laboratory. Kirtland AFB, NM.

DoD. 1993a. Excess Strategic Missile Assets Review. Memorandum from the Office of the Under Secretary of Defense dated January 13, 1993. Department of Defense. Washington, D.C.

DoD. 1993b. DoD Policy on Use of Excess Ballistic Missile Assets. Memorandum from the Office of the Under Secretary of Defense dated May 14, 1993. Department of Defense. Washington, D.C.

DoD. 1993c. Excess Strategic Ballistic Missile Assets Report. Memorandum from the Office of the Secretary of Defense dated September 15, 1993. Department of Defense. Washington, D.C.

Giffin, G. 1993. Space Communications Strategic Plan 1994. Presentation to the Aeronautics and Space Engineering Board, National Academy of Sciences, December 6, 1993. National Aeronautics and Space Administration/Office of Advanced Concepts and Technology. Washington, D.C.

Goldin, D. 1993. Testimony before the Subcommittee on Science, Technology, and Space, Committee on Commerce, Science and Transportation, November 16, 1993. National Aeronautics and Space Administration. Washington, D.C. 
Hanks, B. 1993. NASA Miniature Spacecraft Technology Development Activities. Presentation to the Committee on Advanced Space Technology, January 27, 1993. National Aeronautics and Space Administration Headquarters. Washington, D.C.

Herrera, E.D., and I. Kuck. 1992. Air Force Space Power and Thermal Management Technology: Requirements for the Early 21st Century. Proceedings of the 27th Intersociety Energy Conversion Conference, August 3-7, 1992. Vol. 6 pp. 259. Society of Automotive Engineers, Inc. Warrendale, PA.

Iannotta, B. 1994. DC-X hangs by thin thread despite short-term reprieve. Space News, February 7-13, 1994. Vol. 5 (No. 6): pp. 4 \& 21.

JPL. 1993. Center for Space Microelectronics Technology 1992 Technical Report. JPL Publication 93-27 dated November 1, 1993. Jet Propulsion Laboratory. Pasadena, CA.

Katz, J. 1993. Strategic Defense Initiative, Space Technology Development and Demonstration Overview. Presentation to the Panel on Small Spacecraft Technology, January 27, 1993. Strategic Defense Initiative, Department of Defense. Washington, D.C.

Krueger, D.A. 1993. Brief on Spacecraft Interfaces. Presentation to Dr. Norman Parker, July 15, 1993. National Aeronautics and Space Administration/Goddard Space Flight Center. Greenbelt, MD.

Kurland, R., and P. Stella. 1992. Advanced Solar Array Design and Performance. AIAA-2-058. Briefing at the 1992 Aerospace Design Conference. The Aerospace Corporation. Irvine, CA.

Landis, G.A., and A. F. Hepp. 1991. Applications of Thin-Film Photovoltaics for Space. Proceedings of the 26th Intersociety Energy Conversion Engineering Conference. Vol. 2 IECEC-91, August 4-9, 1991. American Nuclear Society. LaGrange Park, IL.

Larson, W.J., and J.R. Wertz. 1992. Space Mission Analysis and Design. Second Edition. Kluwer Academic Publishers. Norwell, MA. and Microcosm, Inc. Torrance, CA.

Leary, W.E. 1993. NASA to send craft to study asteroid. New York Times, December 16, 1993. pp. B16.

Matlock, R., J. Katz, D. Holtkamp, and S. Nozette. 1993. Overview of SDIO Technology Programs. Presentation to the Committee on Advanced Space 
Technology, January 27-29, 1993. Strategic Defense Initiative Organization/Department of Defense. Washington, D.C.

McCarthy, J. 1993. NASA New Technology Investments Package. Presentation to the Aeronautics and Space Engineering Board, National Research Council, December 6, 1993. National Aeronautics and Space Administration. Washington, D.C.

Mintz, J. 1994. Launching a drive for federal help. U.S. rocket firms, facing tough competition from abroad, seek r\&d aid. Washington Post, January 12, 1994, Final Edition. pp. F1 and F8.

Munro, N. 1993. U.S. Air Force may drop satellite laser-link program. Defense News, October 4-10, 1993. Vol. 8 (No. 39): pp. 28.

NASA. 1990. Report of the Advisory Committee on Future of the U.S. Space Program, 1990. National Aeronautics and Space Administration. Washington, D.C. U.S. Government Printing Office.

NASA. 1993a. NASA selects flight technology proposals. NASA release 93-186, October 15, 1993. National Aeronautics and Space Administration. Washington, D.C.

NASA. 1993b. Third technology reinvestment project selections announced. NASA release No. 575-93. National Aeronautics and Space Administration. Washington, D.C.

NASA/OACT 1993. Small Spacecraft Technology Workshop. Briefing at the NASA/OACT Small Spacecraft Technology Workshop, September 21-24, 1993. National Aeronautics and Space Administration/Office of Advanced Concepts and Technology. Washington, D.C.

Nicastri, E.D. 1993. ARPA's Space Programs. Presentation to the Panel on Small Spacecraft Technology, April 8, 1993. Advanced Systems Technology Office, Advanced Research Projects Agency - Department of Defense. Washington, D.C.

Nozette, S. 1993. Deep Space Program Science Experiment (DSPSE), Clementine Program Overview. Presentation to the Panel on Small Spacecraft Technology, January 27, 1993. Strategic Defense Initiative, Department of Defense. Washington, D.C.

NRC. 1987. Space Technology to Meet Future Needs. Aeronautics and Space Engineering Board. National Research Council. Washington, D.C.: National Academy Press. 
NRC. 1992. From Earth to Orbit, An Assessment of Transportation Options. Aeronautics and Space Engineering Board. National Research Council. Washington, D.C. National Academy Press.

NRL/NCST. 1993. Clementine - Deep Space Program Science Experiment Executive Overview. Presentation to the Panel on Small Spacecraft Technology, April 9, 1993. Naval Research Laboratory/Naval Center for Space Technology. Washington, D.C.

Pak, Z. 1993. Some Ways to Higher Environmental Safety of Solid Rocket Propellant Application. AIAA-93-1755. Presentation to the Panel on Small Spacecraft Technology, June 28-30, 1993. American Institute of Aeronautics and Astronautics. Washington, D.C.

Palsulich, J., and D. Raspet. 1993. Discussion on Expendable Launch Vehicle Technology and Small Satellite/Payload Technology. Presentation to the Committee on Advanced Space Technology, May 26-27, 1993. McDonnell Douglas. Huntington Beach, CA.

Pande, J.B. 1993. Solar Powered Rocket Engine Optimized for High Specific Impulse. 1993 JANNAF Propulsion Conference, November 1993. Hercules Aerospace Company. Wilmington, DE.

Pelton, J.N., B.I. Edelson, N. Helm, C.W. Bostian, E.F. Miller, P. Hager, W. Brandon, A.L. Riley, R. Kwan, V.W.S. Chan, C. Mahle, and R. Jennings. 1993. Satellite Communications in Europe, Russia, and Japan. Presentation at the NASA/NSF Conference, February 5, 1993. National Aeronautics and Space Administration/National Science Foundation. Washington, D.C.

Russell, J.J., R.V. Wick, and T.M. Davis. 1992. Future Space Technology. AIAA-92-1696. Presentation to the AIAA Space Programs and Technologies Conference, March 24-27, 1992. American Institute of Aeronautics and Astronautics. Washington, D.C.

Ryschkewitsch, M.G., and H.H. Plotkin. 1993. TIMED (Small Spacecraft) Technology Infusion Initiative. Presentation to the Technology Challenge Review Panel on TIMED, June 17, 1993. National Aeronautics and Space Administration/Goddard Space Flight Center. Greenbelt, MD.

Scala, T. 1993. Fold-up solar blanket. Popular Science magazine, September 1993.

Schaub, J., and P. Regeon. 1993. NRL Small Spacecraft Initiatives. Presentation to the Panel on Small Spacecraft Technology, April 9, 1993. Naval Research Laboratory/Naval Center in Space Technology. Washington, D.C. 
Seitz, P. 1993a. Little LEO firms trying to exhibit individuality. Space News, August 9-15, 1993. Vol. 4 (No. 31): pp. 10.

Seitz, P. 1993b. Little LEOs win unanimous vote of commission. Space News, October 25-31, 1993. Vol. 4 (No. 42): pp. 4 and 21.

Seitz, P. 1993c. Small launches slowly progressing; lighter cheaper payloads call for small, low-cost vehicles to space. Space News, August 23-29, 1993. Vol 4 (No. 33): pp. 10.

Seitz, P., and P.B. de Selding. 1993. Firms agree to share spectrum; chart on proposed mobile satellite systems. Space News, October 11-17, 1993. Vol. 4 (No. 40): pp. 1 and 20.

Sneegas, Rosenthal, and Vondra. 1993. Space Surveillance Track and Autonomous Reposition (SSTAR) Experiment. 23rd IEPC, September 13-16, 1993. Paper Number IEPC-93-054. Seattle, WA.

Space Microelectronics. 1993. Microelectronics news. Space Microelectronics, Fall 1993. Issue 5: pp. 33-34.

Space News. 1993. Palo Alto company tests Russian thruster system. Space News, October 25-31, 1993. Vol. 4 (No. 42): pp. 12.

Space Technology Innovation. 1994. Arc jet technology provides revolutionary breakthrough. NASA Office of Advanced Concepts and Technology, March/April 1994. Vol. 2 (No. 2): pp. 6.

Staehle, R., S. Brewster, D. Caputo, J. Carraway, E. Hansen, P. Henry, R. Miles, C. Nunez, T. Rivellini, C. Salvo, A. Stern, R. Terrile, and S. Weinstein. 1993. Technology Trades for the Pluto Fast Flyby Mission. Presentation to the Committee on Advanced Space Technology, January 27, 1993. Jet Propulsion Laboratory. Pasadena, CA.

The Update. 1993. Electron-tunneling, producing smaller, more accurate sensors. The Update, October 1993. Quarterly publication of the Ballistic Missile Defense Organization Technology Applications Program.

U.S. Congress. 1993. 103d Congress Conference Report. Report 103-339, November 9, 1993. House of Representatives. Library of Congress. Washington, D.C.

U.S. Space Policy Advisory Board. 1992. A Post Cold War Assessment of U.S. Space Policy. Vice President's Space Policy Advisory Board Report, December 1992, pp. 6. Washington, D.C. 
Venkateswara Rao, K.T., and R.L. Ritchie. 1992. Fatigue of Al-Li alloys. International Materials Reviews, Vol. 37 (No. 4): pp. 153-185.

Venneri, S. 1993. Small Spacecraft Technology Program. Presentation to the Panel on Small Spacecraft Technology at the Small Spacecraft Technology Workshop, September 21, 1993. National Aeronautics and Space Administration/Office of Advanced Concepts and Technology. Washington, D.C.

Wall, S., and K. Ledbetter. 1991. Design of Mission Operations Systems for Scientific Remote Sensing. Taylor and Francis-Hemisphere Publishing Corp. Washington, D.C.

Whitehead, J.C. 1993. A new rocket propulsion system for small spacecraft. Energy and Technology Review, March 1993. pp. 13-25. 


\section{Appendix A: Title I of the National Aeronautics and Space Act of 1958, as Amended}

(Public Law 85-568)

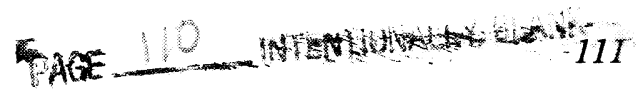




\section{NATIONAL AERONAUTICS AND SPACE ACT OF 1958, AS AMENDED}

AN ACT To provide for research into problems of flight within and outside the earth's atmosphere, and for other purposes.

Be it enacted by the Senate and House of Representatives of the United States of America in Congress assembled,

TITLE I-SHORT TITLE, DECLARATION OF POLICY, AND DEFINITIONS

\section{SHORT TITLE}

Sec. 101. This Act may be cited as the "National Aeronautics and Space Act of 1958".

\section{DECLARATION OF POLICY AND PURPOSE}

Sec. 102. (a) The Congress hereby declares it is the policy of the United States that activities in space should be devoted to peaceful purposes for the benefit of all mankind.

(b) The Congress declares that the general welfare and security of the United States require that adequate provision be made for aeronautical and space activities. The Congress further declares that such activities shall be the responsibility of, and shall be directed by, a civilian agency exercising control over aeronautical and space activities sponsored by the United States, except that activities peculiar to or primarily associated with the development of weapons systems, military operations, or the defense of the United States (including the research and development necessary to make effective provision for the defense of the United States) shall be the responsibility of, and shall be directed by, the Department of Defense; and that determination as to which such agency has responsibility for and direction of any such activity shall be made by the President in conformity with section 201(e).

(c) The aeronautical and space activities of the United States shall be conducted so as to contribute materially to one or more of the following objectives:
Public Law 85568,85 th

Congress, H.R. 12575. July 29 , 1958. 72 Stat.

426.

42 U.S.C. 2451. 
(1) The expansion of human knowledge of phenomena in the atmosphere and space;

(2) The improvement of the usefulness, performance, speed, safety, and efficiency of aeronautical and space vehicles;

(3) The development and operation of vehicles capable of carrying instruments, equipment, supplies, and living organisms through space;

(4) The establishment of long-range studies of the potential benefits to be gained from, the opportunities for, and the problems involved in the utilization of aeronautical and space activities for peaceful and scientific purposes;

(5) The preservation of the role of the United States as a leader in aeronautical and space science and technology and in the application thereof to the conduct of peaceful activities within and outside the atmosphere;

(6) The making available to agencies directly concerned with national defense of discoveries that have military value or significance, and the furnishing by such agencies, to the civilian agency established to direct and control nonmilitary aeronautical and space activities, of information as to discoveries which have value or significance to that agency;

(7) Cooperation by the United States with other nations and groups of nations in work done pursuant to this Act and in the peaceful application of the results thereof; and

(8) The most effective utilization of the scientific and engineering resources of the United States, with close cooperation among all interested agencies of the United States in order to avoid unnecessary duplication of effort, facilities, and equipment.

(d) The Congress declares that the general welfare of the United States requires that the unique competence in scientific and engineering systems of the National Aeronautics and Space Administration also be directed toward ground propulsion systems research and development. Such development shall be conducted so as to contribute to the objectives of developing energyand petroleum-conserving ground propulsion systems 
and of minimizing the environmental degradation caused by such systems. ${ }^{1}$

(e) The Congress declares that the general welfare of the United States requires that the unique competence in scientific and engineering systems of the National Aeronautics and Space Administration also be directed toward the development of advanced automobile propulsion systems. Such development shall be conducted so as to contribute to the achievement of the purposes set forth in section 302(b) of the Automotive Propulsion Research and Development Act of $1978 .^{2}$

(f) The Congress declares that the general welfare of the United States requires that the unique competence of the National Aeronautics and Space Administration in science and engineering systems be directed to assisting in bioengineering research, development, and demonstration programs designed to alleviate and minimize the effects of disability. ${ }^{3}$

(g) It is the purpose of this Act to carry out and effectuate the policies declared in subsections (a), (b), (c), (d), (e), and (f).

\section{DEFINITIONS}

Sec. 103. As used in this Act-

(1) the term "aeronautical and space activities" means (A) research into, and the solution of, problems of flight within and outside the earth's atmosphere, (B) the development, construction, testing, and operation for research purposes of

\footnotetext{
${ }^{1}$ The "Electric and Hybrid Vehicle Research, Development, and Demonstration Act of 1976", Public Law 94-413, September 17, 1976, section 15 (90 Stat. 1270), added this new subsection (d) and redesignated old subsection (d) as subsection (e).

2 The "Department of Energy Act of 1978-Civilian Applications", Public Law 95-238, February 25, 1978, section 311 (92 Stat. 47), added a new subsection (e) and redesignated old subsection (e) as subsection (f).

3

The National Aeronautics and Space Administration Authorization Act, 1979 Public Law 96-401, September 30, 1978, section 7 (92 Stat. 860), added a new subsection (f) and redesignated old subsection (f) as subsection ( $\mathrm{g})$.
} 
aeronautical and space vehicles, (C) the operation of a space transportation system including the Space Shuttle, upper stages, space platforms, and related equipment, ${ }^{4}$ and (D) such other activities as may be required for the exploration of space; and

(2) the term "aeronautical and space vehicles" means aircraft, missiles, satellites, and other space vehicles, manned and unmanned, together with related equipment, devices, components, and parts.

${ }^{4}$ Subsection (C) was added by the "National Aeronautics and Space Administration Authorization Act, 1984," Public Law 98-52, July 15,1983 , section 106 (97 Stat. 285) which also redesignated old subsection (C) as (D). 


\section{Appendix B: Small Spacecraft Applications}

Small spacecraft can play an important role in Earth observations, remote sensing, and communications missions through:

- use of the Global Positioning System (GPS), with which sensed data from several different spacecraft can be temporally and positionally connected, thereby enabling some missions that previously required a large spacecraft to be performed by several small spacecraft;

- deployment of one or more sensors in non-sun-synchronous orbits to avoid diurnal effects (e.g., tides);

- $\quad$ quick-response, rapid-repeat-cycle applications to serve civil and defense operational or quasi-operational needs, such as disaster response planning;

- specialized measurements in a relatively small number of spectral bands, with good radiometric accuracy, high spatial resolution, and a narrow swathwidth;

- deployment of all-electronic, long-lived small-satellite constellations for data collection, search and rescue, or global communications;

- use of autonomous teleoperated spacecraft for the inspection, repair, and maintenance of critical space systems;

- $\quad$ use of planetary microrovers with small, calibrated science instruments and small robotic manipulators capable of extended operations and improved analytical capability on the planets;

- use of small spacecraft for life science studies; and

- augmentation of larger research missions through the flight of complementary sensors.

As the capability of small spacecraft is improved through research and development, their ability to support a broader mission spectrum will be enhanced. Each of the above missions is discussed briefly below. 


\section{Small Spacecraft Surrogates for Large Spacecraft}

With position, velocity, and time signals from the GPS, the data from sensors on several spacecraft can be temporally and positionally connected. This can be used to substitute constellations of smaller spacecraft for one larger spacecraft in those applications where simultaneity of data is a major requirement. Further refinements include control systems based on differential GPS schemes, which accurately establish position to hold constellations of small spacecraft in desirable formations.

\section{Non-Sun-Synchronous or Other Less Common Orbits}

Small spacecraft have notable value in missions requiring the deployment of a few sensors to non-sun-synchronous orbits, as in the case of microwave instruments that do not rely upon the illumination of the sun for their operation and that do not contribute to or require simultaneity of measurement with other sensors. Such orbits are also used for the conduct of measurements where results would be obscured by tidal or other diurnal effects. As a further example, a sensor may require an equator crossing time that differs from that of the majority of sensors to be flown. A small spacecraft might be used to orbit that sensor, rather than forcing overall performance to be compromised in a suboptimum orbit.

\section{Quick-Response Missions for Operational Uses}

Small spacecraft can also play an important role in operational or quasi-operational Earth-observation missions in which quick response is at a premium and where the instrument to be carried can be designed well in advance and held in readiness to meet very specific, well-understood needs. For example, in contrast to the Earth sensors of Mission to Planet Earth, with their wide swathwidths and extensive spectral bands, a high-spatial-resolution, panchromatic sensor with off-nadir ${ }^{1}$ pointing capability might be deployed in an orbit that is chosen to provide rapid repeat coverage of a disaster site or to serve national security needs. Off-nadir pointing at angles that would make the atmospheric correction of multispectral data difficult or impossible may be entirely satisfactory for disaster evaluation or defense applications.

${ }^{1}$ Nadir is the point of a celestial sphere that is directly opposite the zenith and vertically downward from the observer. 


\section{Specialized, Narrow-Swathwidth Measurements}

Other applications (e.g., long-term mapping) may also be well served by multispectral sensors employing a relatively small number of spectral bands and narrow swathwidths. Narrow swathwidths reduce geometric registration errors. In some cases, narrow-swathwidth measurements could be used for quick response-type missions, which were previously discussed.

\section{"All-Electronic" Spacecraft Constellations}

Multiple small spacecraft in different orbits may provide rapid repeat coverage for data collection, commercial communications, and search-and-rescue transceivers. These devices are readily adaptable to small spacecraft. Such all-electronic payloads on small spacecraft may have an inherently long lifetime that could produce a much lower system cost than other alternatives. This is contingent upon a decision being made to seek more-rapid repeat coverage than is currently available.

Data collection and search-and-rescue payloads are currently carried on two to four U.S. and Russian polar-orbiting spacecraft. The number and orbits of the spacecraft produce waiting times of up to six hours before distress signals can be detected or data relayed. Constellations of six to twelve spacecraft would produce profound reductions in delay time, especially at the midlatitudes. Post-accident survival is a direct function of waiting time, so the reduction in delay would also increase the number of lives saved. Both voice and messaging, as well as data-only spacecraft constellations have been proposed. On the commercial communications side, several companies have recently announced their intentions of employing a large number of low-Earth-orbiting small spacecraft for worldwide communications (Seitz, 1993b; Seitz and de Selding, 1993).

\section{Servicing Spacecraft for Space Systems}

The Space Station is a major investment in space infrastructure, where a limited number of humans must be provided with systems that will help improve their efficiency. The proper application of automation and robotics can improve the return on this investment by freeing the crew from repetitious tasks and allowing for more direct involvement of ground-based researchers in mission execution via teleoperations. Within the research environment of the Space Shuttle and the Space Station, small intravehicular activity robots, such as the German ROTEX on the 1993 Space Lab mission can turn a limited flight opportunity into a productive research project. The automation of humantended teleoperated investigations that are based in space is within the technical capability of university and industry investigators.

External to the manned system, small robotics can be developed that can reduce, and in some cases eliminate, the need for extravehicular activity and Shuttle-related operations. In the vicinity of the Space Station, small free-flying robots can be 
programmed for autonomous or teleoperated inspection of critical Space Station systems as an integral part of repair and maintenance. The concepts and technology base to develop automated systems that are efficient and fault tolerant to human safety needs exist within NASA, the universities, and industry. The new, small space robots can become unique, relatively low-cost tools for the crews of the Space Station and can help bring research productivity more in line with earlier (1980) expectations involving larger crew complements.

\section{Deployment of Small, Robotic Planetary Explorers}

In the area of planetary exploration, small spacecraft systems are already being developed. NASA's Mars Pathfinder project employs an innovative microrover operating in the vicinity of a landing craft that serves as a science base and as a communications center with the Earth. The major challenge for this microrover is to apply mobility to a lander experiment, thus providing automated operations that can significantly increase the total returned knowledge. Major enhancements in the capability of such microsystems can be made by investing in the development of small, calibrated science instruments and small robotic manipulators capable of extended operations and improved analytical capability on the planets.

\section{Life Science Studies for Small Spacecraft}

Small spacecraft can be used for life science studies that cover topics ranging from exobiology to the effects of microgravity and radiation during spaceflight on cell cultures, plants, and animals. The feasibility of using small spacecraft for life science experiments depends on the complexity of the studies to be carried out. While there is no great difficulty in providing the appropriate life support systems for plants, fungi, and cell cultures, studies of whole animals on small spacecraft raise special problems because of the complexity of providing adequate life support and a safe return.

Considerable progress could be made using interactive, expert systems where a number of variables could be monitored and appropriate responses made. The animals could be observed with video cameras, and the temperature and humidity of the cages; movement of the animals; mass of the animals; water and food consumption; and temperature, heart rate, and electrocardiogram of the animals could be monitored. For long-duration microgravity and radiation studies, a small animal centrifuge, various levels of shielding, and a miniaturized life support system would be needed on the spacecraft. There would also be a need for access to the payload just prior to launch and rapid access to the payload after spacecraft recovery, so that the animals could be given proper

care. To decrease the spacecraft-landing deceleration shock, a paraglider type of parachute might be employed.

A few years ago, NASA initiated a study of a small spacecraft for life science experiments called Lifesat. The satellite included a life support system for small animals 
and was designed to be recovered by coming down on land. Two types of orbit were envisaged: low Earth orbit, and an elliptical orbit to subject the payload to high radiation levels. Although this program was subsequently cancelled because of its cost, the subject of radiation hazards and proper protection remains as a central issue for long-term human space interplanetary flight. Examination of radiation effects on small animals in small spacecraft offers an excellent opportunity for further exploration of radiation effects and countermeasures.

\section{Mission Augmentation}

Small spacecraft can play a valuable role in augmenting larger Earth-observations research spacecraft that are planned as a part of the Mission to Planet Earth. The aggregate lifetime of the instruments on a large spacecraft may be only a few years, while a single instrument may have a considerably longer lifetime. In such instruments, use of a dedicated, long-life small spacecraft could be the most economical means of carrying out the measurement and ensuring continuity of data. 


\section{Appendix C: Office of Advanced Concepts and Technology's Small Spacecraft Technology Initiative}

\section{Goals}

The Office of Advanced Concepts and Technology's (OACT) Spacecraft and Remote Sensing Division has established a Small Spacecraft Technology Initiative. This initiative is designed to (1) demonstrate a new approach to technology integration which will result in two technology demonstration flights within three years; (2) envelope a range of mission requirements; and (3) develop standard hardware and software interfaces for various applications. The major goals of the initiative are

- to reduce the cost and development time of space missions for science and commercial applications, while achieving mass fractions up to 70 percent and demonstrating development times-to-flight within two years;

- to demonstrate new design and qualification methods for small spacecraft using commercial and performance-based specifications and integration of small instrumentation technology into bus design; and

- to proactively promote commercial technology applications (Venneri, 1993).

The Small Spacecraft Technology Initiative will emphasize a highly integrated spacecraft bus design for the next generation of small spacecraft concepts by incorporating advanced micro-instruments, sensors, and computers; innovative concepts for components and mechanisms; simplified qualification and verification procedures; and advanced on-board data processing.

\section{APPROACH}

\section{Integrated Product Development Teams}

The Small Spacecraft Technology Initiative will be implemented through establishment of industry-led integrated product development (IPD) teams. Each team 
will design, develop, and launch a small spacecraft within two years. The IPD teams will be composed of industry; small, disadvantaged businesses; universities; and possibly NASA researchers. The team leaders will assess the technology development capabilities, skills, and facilities that exist in the government and can ask government technologists to serve as members of the team as appropriate.

The industry-led IPD teams will be provided with a simple objective statement and a set of NASA mission priorities. The teams will lead all aspects of program definition including member selection, organization, concept innovation, and commercial technology transfer requirements. The IPD teams will be free to define all processes used to develop concepts, including analyses, ground tests, and flight tests. They will also be allowed to select from several launch vehicle options.

\section{Use of DoD and Industry Technologies}

Critical, enabling technologies for small spacecraft were identified at an OACTsponsored workshop in Pasadena, California, on September 21-24, 1993. At the workshop, technologies were defined as either state of the practice or state of the art. State-of-the-practice technologies are those which have flown or have been selected to fly. State-of-the-art technologies were defined as those which are over and above the state of the practice and that stretch the technology.

In most cases, state-of-the-art technologies identified at the workshop were not developed at NASA. In the past, most of the advances in miniaturized space technology have been made by industry and DoD, specifically through BMDO and ARPA for military applications. The technologies categorized at the workshop will serve as the performance basis to evaluate new ideas and technology innovation during the proposal evaluation process. Some of the advanced technology areas for small spacecraft identified at the workshop were power, attitude control, thermal management, payload instruments, communications, software, structures, operations, computers and data handling, and integration and producibility.

\section{Nonaerospace Applications}

As stated above, one objective of the Small Spacecraft Technology Initiative is to pro-actively pursue joint ventures and partnerships for the use, development, and spinoff of technology for nonspace applications. In the past, NASA identified spin-off, nonaerospace technology, but usually after the technology was developed. With the Small Spacecraft Initiative approach, the IPD teams will be required to direct a percentage ( 8 to 15 percent) of contract funds to commercial product development. This commercial development activity will identify potential applications, develop specific implementation plans, and establish partnerships to achieve technology transfer to products. This phase of the program may include cost sharing by the IPD team participants. Targeted nonaerospace sectors for advanced space technology include transportation, medical, 
manufacturing, and consumer products. Examples of nonaerospace applications of advanced space technology include high-resolution miniature sensing and imaging medical instruments; advanced data processing; improved structural materials; and lightweight, efficient power systems.

\section{Management}

The IPD teams will define, plan, and implement the detailed program content. The programs will be managed by a small, eight-to-ten-person team at NASA Headquarters, which will include a headquarters procurement representative. Over 95 percent of the Small Spacecraft Technology Initiative funds will go directly to the IPD teams.

\section{Evaluation Procedure and Selection}

The proposals will be evaluated by criteria established at the NASA/OACT Small Spacecraft Technology Workshop held in Pasadena, California, on September 21-24, 1993. Important features of any proposal are the use of advanced, innovative, highrisk/high-payoff technology; clearly defined and substantiated roles for all team members; and specific processes for technology transfer to and from NASA.

Evaluation of the proposals will be made by a team established by NASA Headquarters. After the written proposals are submitted, the IPD teams will be asked to provide specific information in an oral presentation. A Request for Proposal for the Small Spacecraft Technology Initiative was released February 28, 1994, with award dates scheduled for the second quarter of 1994.

\section{OACT SPACECRAFT AND REMOTE SENSING DIVISION: 1994 ACTIVITIES AND BUDGET}

Fiscal year 1994 activities of the Spacecraft and Remote Sensing Division include establishment of the Small Spacecraft Technology Initiative at a level of \$12.5 million. The projects of one or two IPD teams will be selected in 1994, with the first technology demonstration flight scheduled for 1996.

\section{OACT SPACECRAFT AND REMOTE SENSING DIVISION: 1995 ACTIVITIES AND BUDGET}

At the time of this report, the President's fiscal year 1995 budget included $\$ 47.9$ million for the Small Spacecraft Technology Initiative. 


\section{Appendix D: Current NASA and DoD Small Spacecraft Programs}

\section{NASA Programs}

Both JPL and GSFC have programs underway involving the use of small spacecraft. JPL is the lead center on the Mars Pathfinder mission, which is projected for launch in 1996. The Mars Pathfinder mission is one of the Office of Space Science's Discovery missions which represents an entire class of smaller, less expensive, and more frequent science missions. All of the various proposed Discovery missions are intended to proceed from development to flight in three years or less at a development cost of less than $\$ 150$ million. Contingent on funding, Discovery missions are planned for launch at a rate of one every two years (David, 1993; McCarthy, 1993).

JPL has proposed the Pluto Fast Flyby mission, which is a mission to the last unexplored planet, Pluto. The goal is to launch two small spacecraft of less than 140 kilograms each on a direct trajectory to Pluto by 2001 . The total estimated mission cost is $\$ 400$ million plus launch. The severe limitations imposed on spacecraft mass and cost demand technological resourcefulness and an innovative approach to program planning (Staehle et al., 1993).

JPL also assisted the BMDO with the first MSTI spacecraft that was launched in 1992. The MSTI program is designed to test miniature sensor technology. MSTI-II was launched in May, 1994, and MSTI-III and MSTI-IV are scheduled for launch in late 1994 and early 1995, respectively. MSTI V has been transferred to the Air Force and reduced to component development, and MSTI VI has been cancelled.

The GSFC small spacecraft effort is an extension of the long-standing Explorer and Small Explorer programs, while JPL small spacecraft efforts are of more recent origin.

In 1988, GSFC initiated the Solar, Anomalous, and Magnetospheric Particle Explorer project, which was successfully launched in 1992. This mission was the first in the Small Explorer program. Two other Small Explorer missions that have been approved are the Fast Auroral Snapshot Explorer, to be launched in 1994, and the Submillimeter Wave Astronomy Satellite to be launched in 1995. These ongoing efforts predate the recent enthusiasm over small spacecraft and signify the continuing ability of small spacecraft to contribute to focused scientific research-as they have for decades. These projects require competitive selection of experiments and peer review. A NASA 
Announcement of Opportunity has also been issued for the Middle-Class Explorer mission, which uses somewhat larger spacecraft of approximately 450 kilograms, at a cost of around $\$ 75$ million, to be launched on a Taurus-class expendable launch vehicle.

In addition, GSFC has a role in the first Discovery mission, the Near Earth Asteroid Rendezvous. This program received new-start funding in the fiscal year 1994 budget and is scheduled for launch in 1996. The Near Earth Asteroid Rendezvous spacecraft will be built by the Johns Hopkins University's Applied Physics Laboratory. GSFC also is responsible for the Total Ozone Mapping Spectrometer series of spacecraft. The first Total Ozone Mapping Spectrometer spacecraft is currently being built by TRW and is scheduled for launch in 1994. NASA also is proposing the TIMED mission, which includes a system of probes to study little-known aspects of the Earth's upper atmosphere. TIMED is to be the first of the Office of Space Science's series of small spacecraft missions that are known as the Solar Terrestrial Probes. The TIMED mission features a strong emphasis on new technology insertion to reduce mass.

In support of the NASA Administrator's recent efforts to promote missions with lower cost, faster development and launch time, and higher tolerance for risk, while enhancing productivity and economic competitiveness, the Spacecraft and Remote Sensing Division was created within OACT at NASA Headquarters. This division is responsible for the development of technology to reduce the cost and launch weight of spacecraft through exploitation of miniaturized components, advanced instrumentation, operations technology, and sensors integrated into advanced design concepts.

The Spacecraft and Remote Sensing Division is currently working with the Office of Space Science to develop and infuse advanced technology into three scientific small spacecraft missions: (1) the proposed TIMED mission, (2) the Mars Pathfinder mission, and (3) the proposed Pluto Fast Flyby mission. For the proposed TIMED mission, OACT is funding 11 technology items, which include attitude and navigation sensors, power-system components, science instrument components, cryocoolers, thrusters, and lightweight structures. For Mars Pathfinder, OACT is funding the rover development, and for the proposed Pluto Fast Flyby mission, OACT is actively funding 12 technology items, which include attitude and navigation sensors, lightweight structures, communication and propulsion components, and high-density packaging. Sixteen additional items are currently under consideration for future funding (NASA/OACT, 1993).

In addition to the technology infusion activities, OACT's Spacecraft and Remote Sensing Division has established a Small Spacecraft Technology Initiative. This program will demonstrate a new approach to technology integration, resulting in two technology demonstration flights within three years and designed to envelope a range of mission requirements and develop standard hardware and software interfaces for various applications. A Request for Proposal for the Small Spacecraft Technology Initiative was released February 28, 1994, with awards scheduled for announcement in the second quarter of 1994. Programmatic and budget details of the Small Spacecraft Technology Initiative are discussed further in Appendix A.

NASA is currently involved in several joint spacecraft programs, such as the Deep Space Program Science Experiment, also known as the Clementine mission with 
BMDO, that was launched in January, 1994. The 115-kilogram, $\$ 50$ million Clementine spacecraft was built by the Naval Research Laboratory and is flight testing several critical small spacecraft technologies and instruments during its orbit of the moon and subsequent asteroid rendezvous (Schaub and Regeon, 1993). NASA was also working with ARPA on the now-cancelled Collaboration on Advanced Multispectral Earth Observation (CAMEO) spacecraft that was scheduled for launch in 1997 to demonstrate dual-use technologies for civilian and military applications (Davis and Imler, 1993).

\section{DoD Programs}

Although civilian and military space budgets today are roughly comparable, for the last decade, DoD spending on space programs has consistently exceeded the civilian space budget, sometimes by as much as 50 percent (U.S. Space Policy Advisory Board, 1992). Within the framework of its distinct missions, DoD space programs have also faced many of the same technology imperatives as NASA, striving for improved performance at reduced cost. As a result, NASA now stands to benefit in the near term from many of the initiatives undertaken by DoD over the last several years. DoDsponsored programs have produced a broad range of valuable hardware, from component technologies to entire spacecraft and launch vehicle systems.

Over the last four years, ARPA has conducted over 50 projects under its Advanced Space Technology Program to reduce the risk and cost of future spacecraft systems. Projects have included investment in the Pegasus and Taurus small spacecraft launch vehicles, small spacecraft demonstrations with the Microsat and DARPASAT programs, and a number of advanced spacecraft subsystem technologies with the goal of increasing payload mass fraction (Nicastri, 1993). ARPA is involved in the joint Technology for Autonomous Operational Survivability (TAOS) program with the U.S. Air Force to demonstrate advanced technologies and operational concepts (Davis and Imler, 1993). The Technology for Autonomous Operational Survivability spacecraft was successfully launched along with an ARPA spacecraft on the Taurus launch vehicle March 13, 1994. This was the first launch of the U.S. Air Force's Space Technology Experiments Program series of advanced technology spacecraft.

BMDO has also made significant investments over the past several years in miniaturized and lightweight technology programs to support the Brilliant Eyes and the now-cancelled Brilliant Pebbles programs. For instance, the MSTI program is designed to test lightweight sensor technology; the Lightweight Exo-Atmospheric Projectile program generated miniaturized components and improved propulsion technologies; and the Clementine program is demonstrating dual-use military and civilian technology.

The Naval Center for Space Technology located at the Naval Research Laboratory has developed, fabricated, launched, and operated over 80 small spacecraft since the early 1960s, including the Clementine spacecraft for BMDO. This facility is one of the few government facilities capable of spacecraft development, fabrication, and operation at one location. 
However, with the end of the Cold War, space technology budgets significantly decreased, and now DoD efforts are being sharply curtailed. Many valuable and important advances in technology for small spacecraft were achieved in past and ongoing programs and are now available for use by NASA and industry. In the future, however, NASA will no longer be able to look to the same degree to DoD as an alternative technology base. The fact that programs are being curtailed emphasizes the need for NASA to step up its activity in research and development related to small spacecraft. 


\section{Appendix E: Study Participants}

Advanced Research Projects Agency (ARPA) Daniel Bunce

Thomas Kacena

Edward Nicastri

Aerospace Corporation

Robert Abramson

Steve Book

L. K. Konopasek

J. Lang

Richard Lucas

Air Force Phillips Laboratory

Kevin Slimack

Thomas Davis

Thomas Imler

Brian Fortson

Ernest Herrera

Lee Meyer

Jim Wanchek

Maurice Martin

Air Force Space and Missiles Center

Cliff Dixon

Robert Glass

Ron Harris

Craig Martin

Blake Smith

Thomas Utsch

American Rocket Company

Brian Hughes

George Whittinghill
Ames Research Center

Edward Chevers

Stephen Ellis

Anthony Grosse

Butler Hine

Max Reid

Robert Rosen

Jospeh Sharp

Johns Hopkins University

Applied Physics Laboratory

Wayne Bryden

Andrew Cheng

Thomas Coughlin

William Devereux

Mariom Edwards

Robert Henshaw

Eric Hoffman

Richard Huebschman

Robert Jenkins

Stamatios Krimigis

Madeline Marshall

Ball Aerospace

Bob Barry

David Frostman

Robert Kramer

Ballistic Missile Defense Organization (BMDO)

David Holtcamp

Jordan Katz

Richard Matlock 
Stewart Nozette

Pete Rustan

Simon Worden

Boeing Defense and Space Group

Allen Ashby

Tom Blakney

Marty Fritz

Jim Geros

Bruce Landry

Tom McNassar

Chip Meserole

Phyllis Morris

Dick Ouimet

Dennis Smith

Anthony Sutey

Charles Stark Draper Laboratory

Francois Ayer

George Bukow

John Deyst

Jerold Gilmore

Malcolm Johnson

Paul VanBroekhoven

CTA Incorporated

Martin Titland

Tom Velez

CTA Launch Systems

(formerly International Microspace

Incorporated)

Bradley Schwartz

CTA Space Systems

(formerly Defense Systems Incorporated)

George Sebestyen

Department of Energy

Fenton Carey

Franklin Dixon

EER Systems, Inc.
Marshall Kaplan

Fairchild Space and Defense Corporation

Chip Blackwell

Jim Brown

William Cashman

Brian Class

Alan Dunn

Mark Gordon

Carolyn Harrison

Thomas Moser

Goddard Space Flight Center

Dennis Andrucyk

Frank Bauer

Joe Burt

Robert Cromp

Brian Davis

Mark Flanagan

Milt Halem

Johnathan Hartly

Thomas Huber

George Kronmiller

Don Krueger

Kenneth LaBel

Thomas Magner

John McCabe

Warner Miller

Stan Ollendorf

Henry Plotkin

Lloyd Purvis

Michael Ryschkewitsch

Vincent Salomonson

B. Smith

James Trainor

Bill Tumulty

James Watzin

Chris Wilkenson

Don Wilson

Hughes Space and Communications

Nancy Anderson

James Bailey 
Hughes Space and Communications

Nancy Anderson

James Bailey

Mike Delaney

Burton Dobratz

Steven Dorfman

Charles Hoff

George Kuhr

S. Lane

Tony Matthews

Tom Parks

Marc Sabin

Robert Seibold

Steven Stadnick

Sheldon Welles

Thomas Wong

Jet Propulsion Laboratory

Michael Agronin

David Atkinson

Paul Backes

Perry Bankston

Antal Bejczy

Guy Beutelschies

Eric Biefeld

John Brophy

Dan Chang

Steve Chien

Jim Cutts

E. Davis

Leslie Deutsch

Richard Doyle

Usema Fayyad

Frank Grunthaner

Samad Hayati

Mike Hecht

Steve Johnson

James Kelley

Richard Key

Carl Kukkonen

Tom Lear

Lorrine Lee

Jim Lesh

Dankai Liu
Donna Pivirotto

Harry Porta

Dan Rascoe

Rex Ridenoure

Lance Riley

Paul Schenker

George Sevaston

Robert Staehle

Rhoads Stephenson

Nick Thomas

Fernando Tolivar

Dick Turner

Greg Vane

Giulio Varsi

Patrick Waddell

Brian Wilcox

Barbara Wilson

Irene Woerner

Jay Wyatt

Johnson Space Center

Norman Chaffee

Jon Erickson

Al Gist

Charles Gott

Cliff Hess

Dave Homan

Kathy Jurica

Gene Kranz

Charlie Price

Edith Taylor

Kennedy Space Center

Jay Honeycutt

Ed Weber

Langley Research Center

Irvin Abel

Keith Belvin

Charles Blankenship

David Bowles

Harold Bush

Robert Calloway

Timothy Collins 
K. Elliott

Michael Gilbert

William Grantham

Brantley Hanks

Doug Heard

Mark Lake

John Malone

Anne St. Clair

Darrell Tenney

Steve Thompkins

Timothy Towell

Lewis Research Center

Henry Brandhorst

Frank Curran

Salvatore Grisaffe

Robert Miner

Larry Pinson

James Ramler

Lawrence Ross

Lockheed Missiles and Space Company

Gary Auclair

Mel Brashears

Don Damon

Don Davis

Manny Dimiceli

Marty Gerbasi

Bill Walsh

Marshall Space Flight Center

Harry Craft

Martin Marietta Astro Space

Milton Berkowitz

Gerhard Fraz

William Fuldner

Tom Gennaro

Tom Karras

Larry Newman

Michael Smith

Parker Stafford

Carl Zweben
Martin Marietta Corporation

Raymond Colladay

Kenneth Farley

Fred Lukins

Steve O'Neill

Martin Marietta and General Dynamics

(formerly General Dynamics Space Systems) Jeffery Hartnett

David Roldness

McDonnell Douglas

John Fredricks

Joseph Palsulich

Dave Raspet

NASA Headquarters

Charles Force

Leonard Harris

Richard Kline

John Mankins

Robert Norwood

Gregory Reck

Stanley Sadin

Shelby Tilford

Samuel Venneri

Naval Research Laboratory

Michael Brown

Robert Purdy

Paul Regeon

John Schaub

Edward Senonsack

Peter Wilhelm

Orbital Sciences Corporation

Antonio Elias

David Thompson

Rockwell International Corporation

Harry Reynolds

Space Systems/Loral

Kurt Brack 
John Cooney

Steve Flajser

Chris Hoeber

Wah Lim

Victor Moseley

James Reynolds

Craig Thom

John Wickman

Stanford University

Robert Cannon

TRW Space and Electronics Group

Alfred Cellier

Raymon Coronel

Donald Davies

Robert Davis

D. Edwards

Mark Kruer

Richard Kurland

Scott Manlief

Deanna Marshall

Lawrence Peruski

Robert Sackheim

B. Sathoff

Victor Spector

Donald Stager

John Stammereich

University of Maryland

David Akin

USAF Academy

Wiley Larson 


\section{Appendix F: NASA Earth-Observing Instruments}




\section{NASA EARTH-OBSERVING INSTRUMENTS}

\begin{tabular}{|c|c|c|c|c|c|}
\hline Instrument & Capabilities & $\begin{array}{c}\text { Mass } \\
(\mathbf{k g})\end{array}$ & $\begin{array}{l}\text { Power } \\
\text { (W) }\end{array}$ & Status & Developer \\
\hline \multicolumn{6}{|c|}{ Near-Term Instruments (up to 2005) } \\
\hline $\begin{array}{l}\text { Active Cavity Radiometer } \\
\text { Irradiance Monitor }\end{array}$ & $\begin{array}{l}\text { Will extend the long-term solar } \\
\text { luminosity data base, providing a } \\
\text { long-term precision of } 5 \text { parts per } \\
\text { million per year in its monitoring of } \\
\text { the variability of total solar } \\
\text { irradiance. }\end{array}$ & 39 & 40 & $\begin{array}{l}\text { Under } \\
\text { development }\end{array}$ & JPL \\
\hline $\begin{array}{l}\text { Atmospheric Infrared } \\
\text { Sounder }\end{array}$ & $\begin{array}{l}\text { High-resolution, high-precision } \\
\text { sounder employing } 2,300 \\
\text { simultaneous spectral channels } \\
\text { covering the range from } 0.4 \text { to } 15.4 \\
\text { micrometers. }\end{array}$ & 140 & 240 & $\begin{array}{l}\text { Phase C/D } \\
\text { (since 1991) }\end{array}$ & Loral \\
\hline $\begin{array}{l}\text { Advanced Microwave } \\
\text { Sounding Unit }\end{array}$ & $\begin{array}{l}\text { Passive microwave radiometer with } \\
21 \text { channels from } 23.8 \mathrm{GHz} \text { to } 89 \\
\mathrm{GHz} \text {. }\end{array}$ & 100 & 125 & $\begin{array}{l}\text { Under } \\
\text { development }\end{array}$ & $\begin{array}{l}\text { Aerojet } \\
\text { General }\end{array}$ \\
\hline $\begin{array}{l}\text { Microwave Humidity } \\
\text { Sounder }\end{array}$ & $\begin{array}{l}\text { Passive microwave radiometer } \\
\text { tailored to the requirement for } \\
\text { humidity profiling. The Microwave } \\
\text { Humidity Sounder has } 5 \text { channels in } \\
\text { the region from } 89 \mathrm{GHz} \text { to } 183 \\
\mathrm{GHz} \text {. }\end{array}$ & 66 & 190 & Phase B & $\begin{array}{l}\text { Matra Marconi } \\
\text { and British } \\
\text { Aerospace and } \\
\text { will be } \\
\text { provided by } \\
\text { Eumetsat }\end{array}$ \\
\hline $\begin{array}{l}\text { Advanced Spaceborne } \\
\text { Thermal Emission and } \\
\text { Reflection Radiometer }\end{array}$ & $\begin{array}{l}\text { Imaging radiometer to provide high } \\
\text { spatial resolution and radiometrically } \\
\text { precise images of the land surface, } \\
\text { water, ice, and clouds. The } \\
\text { instrument uses a relatively narrow, } \\
60 \text {-km swath that can be pointed } \\
\text { cross-track } \pm 8.5^{\circ} \text { in the mid- and } \\
\text { long-wave infrared and } \pm 24^{\circ} \text { in the } \\
\text { visible and near infrared. The } \\
\text { spectral coverage extends from } 0.5 \\
\text { to } 12 \text { micrometers. The maximum } \\
\text { spatial resolution is } 15 \text { meters in the } \\
\text { visible and near infrared. }\end{array}$ & 400 & 674 & $\begin{array}{l}\text { Under } \\
\text { development }\end{array}$ & $\begin{array}{l}\text { NEC with } \\
\text { MELCO and } \\
\text { Fujitsu }\end{array}$ \\
\hline $\begin{array}{l}\text { Doppler Orbitography and } \\
\text { Radiopositioning } \\
\text { Integrated by Satellite }\end{array}$ & $\begin{array}{l}\text { Dual Doppler receiver tracking } \\
\text { system for orbit determination. }\end{array}$ & 44 & 17.6 & $\begin{array}{l}\text { Under } \\
\text { development }\end{array}$ & $\begin{array}{l}\text { Dessault } \\
\text { Electronique }\end{array}$ \\
\hline
\end{tabular}


NASA EARTH-OBSERVING INSTRUMENTS (Continued)

\begin{tabular}{|c|c|c|c|c|c|}
\hline Instrument & Capabilities & $\begin{array}{c}\text { Mass } \\
(\mathbf{k g})\end{array}$ & $\begin{array}{l}\text { Power } \\
\text { (W) }\end{array}$ & Status & Developer \\
\hline \multicolumn{6}{|c|}{ Near-Term Instruments (up to 2005) } \\
\hline $\begin{array}{l}\text { Clouds and Earth's } \\
\text { Radiant Energy System }\end{array}$ & $\begin{array}{l}\text { Will provide an accurate, self- } \\
\text { consistent cloud and radiation data } \\
\text { base. Clouds and Earth's Radiant } \\
\text { Energy System employs two } \\
\text { broadband scanning radiometers, } \\
\text { with each radiometer having three } \\
\text { channels. The first channel is a total } \\
\text { radiance channel extending from } 0.3 \\
\text { to beyond } 50 \text { micrometers. The } \\
\text { second is a shortwave channel } \\
\text { extending from } 0.3 \text { to } 5 \\
\text { micrometers. The third channel } \\
\text { covers the longwave region from } 8 \\
\text { to } 12 \text { micrometers. }\end{array}$ & 90 & 171 & Phase C/D & TRW \\
\hline Ocean Color Instrument & $\begin{array}{l}\text { High radiometric precision data in } \\
\text { eight spectral bands extending from } \\
402 \text { nanometers to } 885 \text { nanometers. } \\
\text { Daily global coverage is provided } \\
\text { with a maximum spatial resolution of } \\
1.1 \text { kilometers. }\end{array}$ & 80 & 90 & $\begin{array}{l}\text { Data not } \\
\text { available }\end{array}$ & $\begin{array}{l}\text { Data not } \\
\text { available }\end{array}$ \\
\hline $\begin{array}{l}\text { Earth Observing Scanning } \\
\text { Polarimeter }\end{array}$ & $\begin{array}{l}\text { Will provide global maps of cloud } \\
\text { and aerosol properties. The cloud } \\
\text { properties will include optical } \\
\text { thickness, particle size, liquid/ice } \\
\text { phase, and cloud-top pressure. The } \\
\text { aerosol measurements will include } \\
\text { global distribution and optical } \\
\text { thickness in the troposphere and } \\
\text { stratosphere. Earth observing } \\
\text { scanning polarimeter measures } \\
\text { radiance and the degree of linear } \\
\text { polarization in } 12 \text { spectral bands } \\
\text { from } 0.41 \text { to } 2.25 \text { micrometers. }\end{array}$ & 19 & 22 & $\begin{array}{l}\text { Phase C/D in } \\
1994\end{array}$ & $\begin{array}{l}\text { Data not } \\
\text { available }\end{array}$ \\
\hline Lightning Imaging Sensor & $\begin{array}{l}\text { Designed to investigate the global } \\
\text { incidence of lightning, to correlate } \\
\text { the data with rainfall, and to employ } \\
\text { the data in investigating the } \\
\text { relationship of lightning to the global } \\
\text { electric circuit. A } 128 \times 128 \text { charge- } \\
\text { coupled device array locates } \\
\text { lightning flashes within } 5 \text { kilometers } \\
\text { over a } 600 \times 600 \mathrm{~km} \text { field-of-view. }\end{array}$ & 20 & 33 & $\begin{array}{l}\text { Under } \\
\text { development }\end{array}$ & $\begin{array}{l}\text { Marshall Space } \\
\text { Flight Center }\end{array}$ \\
\hline
\end{tabular}


NASA EARTH-OBSERVING INSTRUMENTS (Continued)

\begin{tabular}{|c|c|c|c|c|c|}
\hline Instrument & Capabilities & $\begin{array}{c}\text { Mass } \\
(\mathbf{k g})\end{array}$ & $\begin{array}{l}\text { Power } \\
\text { (W) }\end{array}$ & Status & Developer \\
\hline \multicolumn{6}{|c|}{ Near-Term Instruments (up to 2005) } \\
\hline $\begin{array}{l}\text { Geoscience Laser } \\
\text { Altimeter }\end{array}$ & $\begin{array}{l}\text { Focuses solely on the laser altimetry } \\
\text { mission, and will enable } 10-\mathrm{cm} \\
\text { precision with a } 70 \text {-meter surface } \\
\text { footprint. }\end{array}$ & 125 & 175 & $\begin{array}{l}\text { Phase B } \\
\text { completed } \\
\text { Phase C/D in } \\
1995\end{array}$ & $\begin{array}{l}\text { Data not } \\
\text { available }\end{array}$ \\
\hline $\begin{array}{l}\text { High-Resolution Dynamics } \\
\text { Limb Sounder }\end{array}$ & $\begin{array}{l}\text { Employs } 21 \text { channels at infrared } \\
\text { wavelengths from } 6 \text { to } 18 \\
\text { micrometers in a limb-scanning } \\
\text { radiometer that will sound the upper } \\
\text { troposphere, stratosphere, and } \\
\text { mesosphere to measure temperature, } \\
\text { concentrations of aerosols, locations } \\
\text { of polar stratospheric clouds and } \\
\text { cloud tops, and the concentrations of } \\
\text { key molecules. The molecules to be } \\
\text { studied include } \mathrm{O}_{3}, \mathrm{H}_{2} \mathrm{O}, \mathrm{CH}_{4}, \mathrm{~N}_{2} \mathrm{O} \text {, } \\
\mathrm{NO}_{2}, \mathrm{HNO}_{3}, \mathrm{~N}_{2} \mathrm{O}_{5}, \mathrm{CFC}_{11} \text {, and } \\
\mathrm{CFC}_{12} .\end{array}$ & 150 & 230 & $\begin{array}{l}\text { Phase C/D in } \\
1991\end{array}$ & $\begin{array}{l}\text { Loral and } \\
\text { Matra-Marconi } \\
\text { Space }\end{array}$ \\
\hline $\begin{array}{l}\text { Multifrequency Imaging } \\
\text { Microwave Radiometer }\end{array}$ & $\begin{array}{l}\text { Passive microwave radiometer that } \\
\text { measures precipitation rate, cloud } \\
\text { water content, atmospheric water } \\
\text { vapor, sea-surface roughness, sea- } \\
\text { surface temperature, global ice and } \\
\text { snow cover, and soil moisture. It is } \\
\text { an extension of technology currently } \\
\text { being flown on the Defense } \\
\text { Meteorological Satellite Program, } \\
\text { namely the Special Sensor } \\
\text { Microwave/Imager. Multi-frequency } \\
\text { imaging microwave radiometer } \\
\text { operates at six frequencies from } 6.8 \\
\text { to } 90 \mathrm{GHz} \text {, has a nominal } \\
0.5-\mathrm{Kelvin} \text { radiometric stability with } \\
\text { approximately a 1-Kelvin accuracy. }\end{array}$ & 223 & 200 & $\begin{array}{l}\text { Phase B } \\
\text { Phase C/D in } \\
1995\end{array}$ & Alenia \\
\hline $\begin{array}{l}\text { Moderate-Resolution } \\
\text { Imaging } \\
\text { Spectro-Radiometer }\end{array}$ & $\begin{array}{l}\text { General purpose spectrometer and } \\
\text { imager to examine a wide variety of } \\
\text { biological and physical processes. Its } \\
\text { spatial resolution will be from } 250 \text { to } \\
1,000 \text { meters at nadir and its spatial } \\
\text { coverage will extend from } 0.4 \text { to } 15 \\
\text { micrometers in } 36 \text { discrete bands. }\end{array}$ & 250 & 275 & $\begin{array}{l}\text { Phase C/D in } \\
1991\end{array}$ & $\begin{array}{l}\text { Santa Barbara } \\
\text { Research } \\
\text { Center }\end{array}$ \\
\hline
\end{tabular}


NASA EARTH-OBSERVING INSTRUMENTS (Continued)

\begin{tabular}{|c|c|c|c|c|c|}
\hline Instrument & Capabilities & $\begin{array}{c}\text { Mass } \\
(\mathbf{k g})\end{array}$ & $\begin{array}{l}\text { Power } \\
(\mathbf{W})\end{array}$ & Status & Developer \\
\hline \multicolumn{6}{|c|}{ Near-Term Instruments (up to 2005) } \\
\hline $\begin{array}{l}\text { Multi-Angle Imaging } \\
\text { Spectro-Radiometer }\end{array}$ & $\begin{array}{l}\text { Will provide top-of-the-atmosphere, } \\
\text { cloud, and surface angular } \\
\text { reflectance properties. The time } \\
\text { between multidirectional } \\
\text { observations of each scene will be } \\
\text { within a few minutes, ensuring that } \\
\text { the observations are done with } \\
\text { essentially the same atmospheric } \\
\text { conditions. Nine separate charge- } \\
\text { coupled device pushbroom cameras } \\
\text { observe the earth at nine angles at } \\
\text { nadir and fore and aft of the } \\
\text { spacecraft's track. Images are made } \\
\text { in four spectral bands from } 0.443 \text { to } \\
0.865 \text { micrometers. The instrument } \\
\text { swathwidth is } 356 \mathrm{~km} \text { and the } \\
\text { ground sampling is commandable to } \\
\text { be } 240,480,960 \text {, or } 1,920 \text { meters. }\end{array}$ & 106 & 107 & $\begin{array}{l}\text { Phase C/D in } \\
1991\end{array}$ & JPL \\
\hline Microwave Limb Sounder & $\begin{array}{l}\text { Will employ a microwave limb } \\
\text { sounding radiometer-spectrometer to } \\
\text { study the chemistry of the lower } \\
\text { stratosphere and upper troposphere } \\
\text { for the effects on changes in } \\
\text { greenhouse and related gases } \mathrm{H}_{2} \mathrm{O} \text {, } \\
\mathrm{O}_{3}, \mathrm{ClO}, \mathrm{HCL}, \mathrm{OH}, \mathrm{HNO}_{3}, \mathrm{NO} \\
\left.\mathrm{N}_{2} \mathrm{O}, \mathrm{HF} \text {, and } \mathrm{CO}\right) \text {, radiative forcing } \\
\text { of climate change, and ozone } \\
\text { depletion. It will also examine the } \\
\text { ozone chemistry of the middle and } \\
\text { upper stratosphere. The microwave } \\
\text { limb sounder will measure } \mathrm{SO}_{2} \text { and } \\
\text { other gases in volcanic plumes. It } \\
\text { contains five heterodyne radiometers } \\
\text { at } 215 \mathrm{GHz}, 440 \mathrm{GHz}, 640 \mathrm{GHz} \text {, } \\
1.2 \mathrm{THz} \text {, and } 2.5 \mathrm{THz} \text {. }\end{array}$ & 500 & 540 & $\begin{array}{l}\text { Under } \\
\text { development }\end{array}$ & JPL \\
\hline $\begin{array}{l}\text { Solar Stellar Irradiance } \\
\text { Comparison Experiment II }\end{array}$ & $\begin{array}{l}\text { Four-channel precision ultraviolet } \\
\text { spectrometer that provides daily } \\
\text { measurements of the full-disk solar } \\
\text { ultraviolet irradiance with calibration } \\
\text { maintained by comparison of the } \\
\text { signal with that from bright, early- } \\
\text { type stars. The spectral coverage of } \\
\text { the instrument is from } 5 \text { to } 440 \\
\text { nanometers. }\end{array}$ & 99.5 & 42 & $\begin{array}{l}\text { Phase C/D start } \\
\text { date has not } \\
\text { been set }\end{array}$ & $\begin{array}{l}\text { National } \\
\text { Center for } \\
\text { Atmospheric } \\
\text { Research }\end{array}$ \\
\hline
\end{tabular}


NASA EARTH-OBSERVING INSTRUMENTS (Continued)

\begin{tabular}{|c|c|c|c|c|c|}
\hline Instrument & Capabilities & $\begin{array}{c}\text { Mass } \\
(\mathrm{kg})\end{array}$ & $\begin{array}{l}\text { Power } \\
\text { (W) }\end{array}$ & Status & Developer \\
\hline \multicolumn{6}{|c|}{ Near-Term Instruments (up to 2005) } \\
\hline $\begin{array}{l}\text { Measurements of Pollution } \\
\text { in the Troposphere }\end{array}$ & $\begin{array}{l}\text { Will measure emitted and reflected } \\
\text { infrared radiance in the atmospheric } \\
\text { column. This will permit the } \\
\text { determination of tropospheric } \mathrm{CO} \\
\text { profiles and total column } \\
\text { concentrations of } \mathrm{CH}_{4} \text {. } \\
\text { Measurements of Pollution in the } \\
\text { Troposphere is a correlation } \\
\text { spectrometer that employs an on- } \\
\text { board pressure-modulated cell } \\
\text { containing a sample of the gas to be } \\
\text { measured. }\end{array}$ & 120 & 200 & $\begin{array}{l}\text { Under } \\
\text { development }\end{array}$ & $\begin{array}{l}\text { Canadian } \\
\text { Space Agency }\end{array}$ \\
\hline NASA Scatterometer II & $\begin{array}{l}\text { Will acquire all-weather } \\
\text { measurements of near-surface vector } \\
\text { winds over the ice-free oceans. The } \\
\text { instrument produces two } 600 \text { - } \\
\text { kilometer swaths separated by a } 325- \\
\text { kilometer nadir gap. It has a spatial } \\
\text { resolution of } 25 \text { kilometers. }\end{array}$ & 270 & 290 & $\begin{array}{l}\text { Phase C/D start } \\
\text { date has not } \\
\text { been set }\end{array}$ & JPL \\
\hline $\begin{array}{l}\text { Stratospheric Aerosol and } \\
\text { Gas Experiment III }\end{array}$ & $\begin{array}{l}\text { Stratospheric Aerosol and Gas } \\
\text { Experiment III will improve upon } \\
\text { global profiles of atmospheric } \\
\text { aerosols, ozone, water vapor, } \mathrm{NO}_{2} \text {, } \\
\mathrm{NO}_{3} \text {, OClO, temperature, and } \\
\text { pressure in the mesosphere, } \\
\text { stratosphere, and troposphere. The } \\
\text { instrument will also characterize } \\
\text { upper tropospheric and stratospheric } \\
\text { clouds and extend the solar } \\
\text { occultation data sets begun in } 1978 \text {. } \\
\text { The instrument uses solar and lunar } \\
\text { occultations to measure aerosols and } \\
\text { gases in the atmosphere, measuring } \\
\text { extinction of transmitted energy in } \\
\text { the spectral region from } 0.29 \text { to } 1.55 \\
\text { micrometers. }\end{array}$ & 40 & 60 & $\begin{array}{l}\text { Under } \\
\text { development }\end{array}$ & Ball Aerospace \\
\hline
\end{tabular}


NASA EARTH-OBSERVING INSTRUMENTS (Continued)

\begin{tabular}{|c|c|c|c|c|c|}
\hline Instrument & Capabilities & $\begin{array}{c}\text { Mass } \\
(\mathbf{k g})\end{array}$ & $\begin{array}{l}\text { Power } \\
\text { (W) }\end{array}$ & Status & Developer \\
\hline \multicolumn{6}{|c|}{ Near-Term Instruments (up to 2005) } \\
\hline $\begin{array}{l}\text { Tropospheric Emission } \\
\text { Spectrometer }\end{array}$ & $\begin{array}{l}\text { Provides very high spectral } \\
\text { resolution measurements from } 2.3 \text { to } \\
15.4 \text { micrometers using an infrared } \\
\text { imaging Fourier transform } \\
\text { technique. Its objective is to produce } \\
\text { global three-dimensional profiles of } \\
\text { nearly all infrared active gases from } \\
\text { the Earth's surface to the lower } \\
\text { stratosphere. }\end{array}$ & 340 & 460 & $\begin{array}{l}\text { Data not } \\
\text { available }\end{array}$ & $\begin{array}{l}\text { Data not } \\
\text { available }\end{array}$ \\
\hline \multicolumn{6}{|c|}{ Mid-Term Sensors and Beyond 2005} \\
\hline $\begin{array}{l}\text { Earth-Observing System } \\
\text { Synthetic Aperture Radar }\end{array}$ & $\begin{array}{l}\text { All-weather, day-night, high-spatial- } \\
\text { resolution imagery. It offers the } \\
\text { means to study dynamic phenomena } \\
\text { (e.g., flooding) in all seasons and at } \\
\text { all latitudes, as well as in areas such } \\
\text { as the tropics where cloud cover is } \\
\text { prevalent. In addition, synthetic } \\
\text { aperture radar offers the capability to } \\
\text { measure soil, snow, and canopy } \\
\text { moisture. }\end{array}$ & 1,300 & 5,800 & N/A & N/A \\
\hline $\begin{array}{l}\text { High Resolution Imaging } \\
\text { Spectrometer }\end{array}$ & $\begin{array}{l}\text { Spectral coverage from } 0.4 \text { to } 2.45 \\
\text { micrometers in } 192 \text { bands with } 10 \text { - } \\
\text { nanometer resolution. It provides a } \\
\text { 30-meter spatial resolution at nadir } \\
\text { and a } 24 \mathrm{~km} \text { swathwidth. }\end{array}$ & 450 & 600 & $\mathrm{~N} / \mathrm{A}$ & $\mathrm{N} / \mathrm{A}$ \\
\hline $\begin{array}{l}\text { Laser Atmospheric Wind } \\
\text { Sounder }\end{array}$ & $\begin{array}{l}\text { Employs a Doppler lidar system that } \\
\text { is to make direct wind measurements } \\
\text { in the troposphere. }\end{array}$ & 800 & 2,200 & N/A & N/A \\
\hline
\end{tabular}

SOURCE: Asrar and Dokken, 1993. 
